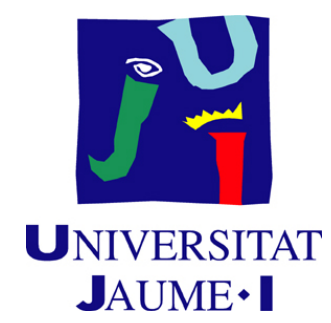

UNIVERSITAT JAUME I

\title{
ON THE EMERGENCE AND SUSTAINABILITY OF CORRUPTION: AN EXPERIMENTAL ANALYSIS
}

Tesis doctoral presentada por Tarek-Taher Jaber-López

dentro del Programa de Doctorado en Economía Industrial e Internacional

Dirigida por Dra. Aurora García-Gallego

y Dr. Nikolaos Georgantzís 



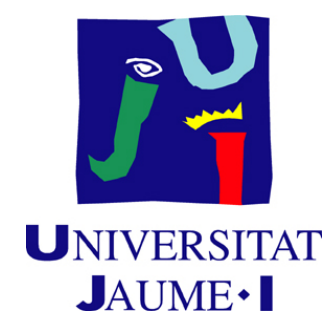

UNIVERSITAT JAUME I

\title{
ON THE EMERGENCE AND SUSTAINABILITY OF CORRUPTION: AN EXPERIMENTAL ANALYSIS
}

\author{
Tesis doctoral presentada por Tarek-Taher Jaber-López \\ dentro del Programa de Doctorado en Economía Industrial e Internacional \\ Dirigida por Dra. Aurora García-Gallego \\ y Dr. Nikolaos Georgantzís
}

El doctorando

El/La director(a)

El/La director(a)

Castellón, June 2015 
On the emergence and sustainability of corruption: An experimental analysis Author: Tarek-Taher Jaber López

Advisor: Aurora García Gallego

Advisor: Nikolaos Georgantzís

Text printed in Valencia

First edition, June 2015 
A mi familia 



\section{Acknowledgements}

I would never have been able to do this thesis without the help of my supervisors. Thank you for being the guides of this trip to Ithaca and for not allowing me to get out of the way. Thank you for believing in me when I did not even believed on my self, for motivating me everyday and for showing me everything I learnt with you. I would be always very grateful to you Nikolaos Georgantzís and Aurora GarcíaGallego. It was a pleasure to be your academic son, your spiritual brother and your friend.

Thank you Pandelis for your lessons, and for your patience when I was trying to understand just a line of Matlab.

Thanks to Ayça Ebru for giving me the opportunity to visit the wonderful Istanbul and for taking care of me. Tessekur ederim! Thanks also to Jean Lainé.

I want also to especially acknowledge all the people who helped me to improve my thesis with their advises and to spend some of their time on me: Miguel, Gerardo, Ivan, Eva, Simone, Ainhoa, Melanie, Gianluca, and all the team of LEE.

A especial thank for the technical assistance. Thanks to them my hearth rate was at a normal level during the experiments. You gave me lot of security during the stressful experiments. Jose Vicente, Alfonso, Sandra.

I want to acknowledge and to tell that it was a pleasure to share this voyage together during the thesis. This part is dedicated to my colleagues from LEE: Adriana and Sascha. From LINEEX: Guillermo, Manu, Guillem, Alex, Ignacio, Maria, Hector, Paloma, Sara, Rebeca 
and Fabio Petruzzi (your soul still among us). From BELIS: Ali Seyhun, Fatma, Deniz, Papatya, Onur. From Bahçesehir University: Çagdas Sirin and from everywhere: Filippos, Georgina, Levent and all the other people I could have forgotten.

Thank you for many people who helped with comments in seminars or conferences, or for helping me in some way: Angela Sutan, Enrique Fatas, Antonio Morales, Charles Nousair, and the many people I can not count that helped me in some way.

I am also grateful with all the institutions that helped me during my trip: Universitat Jaume I, LEE, LINEEX, Belis, Bahçesehir University Financial support by the Spanish Ministry of Economía y Competitividad (project ECO2011-23634 and grant JCI-2010-06790) is gratefully acknowledged and financial support by the Universitat Jaume I (doctoral grant PREDOC/2010/25).

Of course this thesis would be never done without the support of the closest people. Thanks to my parents for encouraging me with their example, to my brothers for suffering my impertinent moments. To all my uncles and ants, and cousins from Spain and Palestine, of course I can not mention all of them otherwise the list would be longer than this thesis. And my grand parents I hope I could honor their legacy. To all my friends who supported me.

Finalement, je veux te remercier mon 'moi', pour ta patience et pour me supporter inconditionnellement. Si je tombai 7 fois, tu me levais 8 fois. Cela n'aura jamais été possible sans toi, tu es ma source d'énergie. Merci pour me montrer les vraies mathématiques de la vie: $1+1=1$

Thank you very much, Tarek-Taher Jaber López June 2015 


$$
\text { الحََمْندُلَهِ }
$$





\section{Contents}

List of Figures

List of Tables xiii

1 Introduction 1

1.1 Resumen ...................... 1

1.2 Introduction .................... 3

2 A procurement auction model with bribes 5

2.1 Introduction . . . . . . . . . . . . . . . 5

2.2 The model ..................... 7

2.2.1 Continuous strategies . . . . . . . . . . 8

2.2.2 Discrete strategies . . . . . . . . . . . 9

2.3 Summary ...................... 10

3 An experimental implementation of a public procurement auction with corruption 11

3.1 Introduction . . . . . . . . . . . . . . . . 11

3.2 Experimental literature on corruption . . . . . . . . . 13

3.2.1 Specific typologies of population . . . . . . . . . 14

3.2 .2 Deterring bribery . . . . . . . . . . . 15

3.3 Experimental Design . . . . . . . . . . . . . . 18

3.3.1 Theory and main hypotheses . . . . . . . . . . 18

3.3 .2 Procedures . . . . . . . . . . . . . . . . . 19

3.3.3 Treatments .................. 20 
3.4 Results . . . . . . . . . . . . . . . . . . . . 20

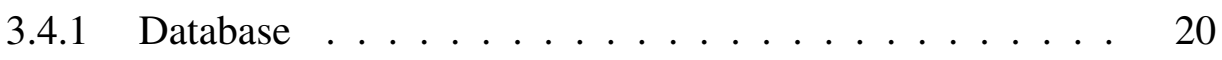

3.4 .2 Officials' decisions . . . . . . . . . . . . . . 21

3.4.2.1 Bribe vs Quality maximizing decisions _... 22

3.4.3 Firms' decisions . . . . . . . . . . . . . . 25

3.4.3.1 Bribe aversion and quality attraction $\ldots \ldots . \quad 25$

3.4.4 Efficiency and Social Welfare . . . . . . . . . . 31

3.4.5 Individual characteristics: Gender . . . . . . . . . . 34

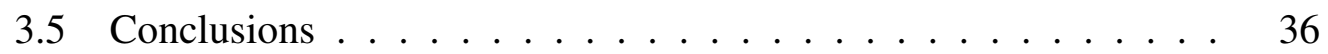

3.6 Appendix: Instructions to experimental subjects (translated from Spanish) . . . . . . . . . . . . . . . . . 39

4 Intrinsic and extrinsic motivations of pro-social behavior in an auction that allows for corruption

4.1 Introduction . . . . . . . . . . . . . . . 43

4.2 Related Literature . . . . . . . . . . . . . . . . . . . 46

4.2.1 Literature on extrinsic motivation $\ldots \ldots \ldots$. . . . 46

4.2.2 Literature on intrinsic motivation . . . . . . . . . 4 48

4.3 Experimental Design $\ldots \ldots \ldots \ldots \ldots \ldots \ldots$

4.3.1 Theoretical Framework . . . . . . . . . . . . . . 51

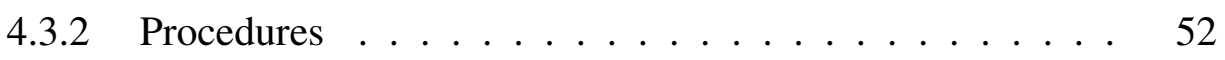

4.3.2.1 Treatments . . . . . . . . . . . 5 52

4.4 Results . . . . . . . . . . . . . . . . . 54

4.4 .1 The sample . . . . . . . . . . . . . . . . . . 5 54

4.4 .2 Treatment effects . . . . . . . . . . . 5 54

4.4.2.1 The citizen . . . . . . . . . . . 55 55

$4.4 .2 .1 .1 \quad$ Firms $\ldots \ldots \ldots \ldots \ldots \ldots$

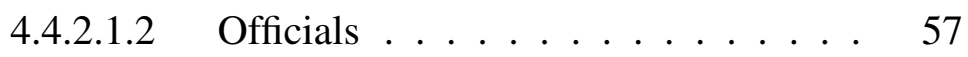

4.4.2.2 Inspection option . . . . . . . . . . . 5 59

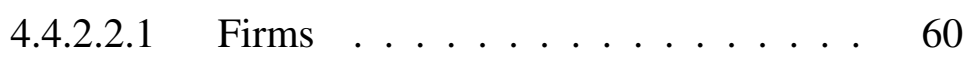

4.4.2.2.2 Officials . . . . . . . . . 62

4.4.2.3 Social welfare . . . . . . . . . . . . . 63

4.4 .3 Idiosyncratic features $\ldots \ldots \ldots \ldots$ 
4.4.3.1 Gender ................. 64

4.4.3.2 Risk Aversion ........... . 67

4.5 Conclusion ....................... 68

4.6 Appendix: Instructions to experimental subjects (translated from Spanish) ..................... 70

4.6.1 [Treatment B] \& [Treatment C] Subsession I . . . . . . . 70

4.6.2 [Treatment Bi] \& [Treatment Ci] Subsession II . . . . . . 72

4.7 Appendix: Risk aversion tests . . . . . . . . . . . . 74

4.8 Appendix: Croquis of the laboratory. . . . . . . . . . 76

5 Physiological and behavioral patterns of corruption 77

5.1 Introduction . . . . . . . . . . . . 77

5.2 Material \& Methods . . . . . . . . . . . . . . . 80

5.2.1 Theoretical framework . . . . . . . . . . . 80

5.2.1.1 Monetary payoff equilibrium prediction . . . 81

5.2.1.2 Psychological payoff equilibrium prediction . . 82

5.2.2 Experimental design .............. 83

5.2 .3 Procedures ................... 84

5.2.3.1 Behavioral and physiological data collection procedures ................ 84

5.2.3.2 Timing of behavioral events for continuous-time physiological measurements . . . . . . . 85

5.3 Results ....................... 86

5.3 .1 The sample ................ 86

5.3.2 Behavioral results . . . . . . . . . . . 86

5.3.3 Physiological results . . . . . . . . . . . 87

5.3.3.1 Response times ........... . . 92

5.4 Discussion . . . . . . . . . . . . . . . 95

5.5 Appendix: Instructions to experimental subjects (translated from Spanish) ...................... 96

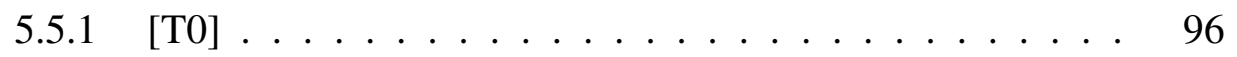

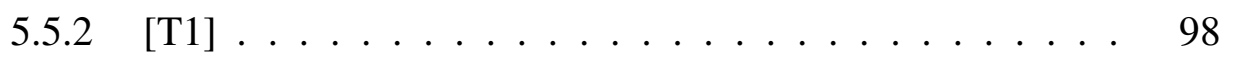


CONTENTS

Bibliography

99 


\section{List of Figures}

2.1 Matrix for discrete strategies. . . . . . . . . . . . 10

3.1 Distribution of officials' decisions according to the two profiles: bribe maximizer or quality maximizer. . . . . . . . . . 22

3.2 Percentage of officials' bribe maximizing decisions over time, for full sample. . . . . . . . . . . . . . . 23

3.3 Officials' decisions per treatment . . . . . . . . . . 24

3.4 Officials' decisions per treatment: Bribe maximizing decisions over time.......................... 25

3.5 Distribution functions for bribe and quality. . . . . . . . 26 26

3.6 Time evolution of bribe and quality. . . . . . . . . . . . 27

3.7 Treatment effects in time evolution of quality. . . . . . . . . . 28

3.8 Treatment effects in time evolution of bribe. . . . . . . . . . 28

3.9 Distribution functions of quality. . . . . . . . . . . . . 30

3.10 Treatment effects in distribution functions. . . . . . . . . . . 30

3.11 Time evolution of spendings (quality + bribe) . . . . . . . . 31

3.12 Observations density for treatment PT . . . . . . . . . 32

3.13 Observations density for treatment ST . . . . . . . . . . 33

3.14 Evolution of social welfare, by treatment. . . . . . . . . 33

3.15 Officials' preferences, by gender. . . . . . . . . . . . 35

3.16 Time evolution of quality. . . . . . . . . . . . 35

3.17 Time evolution of bribe. . . . . . . . . . . . . 36

4.1 The evolution of bribe . . . . . . . . . . . 56 
4.2 The distribution of the bribe, by treatment . . . . . . . . 57

4.3 Net effect of the citizen on bribe . . . . . . . . . . 58

4.4 Official's preferences: differences among treatments . . . . . . 59 59

4.5 The evolution of bribe: Inspection effect. . . . . . . . . . . . . . 60

4.6 Net effect of inspection on bribe . . . . . . . . . . . 61

4.7 The evolution of inspecting. . . . . . . . . . . . 62

4.8 The evolution of the efficiency of groups, by treatment. . . . . . . 64

4.9 The evolution of bribe, by gender. . . . . . . . . . . 65

4.10 The evolution of bribe according to subjects' risk aversion levels. . 68

4.11 Risk aversion. . . . . . . . . . . . . . . 74

4.12 Risk aversion with losses 2. . . . . . . . . . . . 75

4.13 'Blue' players represent citizens, 'green' players represent firm and officials playing treatments $\mathrm{B}$ and $\mathrm{Bi}$, 'red' players represent firms and officials playing treatments $\mathrm{C}$ and $\mathrm{Ci}$. . . . . . . . 76

5.1 Behavioral results: (a) Officials' decisions. (b) Bribe evolution.

(c) Bribe distribution. (d) Inspection frequency evolution . . . . 88

5.2 Officials' SCR following project choice screen (T0). . . . . . . 90 90

5.3 Officials' SCR following project choice screen (T1). . . . . . . 90 90

5.4 Firms' SCR following bid decision screen (T0) . . . . . . . . . . 91

5.5 Firms' SCR following bid decision screen (T1) . . . . . . . . . . 91

5.6 Winners' skin-conductance while waiting for loser to decide whether to order an inspection. . . . . . . . . . . . . . 92

5.7 Response time for T1: Bribe vs Quality maximization (officials). . 93

5.8 Response time for T1: Bribe vs No Bribe (firms). . . . . . . . . . 94

5.9 Response time for T1: Inspection vs No Inspection. . . . . . . . . 94 


\section{List of Tables}

3.1 General Desriptive Statistics _. . . . . . . . . . . . . 21

3.2 Bribe and quality averages, and Mann-Whitney test, per period. . 29

4.1 Summary of treatments. . . . . . . . . . . . . . . . 54

4.2 Average bribe offers. . . . . . . . . . . . 56

4.3 Non parametrics tests for a comparison among treatments. . . . 5 57

4.4 Mann-Withney rank-sum tests for comparison of social welfare among treatments. . . . . . . . . . . . . . 63

4.5 Quality maximizing decisions comparing gender within treatments and the corresponding values for $\chi^{2}$ test. . . . . . . . . 66 



\section{Introduction}

\subsection{Resumen}

En este trabajo estudiamos diferentes dimensiones del fenómeno de la corrupción. Debido a la dificultad que conlleva estudiar la corrupción, hemos escogido abordar este tema utilizando principalmente la metodología experimental. En el capítulo dos proponemos un modelo teórico en el cual dos empresas compiten para obtener la licencia de un proyecto público y un subastador, que actúa como un funcionario público y representa el poder politico, decide cuál es la empresa ganadora del concurso. Los jugadores tipo empresa se enfrentan a un dilema social ya que cuanto mayor es el soborno ofrecido, mayores serán los beneficios del funcionario y la probabilidad de que la empresa gane el concurso, pero esto es perjudicial para la otra empresa y para la sociedad entera. Cuando el espacio de estrategias de las ofertas de soborno y calidad es discreto, múltiples equilibrios emergen, incluyendo ofertas más pro-sociales que las predichas en un espacio estratégico continuo.

En el tercer capítulo, testamos este modelo en el laboratorio. Obtenemos como resultado que los sujetos parecen revelar valores intrínsecos ya que se desvían de la estrategia que maximiza sus beneficios. También comparamos dos protocolos de emparejamiento: un emparejamiento fijo durante todo el experimento versus un emparejamiento aleatorio en cada ronda. Nuestros resultados sugieren que un 
emparejamiento aleatorio disminuye la propensión a sobornar o a ser sobornado además de que, con el tiempo, aumenta el bienestar social.

En el cuarto capítulo, ampliamos el estudio experimental de corrupción añadiendo nuevos tratamientos al tratamiento base visto en el tercer capítulo: primero, la empresa perdedora tiene la opción de inspeccionar, y segundo, añadimos un jugador pasivo y observador (lo llamamos "ciudadano"), cuyos beneficios están determinados por la calidad del proyecto ganador. El mecanismo de inspección y castigo, consiste en que si un soborno es descubierto, ambos agentes corruptos pierden las ganancias del periodo. Por el contrario, si un soborno no es descubierto, la empresa denunciadora pierde las ganancias de dicho periodo. Esto convierte la inspección en una opción no provechosa para el perdedor y es raramente utilizada, especialmente hacia el final de la sesión cuando el comportamiento pro-social se vuelve predominante. Ejecutamos cuatro tratamientos en una única sesión, con 22 grupos independientes que jugaron una versión repetida del juego. Además, en una sesión previa elicitamos el grado de aversión al riesgo de los sujetos. Encontramos como resultados principales que la opción de inspección activa significativamente la motivación extrínseca de los sujetos, y el jugador pasivo activa significativamente la motivación intrínseca de los sujetos, ambas provocando un descenso de los sobornos. Además, los jugadores con una alta aversión al riesgo tienden a ofrecer mayores sobornos. Por último, el tratamiento con ciudadano parece aumentar más el bienestar social que el tratamiento con inspección, pero la combinación de ambos lleva al mayor nivel de bienestar social.

En el capítulo cinco estudiamos el comportamiento y la reacción emocional de los participantes. Replicamos el tratamiento base y el tratamiento con inspección. La excitación emocional de los sujetos se obtiene a través de las respuestas de dermo-conductancia. En general, nuestros resultados sugieren que las emociones más fuertes están asociadas con las desviaciones de la pura maximización monetaria, en lugar de estar asociadas con un un comportamiento (no) ético per se. Dicho de otro modo, las personas que toman decisiones retando su propio interés económico sufren una mayor excitación que aquellas que se preocupan únicamente por su beneficio económico personal. De hecho, utilizando tiempos de respuesta como medida de la reflexión de los sujetos durante el proceso de toma de decisiones, podemos asociar la respuesta emocional con un conflicto entre motiva- 
ciones primarias o instintivas y emociones secundarias o contemplativas y, más específicamente, con desviaciones del puro interés monetario de los sujetos. Observamos que aquellos que sufren mayor excitación presentan mayores tiempos de respuesta.

\subsection{Introduction}

This thesis studies corruption from different perspectives. In chapter two we propose a theoretical model where two firms compete for obtaining the license for a public project and an auctioneer acting as a public official representing the political power, decides the winner of the contest. Firm players face a social dilemma in the sense that higher bribes increase the officials' payoff and the bribers' probability of obtaining the license, but harm the other firm and society as a whole. The presence of bribe aversion in either the officials' or the firms' utility function shifts equilibrium towards more pro-social behavior. When the quality and bribe-bid strategy space is discrete, multiple equilibria emerge including more pro-social bids than would be predicted under a continuous strategy space.

In the third chapter, we test this model in the laboratory. We obtain that subjects exhibit pro-social intrinsic values by deviating from the monetary strategy. We also compare two different matching protocols: a fixed matching over the whole experiment versus random matching in every round. Our results suggest that a random matching protocol decreases the propensity to engage in bribery, and increases social welfare after some periods.

In the fourth chapter we report results from an experimental study on corruption, based on the baseline setting of the third chapter. We add new treatments to this baseline: an inspection option to the losing firm of the auction and a passive observer player ('citizen'), whose benefits are determined by the quality of the winning project. The inspection and punishment mechanism is such that, if a bribe is (not) revealed, both corrupt agents (the denouncing bidder) lose(s) this period's payoffs. This renders the inspection option unprofitable for the loser and is rarely used, especially toward the end of the session, when pro-social behavior becomes pervasive. We conducted 4 treatments in one session where 22 independent groups played a repeated version of the game, and in a pre-play session, we 


\section{INTRODUCTION}

elicit subjects' risk preferences. We found that the extrinsic motivation of people is activated through the inspection option, and the intrinsic motivation is activated as well, through the passive receiver yielding to a decrease of bribe offers. In addition, more risk averse subjects tend to offer higher bribes. In terms of efficiency we found that groups' profits are higher due to the effect of the citizen alone than with just the inspection. The combination of both yields to the highest levels of social welfare.

In chapter five, we study the behavior and emotional arousal of the participants. We replicate the baseline and the inspection treatments. Subjects' emotional arousal was obtained through skin conductance responses. Generally speaking, our findings suggest that stronger emotions are associated with decisions deviating from pure monetary reward maximization, rather than with (un)ethical behavior per se. In fact, using response times as a measure of the subject's reflection during the decision-making process, we can associate emotional arousal with the conflict between primary or instinctive and secondary or contemplative motivations and, more specifically, with deviations from the subject's pure monetary interest. 


\section{A procurement auction model with bribes}

\subsection{Introduction}

Public procurement auctions are source of potential corrupt exchanges. All over the world many public projects have been uncovered as resulting from the use of bribes. Bribery is bilateral, either active or passive. If we focus on the scenario of public procurement auctions, firms are active bribers as they offer bribes to an auctioneer, who is considered a passive briber. Despite the countless scandals discovered, we are still far from knowing the actual volume of bribery in public procurement because corruption is illegal and secret per se, thus difficult to measure with real data. According to Transparency International this particular kind of corruption is harmful as project's cost can increase more than $50 \%$ due to bribe expenses but it also has a direct implication on the execution of the projects by reducing their quality. Moreover, according to the World Bank, worldwide bribes are calculated to be around US\$1 trillion (Kaufmann, 2005).

Despite the huge effort exerted and the big contributions to the literature on this field, any empirical research about corruption and bribery remains a mere approx- 


\section{A PROCUREMENT AUCTION MODEL WITH BRIBES}

imation from extrapolating some data from, for example, perception surveys 1 . This is not surprising due to the difficulty in getting the real amount of bribe as it is uncovered by definition, therefore, the implicated parts are not interested in revealing it. However, we cannot omit the big progress that has been made by researchers in recent years and the reliability of the results obtained. Indeed, all the available indexes have been very useful to make progress in the investigation of corruption, concretely in an empirical way. The researches are mainly oriented to understand how corruption affects development, growth, poverty, and gender equality among others. From a total of 70 countries, Mauro (1995) demonstrates the negative effect that corruption may have on growth. Van Rijckeghem and Weder (2001) find evidence that corruption gets lower levels when the public employees' wages are high compared to those of the manufacturing sector. Gupta et al. (2002) show that corruption is positively correlated to poverty in terms of income distribution. Dollar et al. (2001), using a sample of more than 100 countries, give a gender oriented approach and prove that the higher is the representation of women in the parliament the lower the level of corruption.

This chapter is addressed to present a theoretical model combining two elements, bribery and auctions. In particular, our model is oriented to the study of corruption in public procurement auctions in which firms compete between them and interact with a public official. In addition to empirical works, a large literature concerning theoretical models exists. Works as Lien (1986), Beck and Maher (1986), Büchner et al. (2008), Burguet and Che (2004), Che (1993) have inspired our model. Although those models reflect mainly the situation where the bidders take simultaneously decisions on bribes and prices, our model presents rather the tradeoff between bribe and quality. In particular, our work is based on Büchner et al. (2008) who propose an auction model where two providers of procurement compete bidding prices and bribe. Their game displays the kind of corruption that we personally consider is creating all over the world the highest damages, the one that involves public procurement auctions. Such a bribery can have fatal effects on

\footnotetext{
${ }^{1}$ Transparency International publishes annually the Corruption Perceptions Index (CPI) which ranks countries 'by their perceived levels of corruption, as determined by expert assessments and opinion surveys'. Surveys/assessments are either business people opinion or performance assessments from a group of analysts.
} 
the quality of public projects or services. In fact, this bribery is hard to denounce and to demonstrate as far as the political class has the power to control their transparency and the separation of powers is not always as true as desirable.

Hence, we propose a theoretical set up in which we focus on an auction where two firms compete for obtaining the license for a public project and an auctioneer acting as a public official representing the political power, decides the winner of the contest. This model has the peculiarity of inducing players to engage in bribe as a monetary maximization behavior. Players as firms face a social dilemma in the sense that the higher is the bribe offered, the higher would be the willingness of a pure monetary maximizer public official to give her the license. However, it implies inducing a cost of reducing all players' payoffs as far as our model includes an endogenous externality, which depends on bribe. All players' payoffs decrease with the bribe (and increase with higher quality).

As we will see in the next section, our model presents multiple equilibria for firms. The interesting point is that, according to the monetary maximization theory, public officials should always prefer the firm that offers the highest transfer of bribe. Therefore firms and officials have divergent preferences.

The chapter is organized as follows: in section 2 we present the model. Third section concludes.

\subsection{The model}

Our model is inspired on the theoretical framework of Büchner et al. (2008) in which pairs of sellers bid to obtain a public contract and the bid of each seller could include a bribe to be paid to the public official. Consider the variation of the previous model. A game is played between two firms $(i, j)$ bidding for a procurement contract which will be granted to one of the two firms by a public auctioneer (official). Like in the original framework, bidding takes place in two dimensions. However, in our version, the social externality of the winning project, net of social or private costs affects uniformly to all agents. Thus, rather than the price paid by the state to the winning firm, the first bidding dimension is a bidder quality net of costs ( $Q_{i} \leq A$, where $A$ represents an exogenously given upper bound to quality). This allows us to model the first dimension of bidding as a simple linear, 


\section{A PROCUREMENT AUCTION MODEL WITH BRIBES}

monotonically increasing function of the winning project social quality benefiting unambiguously all agents, the auctioneer, the two firms and, potentially (as we do in a follow-up of this chapter), the society surrounding them. The second dimension is a bribe $\left(B_{i}\right)$ promised and finally paid by the winner of the auction to the auctioneer. Furthermore, in order to guarantee that a social dilemma emerges in this bribery game, we impose a restriction on bribes and qualities? $Q_{i}+B_{i} \leq A$. We use a linear specification of the three agents' monetary (induced) utilities, adding a psychological cost parameter, $\gamma$, capturing an agent's aversion to bribe due to ethical reasons, expressed in monetary loss per monetary unit of bribe received by the official. Thus, the three agents' utility levels are given by:

$$
\begin{gathered}
\pi_{\text {official }}=F+a \cdot Q_{\text {winner }}+\left(1-\gamma_{\text {official }}\right) \cdot B_{\text {winner }} \\
\pi_{\text {winner }}=F+a \cdot Q_{\text {winner }}-\left(c+\gamma_{\text {winner }}\right) \cdot B_{\text {winner }}+R \\
\pi_{\text {loser }}=F+a \cdot Q_{\text {winner }}
\end{gathered}
$$

Where $F$ is a fixed amount earned by each subject in each period, $R$ is a fixed private profit obtained by the firm winning the procurement. Finally, $a$ denotes the social return of the winning project's quality on each player's utility and $c$ a per monetary unit of bribe cost, borne by a bribing winner, denoting that the bribe may yield further monetary costs on its way from the firm to the official. Assuming perfect information on the agents' preferences, the resolution of the game depends on the hypothesis of continuous versus discrete strategies.

\subsubsection{Continuous strategies}

In this section we study the theoretical prediction of the game assuming a continuos space of strategies. We first solve the case in which agents have non-monetary (psychological) concerning, then the case in which agents purely maximize their payoffs.

\footnotetext{
${ }^{1}$ Corresponding, for example, to a resource-driven budget constraint in a more general version of the model.
} 
1. If $a>1-\gamma_{o f f i c i a l}$, the highest quality project will be chosen and firms will bid only in qualities, leading to the equilibrium: $\left(Q_{i}, B_{i}\right)=\left(Q_{j}, B_{j}\right)=(A, 0)$ independently of the firms' preferences.

2. If $a<1-\gamma_{\text {official }}$, the highest bribe will be preferred by the auctioneer. In that case, firms will bid with the maximum bribe they can, as long as the bribing (monetary and psychological) cost does not exceed the fixed amount $R$ earned by the winner. Thus, in equilibrium, firm $i$ will bid $\left(Q_{i}, B_{i}\right)=$ $\left(A-\frac{R}{c+\gamma_{i}}, \frac{R}{c+\gamma_{i}}\right)$.

Thus, we would expect officials to choose the highest quality proposals if they are sufficiently bribery-averse, while they will choose the bidder with the highest bribe otherwise. Firms (believing that they are) faced with a quality-maximizing auctioneer will not bid with bribes, independently of their own preferences, whereas firms anticipating a bribery-maximizing behavior by the auctioneer will promise higher bribes, the less bribery averse they are.

Finally, in absence of psychological, bribe-regarding considerations, a monetaryreward maximizing behavior would predict maximal quality bids, $\left(Q_{i}, B_{i}\right)=\left(Q_{j}, B_{j}\right)=(A, 0)$, if $a>1$, and $\left(Q_{i}, B_{i}\right)=\left(A-\frac{R}{c}, \frac{R}{c}\right)$, if $a<1$, in which case, the social dilemma leads to a socially suboptimal equilibrium. In the linear version, the following parameters are adopted, $(F, a, A, R, c)=(10,1 / 2,10,10,2)$, which guarantee the emergence of the social dilemma equilibrium bids: $\left(Q_{i}, B_{i}\right)=$ $\left(Q_{j}, B_{j}\right)=(5,5)$ in the case of bribery-neutral agents with universal preference for the bribe-maximizing bids by the official, or top quality $\left(Q_{i}, B_{i}\right)=\left(Q_{j}, B_{j}\right)=$ $(A, 0)$, and quality maximizing auctioneer behavior if $\gamma_{\text {official }}>1 / 2$.

\subsubsection{Discrete strategies}

Our game's theoretical prediction differs when considering discrete strategies. The matrix in figure 2.1 shows the payoffs of both firms for different combinations of bribe (and quality). In the discrete game there are two strong Nash equilibria $\left(Q_{i}, B_{i}, Q_{j}, B_{j}\right)=(7,3,7,3)$ and $\left(Q_{i}, B_{i}, Q_{j}, B_{j}\right)=(6,4,6,4)$ where the former is Pareto superior to the latter. 


\section{A PROCUREMENT AUCTION MODEL WITH BRIBES}

The $\left(Q_{i}, B_{i}, Q_{j}, B_{j}\right)=(5,5,5,5)$ is still a weak equilibrium and also Pareto dominated by both the other two. It is weak, because each firm is indifferent between this and bidding lower bribes just to become a loser (it earns 12.5 units in both cases).

\begin{tabular}{|c|c|c|c|c|c|c|c|c|c|c|c|c|c|c|c|c|c|c|c|c|c|c|c|}
\hline & & \multicolumn{22}{|c|}{ Player 2} \\
\hline & Bribes & \multicolumn{2}{|c|}{10} & \multicolumn{2}{|c|}{9} & \multicolumn{2}{|c|}{8} & \multicolumn{2}{|c|}{7} & \multicolumn{2}{|r|}{6} & \multicolumn{2}{|c|}{5} & \multicolumn{2}{|r|}{4} & \multicolumn{2}{|c|}{3} & \multicolumn{2}{|c|}{2} & \multicolumn{2}{|c|}{1} & \multicolumn{2}{|c|}{0} \\
\hline \multirow{11}{*}{ 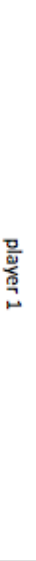 } & 10 & 5 & 5 & 0 & 10 & 0 & 10 & 0 & 10 & 0 & 10 & 0 & 10 & 0 & 10 & 0 & 10 & 0 & 10 & 0 & 10 & 0 & 10 \\
\hline & 9 & 10 & 0 & 6,5 & 6,5 & 2,5 & 10,5 & 2,5 & 10,5 & 2,5 & 10,5 & 2,5 & 10,5 & 2,5 & 10,5 & 2,5 & 10,5 & 2,5 & 10,5 & 2,5 & 10,5 & 2,5 & 10,5 \\
\hline & 8 & 10 & 0 & 10,5 & $5 \quad 2,5$ & 8 & 8 & 5 & 11 & 5 & 11 & 5 & 11 & 5 & 11 & 5 & 11 & 5 & 11 & 5 & 11 & 5 & 11 \\
\hline & 7 & 10 & 0 & 10,5 & $5 \quad 2,5$ & 11 & 5 & 9,5 & 9,5 & 7,5 & 11,5 & 7,5 & 11,5 & 7,5 & 11,5 & 7,5 & 11,5 & 7,5 & 11,5 & 7,5 & 11,5 & 7,5 & 11,5 \\
\hline & 6 & 10 & 0 & 10,5 & $5 \quad 2,5$ & 11 & 5 & 11,5 & 7,5 & 11 & 11 & 10 & 12 & 10 & 12 & 10 & 12 & 10 & 12 & 10 & 12 & 10 & 12 \\
\hline & 5 & 10 & 0 & 10,5 & $5 \quad 2,5$ & 11 & 5 & 11,5 & 7,5 & 12 & 10 & 12,5 & 12,5 & 12,5 & 12,5 & 12,5 & 12,5 & 12,5 & 12,5 & 12,5 & 12,5 & 12,5 & 12,5 \\
\hline & 4 & 10 & 0 & 10,5 & $5 \quad 2,5$ & 11 & 5 & 11,5 & 7,5 & 12 & 10 & 12,5 & 12,5 & 14 & 14 & 15 & 13 & 15 & 13 & 15 & 13 & 15 & 13 \\
\hline & 3 & 10 & 0 & 10,5 & $5 \quad 2,5$ & 11 & 5 & 11,5 & 7,5 & 12 & 10 & 12,5 & 12,5 & 13 & 15 & 15,5 & 15,5 & 17,5 & 13,5 & 17,5 & 13,5 & 17,5 & 13,5 \\
\hline & 2 & 10 & 0 & 10,5 & $5 \quad 2,5$ & 11 & 5 & 11,5 & 7,5 & 12 & 10 & 12,5 & 12,5 & 13 & 15 & 13,5 & 17,5 & 17 & 17 & 20 & 14 & 20 & 14 \\
\hline & 1 & 10 & 0 & 10,5 & $5 \quad 2,5$ & 11 & 5 & 11,5 & 7,5 & 12 & 10 & 12,5 & 12,5 & 13 & 15 & 13,5 & 17,5 & 14 & 20 & 18,5 & 18,5 & 22,5 & 14,5 \\
\hline & 0 & 10 & 0 & 10,5 & $5 \quad 2,5$ & 11 & 5 & 11,5 & 7,5 & 12 & 10 & 12,5 & 12,5 & 13 & 15 & 13,5 & 17,5 & 14 & 20 & 14,5 & 22,5 & 20 & 20 \\
\hline
\end{tabular}

Figure 2.1: Matrix for discrete strategies.

\subsection{Summary}

A model of public procurement auction is developed in this chapter where two firms compete and have the possibility to bribe for winning the contest. We imposed a social dilemma to the firms and we added a psychological cost parameter coming from bribing as it consists of an "unethical" behavior. We also consider the situation where no psychological parameters are included. Specific parameters are included in the model and we obtain the theoretical prediction either with continuous strategies or with discrete strategies. We believe that this model is interesting to be implemented in the laboratory to investigate people's preferences in this specific social dilemma. 


\section{An experimental implementation of a public procurement auction with corruption}

\subsection{Introduction}

As many studies have already demonstrated, corruption has fatal consequences, and this is why the study of this phenomenon is gaining a high interest among academics. By fatal consequences we understand the negative effect that corruption has at a macroeconomic level. From a total of 70 countries, Mauro (1995) demonstrates the negative effect that corruption may have on growth. Gupta et al. (2002) show that corruption is positively correlated to poverty in terms of income distribution. Moreover at a microeconomic level there are huge repercussions. For instance, corrupt officials can deny basic goods procurement, medicines, house light and water or even they extract people's income by imposing 'unfair' conditions 11 Corruption

\footnotetext{
${ }^{1}$ Many of these examples can be found in www.ipaidabribe.com. Through this website, everybody can report its own experience with bribery.
} 


\section{AN EXPERIMENTAL IMPLEMENTATION OF A PUBLIC PROCUREMENT AUCTION WITH CORRUPTION}

is commonly defined as the abuse of public office for private gain. When researchers contemplate the idea of studying corruption, they are confronting a big challenge, since no real, accurate and accounted data exists on bribes amounts. Indeed, this is due to the pure nature of corruption: it is secret and illegal. Corruption could be compared to drug dealing as it is an illegal and secret activity as well. Thus, an attempt of calculating the actual transfer values are just speculation. Despite the impediments, there are alternative ways to study corruption. For instance, the empirical studies on corruption are generally based on surveys 11 Van Rijckeghem and Weder (2001) find evidence that high wages for public employees decrease the attraction for bribery. Dollar et al. (2001), prove that the high representation of women in the parliament is associated with lower levels of corruption. Although the surveys' results are used as a proxy of corruption levels, some works demonstrate their limitations. Olken (2009) finds biases in the reported corruption perception, which may lead to wrong results. The author conducted an experiment in Indonesia finding differences between what villagers reported as perception of corruption in a road-building project in their village, and a more objective measure called 'missing expenditures', in the project. One of the explanations given for this divergence is that, in this village, the corruption is hidden by magnifying the quantities employed for the project. This way makes more difficult to detect the corruption by the civil population.

An alternative way to deal with the study of corruption is the experimental methodology which consists of collecting data from a controlled environment seeking to eliminate outside factors. Experiments on corruption may provide the outcome of real behavior in a corruption controlled simulated scenario. Knowing that the real data of corruption are impossible to observe and, although subjects knowing they are being observed may take the moral decision when morality and wealth are competing (Levitt and List, 2007), we believe that experimental economics is a powerful approach for this topic especially in the field of procurement auctions. By

\footnotetext{
${ }^{1}$ Transparency International publishes annually the Corruption Perceptions Index (CPI) which ranks countries by their perceived levels of corruption, as determined by expert assessments and opinion surveys. Surveys/assessments are either business people opinion surveys or performance assessments from a group of analysts.
} 
using the experimental methodology, we aim at contributing to the understanding of the behavioral components of bribery.

In this chapter we experimentally test the auction model introduced in chapter 2 where two firms compete, by posting their bids on quality and bribe, for obtaining the license of a public project. Then, an official in charge of designating the winner of the auction observes firms' bids and decides which one he considers as the deserving of the license.

The theoretical prediction of the game has the property to induce firms to bribe in a specific amount and officials to decide in favor of the highest bribe offer received. Therefore, the aim of this work is to test in the laboratory the real behavior of people with respect to the theoretical prediction of the game. We analyze subjects' decisions in the role of firms or officials in the context of a specific auction, where bribery is permitted. Our results suggest that people deviate from the theoretical prediction, exhibiting pro-social preferences.

In addition, we evaluate an alternative and, a priori, more efficient way to deter bribery, i.e. without the costs of monitoring and legal prosecutions. Thus, we run two treatments to compare the effect of two different matching protocols: partners with fixed matching over time and strangers with random matching in each interaction. We obtain that a strangers matching protocol reduces the propensity to engage in bribery and, after some periods, it increases the social welfare. This result is in line with Abbink (2004).

Finally, some gender effects have been found, as women in the role of officials are more willing than men to choose the pro-social option.

\subsection{Experimental literature on corruption}

When we explore the experimental literature on bribery we perceive that the experiments are mainly used for two purposes: on the one hand, to extract characteristics that may explain a pro-bribe behavior or, on the contrary an aversion to bribery, on the other hand, to examine how to deter the incentives to bribe. 


\section{AN EXPERIMENTAL IMPLEMENTATION OF A PUBLIC PROCUREMENT AUCTION WITH CORRUPTION}

\subsubsection{Specific typologies of population}

Part of the experimental literature on corruption is addressed to find some characteristics of a specific population that could explain a determined behavior concerning bribery. Those works study, for instance, whether a specific group of population has more aversion to bribe, more tolerance, or the opposite. Frank and Schulze (2000) study subjects in the role of public officials. Participants face a trade-off between maximizing individual profit and maximizing the gains of the public interest. Apparently due to self-selection, economics students tend more to corruptibility than non-economics students. Some gender results were found, such as economists men are the most corrupt and non-economist men the least.

Alatas et al. (2009b) execute an experiment in Indonesia with public servants and students finding that those who are more exposed in daily life to corruption (public servants) are significantly less tolerant to corruption than students.

The effect of culture has been also studied in the experimental literature of bribery. Cameron et al. (2009) study the effect of culture on the propensity to engage on bribery or on punishing it. Their main interest was to observe whether those countries ranked with low levels of corruption were those where there is a lower engagement on bribery and higher punishment. Their cross-cultural study is replicated in Australia, India, Indonesia and Singapore. Their results show that, on the one hand, in India subjects are more tolerant to corruption than in Australia, on the other hand, surprisingly, in Indonesia are much less tolerant than in Singapore. However, the authors did not find important differences in the propensity to engage on bribery. Barr and Serra (2010) explore the correlation between Oxford University students' country of origin and their decision on a bribery game. In a first study done in 2005, they find that a correlation exists as subjects coming from more corrupt countries are those taking the more pro-bribe decisions, but this result was true just for undergraduate students. In the second study, run in 2007, the authors slightly modify the design and now the public officials are the ones moving first and asking for a bribe. The authors also though about an important variable to consider: they ask subjects about the time spent in UK. As a result, they find a socialization effect. Thus, the propensity to bribe decreases over time spent in UK.

Banuri and Eckel (2012) run a bribery game with punishment in US and Pakistan, 
finding that without punishment, the levels of bribery are not different between the two countries, but cross-cultural differences appear in the levels of punishment.

Some works analyze the effect of framing on experiments of corruption, obtaining different results. Abbink and Hennig-Schmidt (2006) run two treatments of their bribery game, one with negative connotation in the instructions and the second with neutral framing, finding no significant differences between them. Barr and Serra (2009), however, find some significant differences when comparing framed versus neutral instructions. Differently from Abbink and Hennig-Schmidt (2006), in their design, the agents implied on the bribery exchange are a citizen and an official. The authors claim that subjects feel more identified with the word 'citizen' than with 'firm' when playing in a bribery experiment. The authors study the framing effect combined with high versus low negative externalities on other players. Their main results suggest that framed instructions decreases the propensity to offer bribe from citizens, specially with high negative externalities. However, weak differences are found on public officials propensity to accept or reject bribes when comparing framed versus abstract instructions. Lambsdorff and Frank (2010) study framing from another perspective. The authors analyze the effect of choosing endogenously between two loaded frames in which a business-person as first mover chooses whether to use the word 'bribe' versus 'gift' to give to the public servant. As a result, business people who choose the word 'bribe' exhibited a higher propensity to punish public servants who did not reciprocate them than those choosing the word 'gift'.

As is recurrent in the experimental literature, bribery is found to be correlated to gender. Rivas (2013), Alatas et al. (2009a), Frank and Schulze (2000), or Schulze and Frank (2003) are good examples. 1

\subsubsection{Deterring bribery}

Researchers dealing with corruption are mainly interested in understanding what is provoking people to engage on bribery and, furthermore, how it can be stopped. In fact, an important part of the experimental literature on corruption deals with

\footnotetext{
${ }^{1}$ For a deep understanding of this specific feature see the survey on gender and bribery experiments by Frank et al. (2010).
} 


\section{AN EXPERIMENTAL IMPLEMENTATION OF A PUBLIC PROCUREMENT AUCTION WITH CORRUPTION}

the severals ways in which bribery can be deterred. Most of the settings consist of running firstly a baseline treatment where bribe is permitted with no repercussions on those who are engaging on bribe. Then subjects play treatments in which a variable is manipulated in order to evaluate the effect of this modification. Generally, in these settings bribe-offers, bribe-takers or both are potentially exposed to some sanctions that are supposed to dissuade them from bribing.

For instance, the effect of the risk of detection has been studied by several authors. Schulze and Frank (2003) compare a baseline treatment with no possibility of detection and a control treatment with a probability of detection. Their results suggest that monitoring reduces the propensity to bribe at the cost of reducing the intrinsic motivation of being honest.

In the design made by Serra (2012), the public official is the one who asks for a bribe and the citizen may accept paying it or not. The research interest of this work is to compare the effect of different systems of monitoring. Considering weak institutional contexts where top-down monitoring systems are not effective because of a lack of incentives among other reasons, the author wonders whether bottom-up monitoring could deter corruption. The results show that the combination of both, top-down and bottom-up, can reduce corruption levels.

Armantier and Boly (2011) execute a field experiment in Burkina Faso where subjects have to grade 20 exams from which the eleventh, with many mistakes, contains a banknote and post-it paper with the following sentence: 'Please, find few mistakes in my exam paper'. They manipulate the interesting variables of bribe, wages and monitoring levels and they obtain that the higher the bribe the higher is the probability to accept it. Higher wages reduce the probability of accepting the bribe, however it increases the reciprocation from the bribee. They found also that monitoring and punishment can be effective anti-corruption measures. However, in line with Schulze and Frank (2003), a crowding out effect on intrinsic motivation for being honest appears. Reporting has been also studied to analyze its effects on the propensity to bribe.

Abbink et al. (2014) run a set of experiments attempting to test the validity of Basu (2011) in which he proposes, on the one hand, punishing public officials as bribetakers and, on the other hand, legally protecting bribe-givers like ordinary citizens who just seek to receive a service. Their results suggest that immunity for bribe 


\subsection{Experimental literature on corruption}

givers reduce the propensity to demand bribes from bribe-takers and increases the willingness to report. Furthermore, the authors compare a treatment with bribe refunded to the citizen with one in which the bribe is not refunded. They find that reporting behavior does not depend just on monetary incentives but also on intrinsic motivations.

In this work we are specially interested in the one by Abbink (2004) as they analyze the net effect of partners matching vs strangers matching, as a potential policy to deter bribery. The author replicated the design of Abbink et al. (2002) where three treatments were run: the baseline consists of a variation of a trust game between a firm, as potential briber and an official, as bribee. In the second treatment, they analyze the effect of an exogenous negative externality that affects all the players when a pair is engaging on bribe and finally, the third treatment studies the effect of having a risk of being detected and punished. Their results demonstrate that the penalty risk reduces significantly the propensity to engage in bribe, although the negative externality treatment has not significant effect. Each treatment was a repeated interaction during 30 periods, thus the matching protocol used was partners. Therefore, the aim of Abbink (2004) is to calculate the effect of a long term relationship among agents (partners) versus a one-shot repeated interaction where pairs of firm-official change every period (strangers). Their main results suggest that a rotation among agents, first, decrease the propensity to engage on bribery from both sides, i.e. lower transfers of bribes and lower reciprocation, and second, the efficiency increases.

As suggested by Abbink, we develop the study of the effect produced by the different matching protocols, in a different context. Specifically, our scenario consists of an auction for a public procurement where two firms compete for wining the contest by posting their bids on quality and bribe. After observing the bids, an official as auctioneer decides on the winner firm. We rather choose a public auction with two firms competing, as we believe that is the kind of corruption which is causing the highest damage in the society. In contrast with Abbink's, in our game the theoretical prediction is such that it induces people to engage in bribery. Moreover, our model has an endogenous externality depending on quality, i.e. the higher is the quality of the winning firm, the higher are the earnings for all the members in the group, however, Abbink includes an exogenous externality as a treatment. We also 


\section{AN EXPERIMENTAL IMPLEMENTATION OF A PUBLIC PROCUREMENT AUCTION WITH CORRUPTION}

compare a fixed matching (partners) with a random matching (strangers) along 10 periods instead of 30 .

\subsection{Experimental Design}

\subsubsection{Theory and main hypotheses}

We explicitly introduce a tradeoff between bribe and quality bids. In the bidding stage, two firms post simultaneously sealed quality bids and bribes to be paid in case the bidder is the winner of the auction. In the final stage, on the basis of the bids received, an official chooses one of the bids. The winner's quality benefits all players, whereas the bribe is antisocial and inefficient, as it is paid at the cost of a lower quality and an extra loss by the bribing winner. Thus, firms face a moral dilemma in the sense that the higher a firm's promised bribe, the more likely for the firm to be the winner of the auction. Also, officials face a dilemma, as their selfish preference for bids entailing higher bribes goes against the interest of all other players and overall welfare ${ }^{1}$

For the implementation in the laboratory, we have applied the restriction: $Q+B \leq$ $A$ for each firm-subject's strategies, reflecting the trade-off between quality and bribe. We have used the parameter set $(F, a, c, A, R)=\left(10, \frac{1}{2}, 2,10,10\right)$. Taking this payoff structure into account, implying that agents care only for the monetary consequences of their actions and assuming a continuous strategy space, the unique Nash equilibrium is such that both firms' bids involve $(Q, B)=(5,5)$. That is, like in Bertrand competition, in equilibrium firms will be willing to spend on the bribe as much as the bonus they obtain from winning the auction. However, for simplicity, our experiment is run with a discrete strategy space, allowing only for integer quality and bribe bids. Then, multiple equilibria emerge including $(Q, B)=$ $(7,3)$ and $(Q, B)=(6,4)$. In this case, the unique continuous-strategy equilibrium $(Q, B)=(5,5)$ becomes a weak equilibrium, since each firm is indifferent between this and posting lower bribes, then becoming a loser (with a 12.5 payoff in both cases).

\footnotetext{
${ }^{1}$ The theoretical model and its predictions are developed in chapter 2
} 


\subsection{Experimental Design}

Based on this game and the parameters implemented in the laboratory, we aim at testing three hypotheses concerning firms' behavior.

- Hypothesis 1: Firms will collude on high bribes and low quality.

- Hypothesis 2: Firms will coordinate in the Pareto superior equilibrium.

- Hypothesis 3: A rotation among agents (strangers matching) will decrease the propensity to engage on bribery.

\subsubsection{Procedures}

Two sessions were conducted in the Laboratory of Experimental Economics (LEE) at the University Jaume I. The experiment was programmed and conducted with the software z-Tree (Fischbacher, 2007). The sample consisted of 66 subjects. Each 'market' consisted of a group of 3 players: 2 firms and 1 official. They never knew the identity of other group members and communication among them was strictly forbidden. Participants played 10 rounds. The information received at the end of each round was different for firms and for officials: firms knew their payoff in current round, accumulated payoff and who was the winner firm of the license. They never knew the offer made by the other firm. Firms had the option to not exhaust their budget restriction, although it is inefficient. The official knew quality and bribe offers from both firms, own payoff in the current round and accumulated payoffs.

To complete the study, the experimental subjects performed a standard demographic questionnaire, so that we could extract some data on variables like gender 1 , Trust

\footnotetext{
${ }^{1}$ Dummy variable that takes the value 1 if female, 0 for men.

${ }^{2}$ For this variable, we have been inspired on the World Value Survey (1981-2008) where we asked subjects the following questions. (Our answers where Yes / NO):

1. Generally speaking, would you say that most people can be trusted or that you need to be very careful in dealing with people?

2. Do you think most people would try to take advantage of you if they got a chance, or would they try to be fair?

3. Do you think most people try to help others or most people worry for themselves?
} 


\section{AN EXPERIMENTAL IMPLEMENTATION OF A PUBLIC PROCUREMENT AUCTION WITH CORRUPTION}

Parents Education ${ }^{1}$, Religion ${ }^{2}$, Membership ${ }^{3}$, To perform our analysis, all these variables have been normalized to dichotomous variables.

\subsubsection{Treatments}

We carried out two treatments to compare results through a between subjects analysis: first a treatment with matching partners (henceforth PT) in which each subject remains in the same group and with same role throughout 10 periods. In the first period, subjects were grouped randomly and anonymously in groups of three. They received information about their payoffs at the end of each period. In the second treatment, matching was strangers (henceforth ST) where the groups are also formed randomly and anonymously, but its components change every round. The role of each subject (firm or official) remains the same for all rounds.

\subsection{Results}

The analysis of the experimental data is organized as follows. First, we present an overview of the descriptive statistics of the sample, then we analyze the behavior of subjects in the role of officials, and, finally we make an analysis of the decisions of subjects in the role of firms.

\subsubsection{Database}

Table 3.1 gives us an overview of the sample according to the results from the questionnaire of socio-demographic variables. We include the results of testing whether significant differences exist between men and women for those magnitudes.

The sample is almost balanced between men and women: 36 women and 30 men. A total of 27 subjects played PT and 39 played ST. In table 3.1 we observe

\footnotetext{
${ }^{1}$ Measures the level of education received by the parents of the subject. Subjects were asked about the level of studies of their parents: elementary school / high school / university / $\mathrm{PhD}$. The more level of studies they have, the higher is the value.

${ }^{2}$ Indicates whether the individual has received a religious education in elementary school, secondary and high school. The result is between 0 and 3, 3 being the sum of the three options.

${ }^{3}$ Was obtained by questioning subjects on the number of organizations to which they belonged (sports organizations, unions, political, local, N.G.O...).
} 
Table 3.1: General Desriptive Statistics

\begin{tabular}{lccccc}
\hline \hline Statistics & Men & Women & Total & Rank & M.-W.(z) \\
\hline \hline $\mathrm{N}$ & 30 & 36 & 66 & & \\
$\mathrm{PT}$ & 13 & 14 & 27 & & \\
$\mathrm{ST}$ & 17 & 22 & 39 & & \\
Economists & 17 & 22 & 39 & & \\
Other Studies & 13 & 14 & 27 & & \\
Trust (avg) & 1.28 & 1.00 & 1.15 & {$[0-3]$} & $3.10^{* * * *}$ \\
Parents education (avg) & 5.48 & 5.39 & 5.44 & {$[0-12]$} & 0.13 \\
Membership (avg) & 1.04 & 0.74 & 0.90 & {$[0-5]$} & $4.70^{* * *}$ \\
Religion (avg) & 1.28 & 1.09 & 1.19 & {$[0-3]$} & 1.28 \\
\hline \hline$* * * p<1 \%, * * p<5 \%, * p<10 \%$ & & & &
\end{tabular}

that men are significantly more trustful than women (Wilcoxon-Mann-Whitney test $\mathrm{Z}=3.10, p<0.01)$. Moreover, men belong significantly to more organizations than women (Wilcoxon-Mann-Whitney test $\mathrm{z}=4.70, p<0.01$ ). No other significant differences are found.

\subsubsection{Officials' decisions}

This subsection is addressed to understand the decisions made by officials. Officialsubjects as auctioneers decide the firm that will win the license in the current period. Officials' decisions are based on the offers of bribe and quality made by the two firms. In that way, we induce them to face several dilemmas since in our setup officials are not allowed to reject bribes, hence their decisions are either to maximize bribe or to maximize quality. Taking this aspect into account, we distinguish between two types of decisions made by officials: monetary payoffs maximizing decisions and pro-social decisions. The payoff maximizing decisions consist in giving the license to the firm offering more bribe, given that the quality level of the winning firm is equal or inferior to that of the loser firm.

Pro-social are those decisions corresponding to quality maximization. This option reveals that officials are exhibiting other preferences than just monetary maximization. In fact, officials when deciding according to quality are taking into consideration other than own personal benefit but rather social earnings, in the sense that 


\section{AN EXPERIMENTAL IMPLEMENTATION OF A PUBLIC PROCUREMENT AUCTION WITH CORRUPTION}

they reveal a pro-social attitude. In this case, the official gives the license to the firm that offers higher quality level, given that the bribe of the winning firm is at least equal than the one of the loser. ${ }^{1}$

\subsubsection{Bribe vs Quality maximizing decisions}

Figure 3.1 presents, on aggregate for the two sessions, the distribution of officials' decisions according to the two profiles: bribe or monetary maximizing decisions and pro-social or quality maximizing decisions. Among all the offers received by officials, in $67.01 \%$ of the cases, they decided according to bribe, that is to say, following a pure monetary maximization. In contrast, $32.99 \%$ of their choices are in favor of quality, hence acting in a pro-social way.

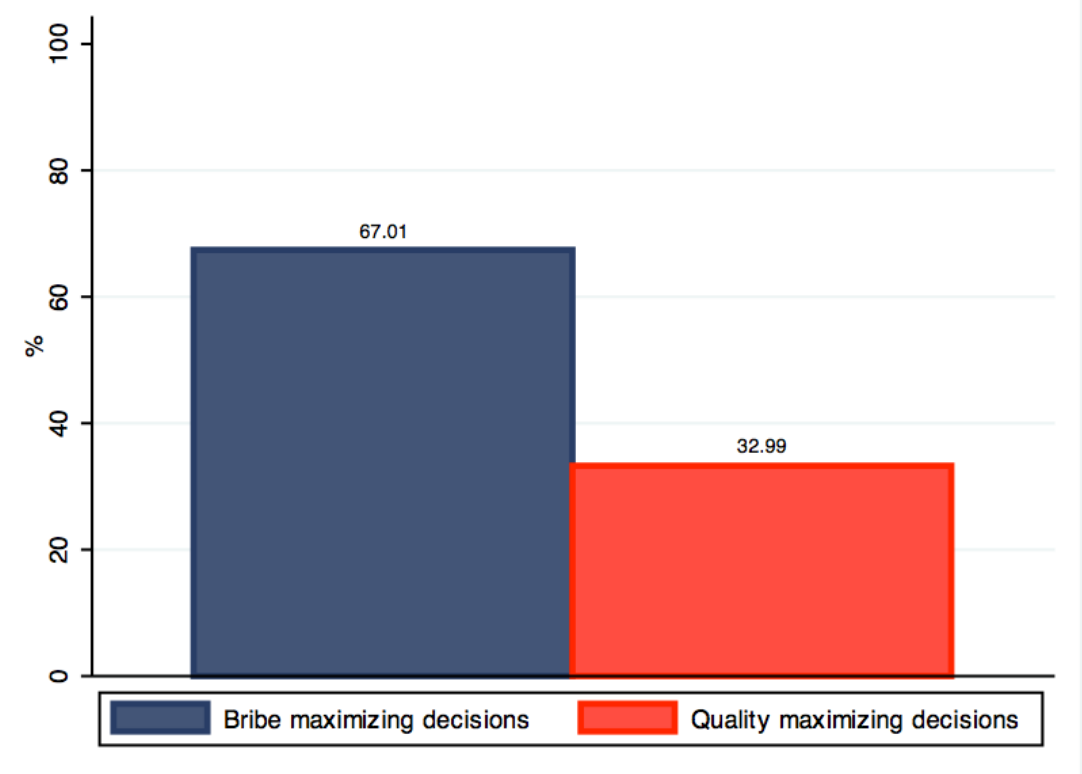

Figure 3.1: Distribution of officials' decisions according to the two profiles: bribe maximizer or quality maximizer.

Aggregatif the data of the two session, we show in figure 3.2 the time evolution of officials' decisions. In the first period, bribe maximizing decisions taken by

\footnotetext{
${ }^{1}$ We exclude from the analysis the irrational decisions which consist of giving the license to the firm offering lower quality and lower or equal bribe than the loser firm.
} 
officials are around 40\%. Compared to quality maximizing profile, along time this payoff maximizing behavior predominates until the end, being around $60 \%$ on average.

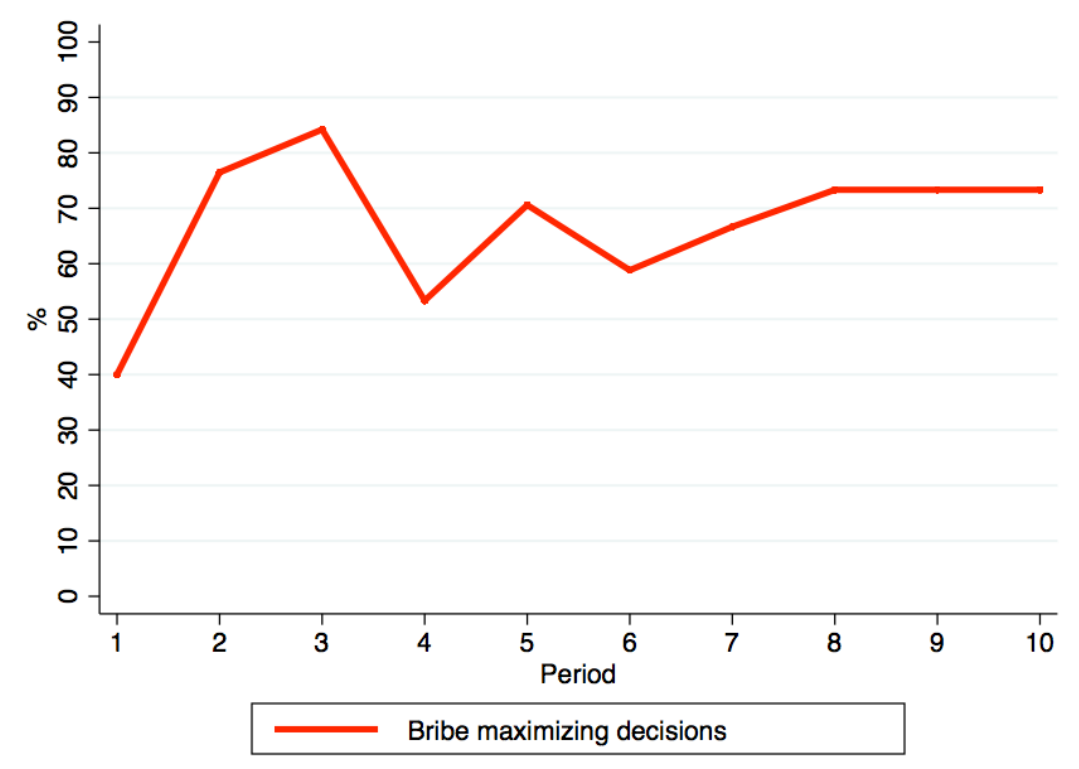

Figure 3.2: Percentage of officials' bribe maximizing decisions over time, for full sample.

This setup induces officials to act in a selfish way by choosing the highest bribeoffer made by firms. However, it is remarkable the fact that one third of the decisions made by officials are against the pure selfish monetary interest. Rather they are compatible with a pro-social behavior.

When a potential pair of briber and bribee interact in a long term relationship, the propensity to engage on bribery is higher as an outcome of a trustful relationship. In fact, we expect that a strangers matching protocol would eliminate the long term trustful relationship among agents, which is a factor that encourages corruption in real life. Figures 3.3 and 3.4 illustrate for officials the differences between their decisions in the two treatments. Observe that in ST pro-social behavior significantly increases given that the amount of quality maximizing decisions are higher than they are in PT (35.87\% versus $27.94 \%$, respectively) ${ }^{1}$. As in Abbink (2004),

\footnotetext{
${ }^{1}$ Pearson $\chi^{2}(1)=3.36, p<0.10$.
} 


\section{AN EXPERIMENTAL IMPLEMENTATION OF A PUBLIC PROCUREMENT AUCTION WITH CORRUPTION}

we find that a rotation among agents increases the pro-social attitudes of officials.

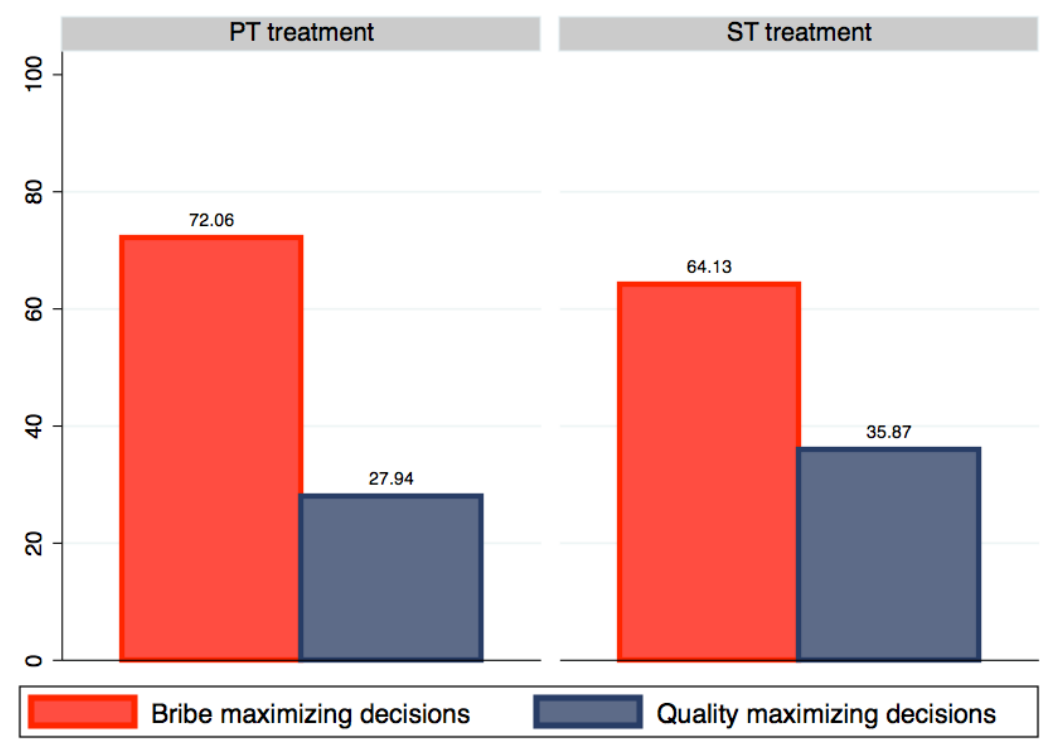

Figure 3.3: Officials' decisions per treatment

Some conclusions from this section can be extracted so far: officials are not exclusively maximizing their private payoff. Rather, one third of the times they reject bribes and they prefer to seek a more socially efficient outcome. Moreover, a rotation among firms and public officials in each interaction increases pro-social behavior by officials. Then, a recommendation addressed to policy makers claims that forcing public officials to rotate when interacting with private firms might reduce the propensity of engaging in bribery.

Result 1: Although the game induces officials to accept the highest bribe, one third of them reveal other-preferences and deviate from monetary maximization.

Result 2: A rotation among agents in every period (ST) increases significantly officials' deviation from the monetary maximization in favor of a pro-social behavior. 


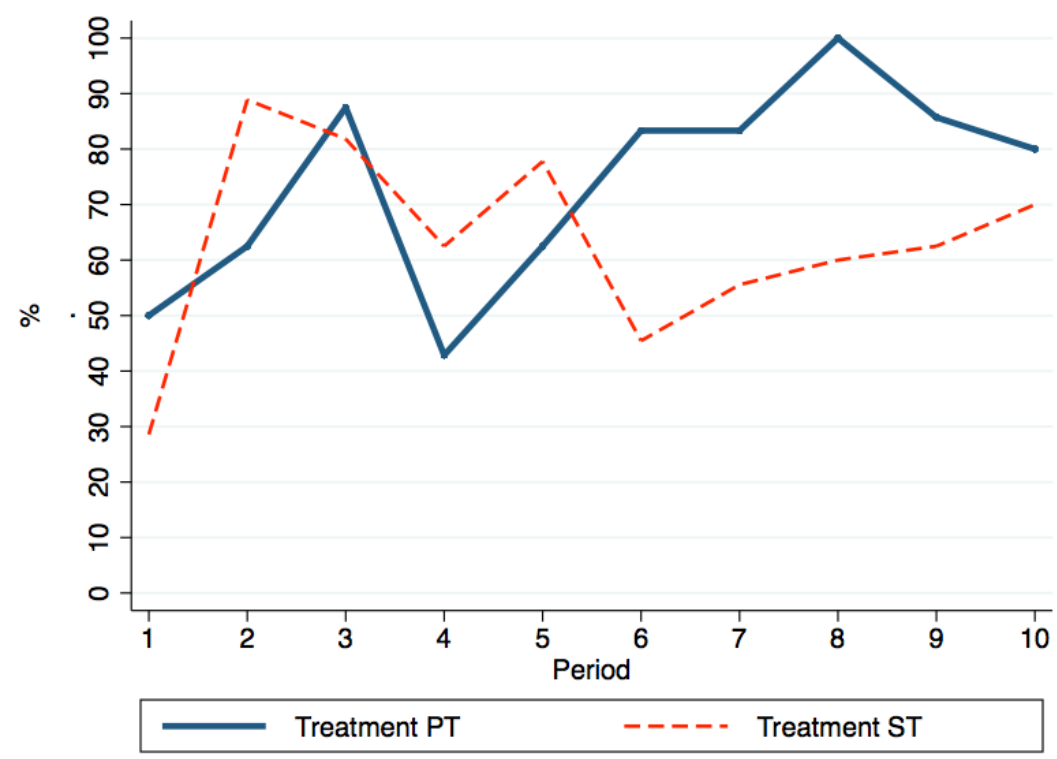

Figure 3.4: Officials' decisions per treatment: Bribe maximizing decisions over time.

\subsubsection{Firms' decisions}

In this subsection we analyze firms-subjects' decision making. Remember that subjects' deciding as firms have to post their bids of quality and bribe to the official.

\subsubsection{Bribe aversion and quality attraction}

On average, firms invest 6.22 units in quality and offer 2.5 units of bribe. Figure 3.5 shows the aggregate distribution of quality and bribe. This picture reflects the deviations existing from the induced utility in our model. The distribution for quality and bribe are mostly concentrated on the right hand side and left hand side of the Nash equilibria, respectively.

Figure 3.6 shows, on aggregate, the evolution of average bribe and quality amounts over time. This plot enhances our result on deviations from the theoretical prediction and it is consistent in time, specially for the case of bribing. We observe a propensity to offer lower bribes than the theoretical prediction. In addition, the curve of bribe slightly decreases over time: the average bribe is 2.7 units in the first period and 2 units in period 10 (Wicoxon matched-pairs signed-rank 


\section{AN EXPERIMENTAL IMPLEMENTATION OF A PUBLIC PROCUREMENT AUCTION WITH CORRUPTION}
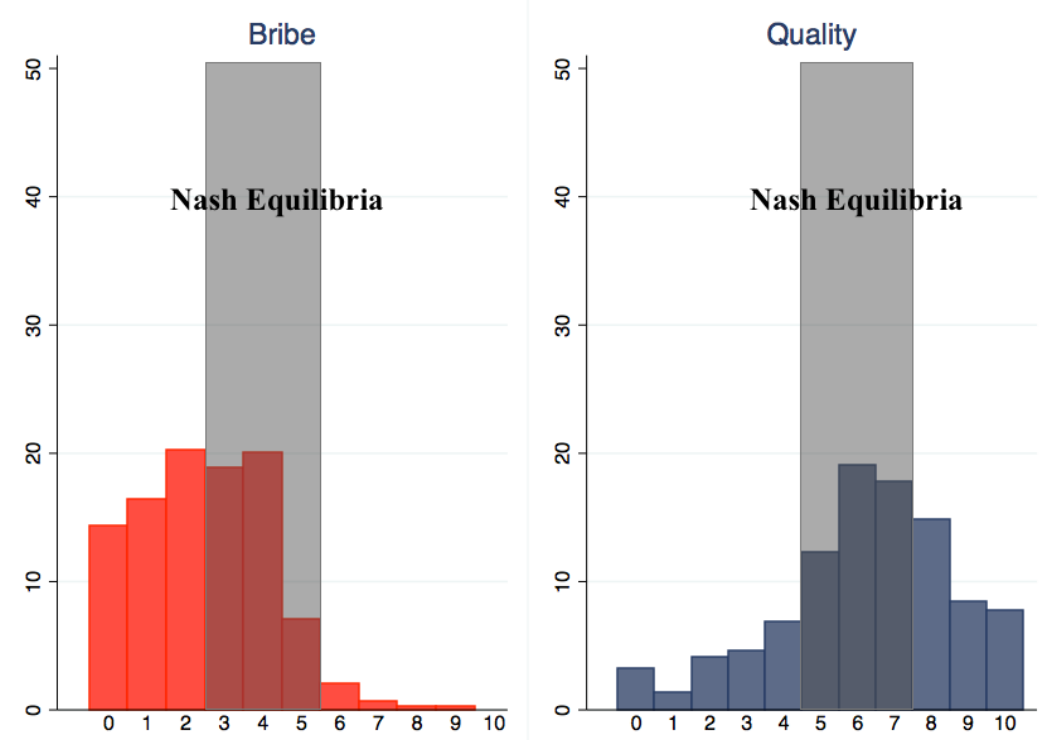

Figure 3.5: Distribution functions for bribe and quality.

test $p<0.10$ ). As a consequence, quality has a growing slope and remains above the Nash equilibrium values over time. The average quality in the first period is 5.8 units and reaches 7 in the last period (Wicoxon matched-pairs signed-rank test $p<0.01)$.

Subjects in the role of firms behave in a particular way. On the one hand, their decisions on quality fit with the theoretical prediction. On the other hand, their decisions on bribe reveal that subjects playing as firms do not behave as purely payoff maximizers as they deviate from the Nash equilibria by posting lower bribes than predicted.

If we analyze the data by treatment, we obtain that the average bribe in PT is 2.99 units, which is significantly higher than the average bribe in ST, 2.15 units (Wilcoxon-Mann-Whitney test $\mathrm{z}=5.76, p<0.01$ ). Consistently with Abbink (2004) we find that a random and anonymous rotation system among agents when interacting in this type of environment can be a good way to slow corruption down. The average quality bid in PT is 6.55 units, versus 5.99 units in ST. Thus, the average level of quality with a fixed matching is higher than with a random match- 


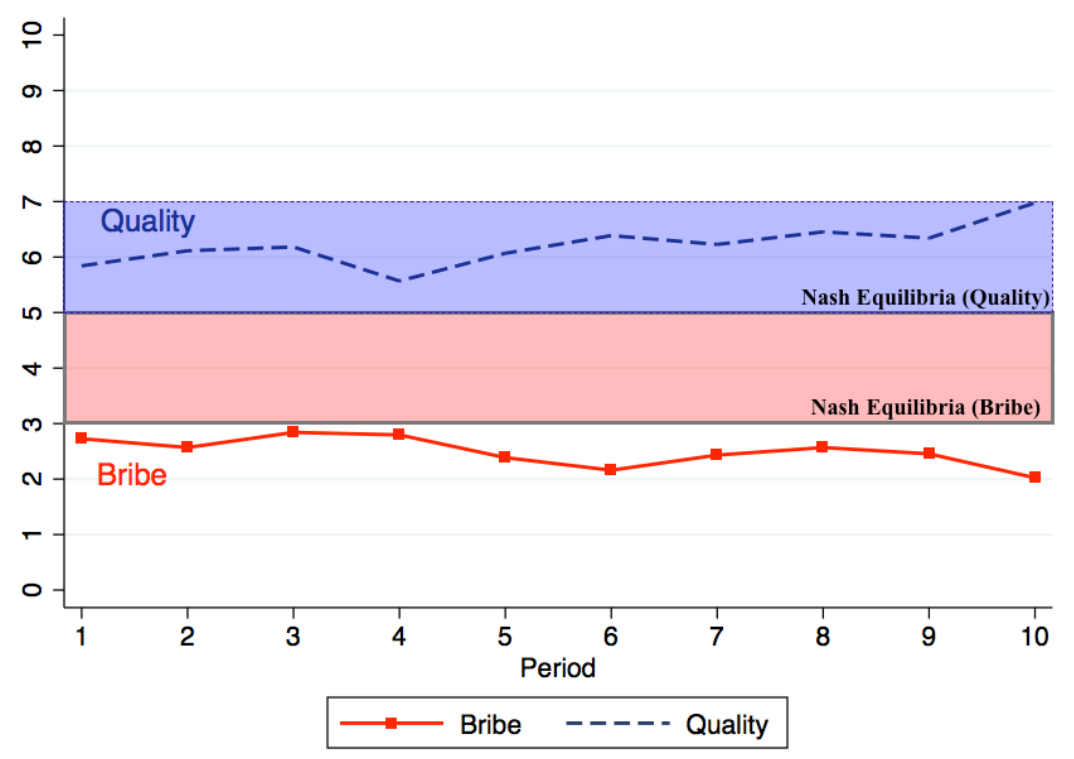

Figure 3.6: Time evolution of bribe and quality.

ing protocol, although this difference is not significant (Wilcoxon-Mann-Whitney test $\mathrm{z}=1.40, p=0.16$ ). Our firms achieve at reducing bribery but at the cost of also slightly reducing quality. Figure 3.7 and 3.8 shows the time evolution of average decisions for quality and bribe, by treatment. Observe that in ST bribes are lower than in PT for all periods, however, quality bids are also lower. The differences in bribing are significant in periods $1,3,4,6,7$, and 10 . No significant differences are found on quality, for any period (data in table 3.2 support this result). On the one hand, a rotation mechanism reduces bribery, and, on the other hand, it reduces quality which, as a consequence, yield social externality to be lower for all players.

This result is confirmed when observing the distribution of bribe and quality for each treatment. We clearly observe a higher frequency of bidding 10 units of quality in ST than in PT (figure 3.9). The modal in PT is 6 units of quality compare to the 8 units in ST. Distributions are significantly different (Kolmogorov-Smirnov $\mathrm{D}=0.27, p<0.01)$. Likewise, for bribe bids we observe clear differences in distributions by comparing PT vs ST (figure 3.10). First, the frequency of bidding 0 units bribe by firms is clearly higher in ST. Second, the modal in PT is 4 units while in ST is 2 units. Distributions are significantly different (Kolmogorov-Smirnov $\mathrm{D}=0.21$, 


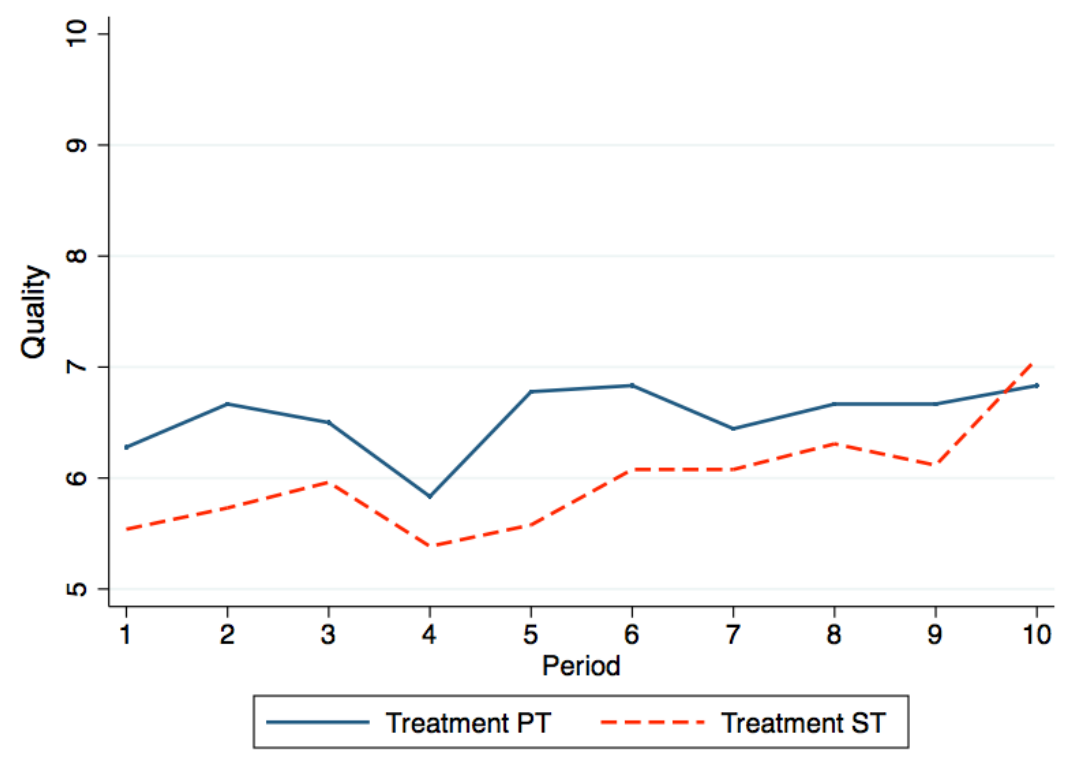

Figure 3.7: Treatment effects in time evolution of quality.

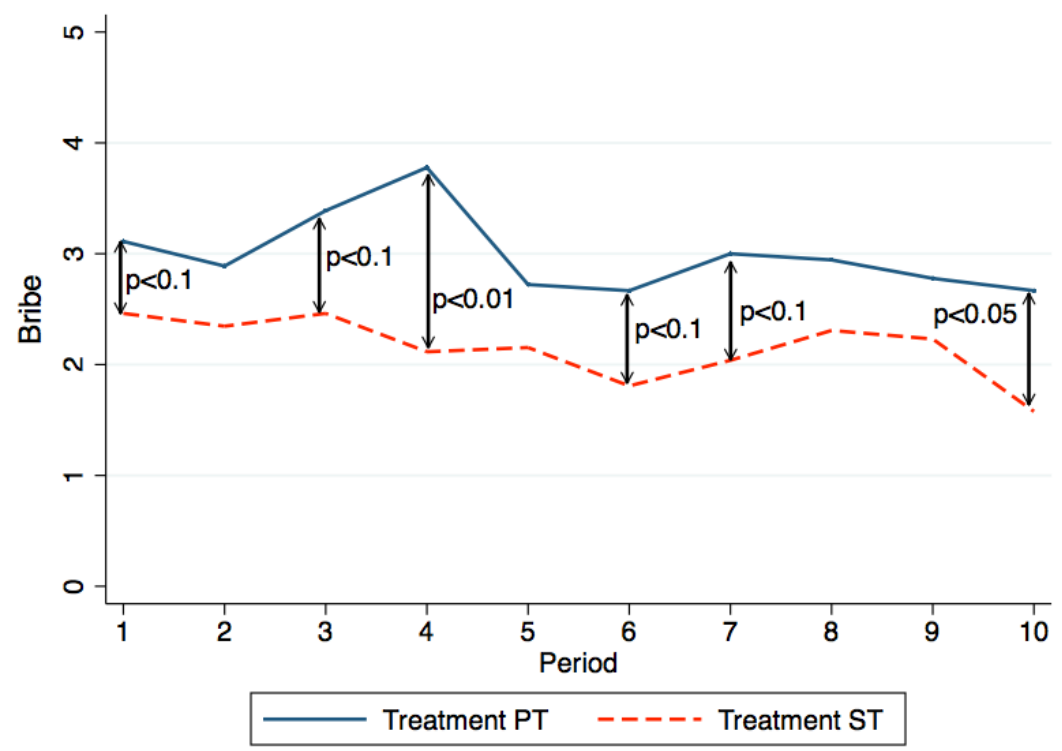

Figure 3.8: Treatment effects in time evolution of bribe. 
Table 3.2: Bribe and quality averages, and Mann-Whitney test, per period.

\begin{tabular}{|c|c|c|c|c|c|c|c|c|c|c|}
\hline \multirow[t]{3}{*}{ Period } & \multicolumn{4}{|c|}{ Bribe } & \multicolumn{5}{|c|}{ Quality } & \multirow[b]{3}{*}{ M.W. (z } \\
\hline & \multicolumn{2}{|c|}{$\mathrm{PT}$} & \multicolumn{2}{|c|}{ ST } & \multirow[b]{2}{*}{ M.W. (z) } & \multicolumn{2}{|c|}{$\mathrm{PT}$} & \multicolumn{2}{|c|}{$\overline{\text { ST }}$} & \\
\hline & avg. & s.d. & avg. & s.d. & & avg. & s.d. & avg. & s.d. & \\
\hline 1 & 3.11 & 1.02 & 2.46 & 2.21 & $1.81^{*}$ & 6.28 & 1.27 & 5.54 & 2.72 & 0.22 \\
\hline 2 & 2.89 & 1.37 & 2.35 & 1.72 & 1.12 & 6.67 & 1.61 & 5.73 & 2.58 & 0.29 \\
\hline 3 & 3.39 & 1.29 & 2.46 & 1.94 & $1.92 *$ & 6.50 & 1.34 & 5.96 & 2.57 & 0.39 \\
\hline 4 & 3.78 & 1.21 & 2.12 & 1.88 & $3.37 * * *$ & 5.83 & 1.62 & 5.38 & 2.91 & 0.93 \\
\hline 5 & 2.72 & 1.45 & 2.15 & 2.07 & 1.26 & 6.78 & 1.80 & 5.58 & 3.13 & 0.19 \\
\hline 6 & 2.67 & 1.49 & 1.81 & 1.30 & $1.84 *$ & 6.83 & 1.69 & 6.08 & 2.65 & 0.52 \\
\hline 7 & 3.00 & 1.75 & 2.04 & 1.61 & $1.73^{*}$ & 6.44 & 2.03 & 6.08 & 2.75 & 0.83 \\
\hline 8 & 2.94 & 1.40 & 2.31 & 1.85 & 1.45 & 6.67 & 1.61 & 6.31 & 2.90 & 0.88 \\
\hline 9 & 2.78 & 1.52 & 2.23 & 1.53 & 1.24 & 6.67 & 1.88 & 6.12 & 2.85 & 0.69 \\
\hline 10 & 2.67 & 1.33 & 1.58 & 1.42 & $2.38^{* *}$ & 6.83 & 1.42 & 7.08 & 2.65 & 0.24 \\
\hline Total & 2.99 & 1.40 & 2.15 & 1.76 & $5.76^{* * * *}$ & 6.55 & 1.63 & 5.99 & 2.77 & 0.16 \\
\hline
\end{tabular}

$p<0.01)$.

Result 3: A random matching protocol reduces both, quality (not significantly) and bribe (significantly) bids made my firms.

This result gives us interesting evidence concerning the testable hypotheses exposed in subsection 3. First, hypothesis 1 of collusion is rejected since collusion is possible just in PT because there is a repeated interaction among the same subjects, however, we find significantly higher bribes in the majority of the periods in PT compared to ST. Therefore, we discard hypothesis 1. Hypothesis 2 remains possible because deviations from the theoretical prediction could plausibly be explained by coordination in Pareto-superior equilibria. Second, hypothesis 3 is confirmed as a rotation among agents decreases the propensity to engage on bribery. 


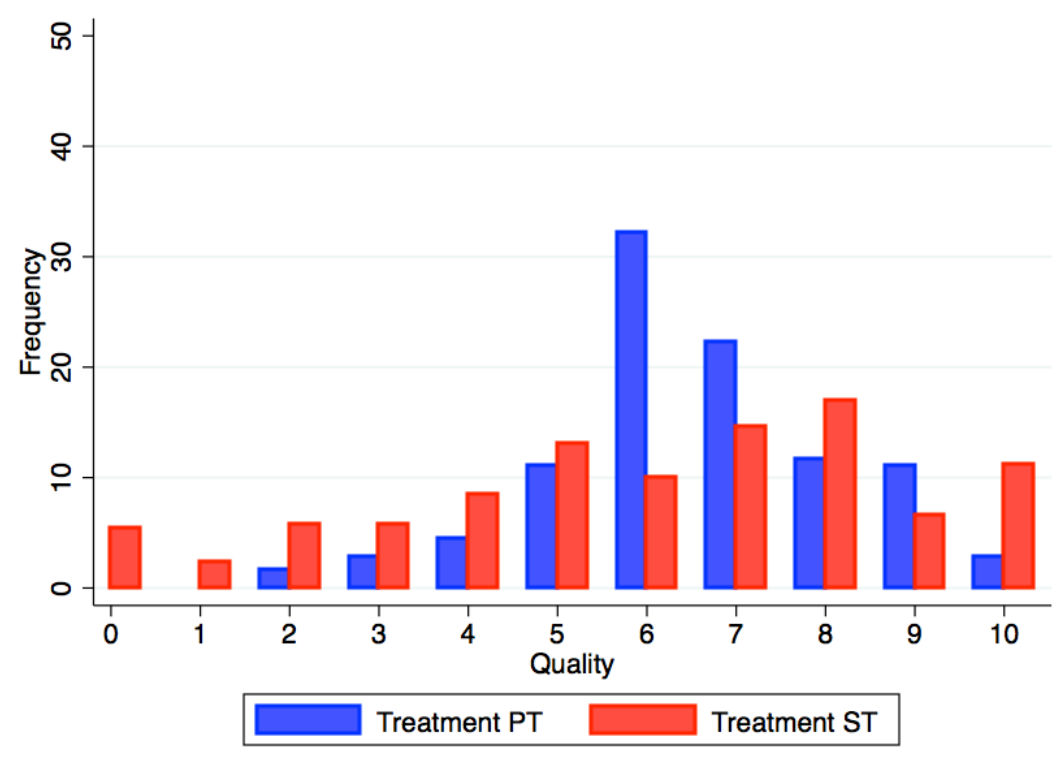

Figure 3.9: Distribution functions of quality.

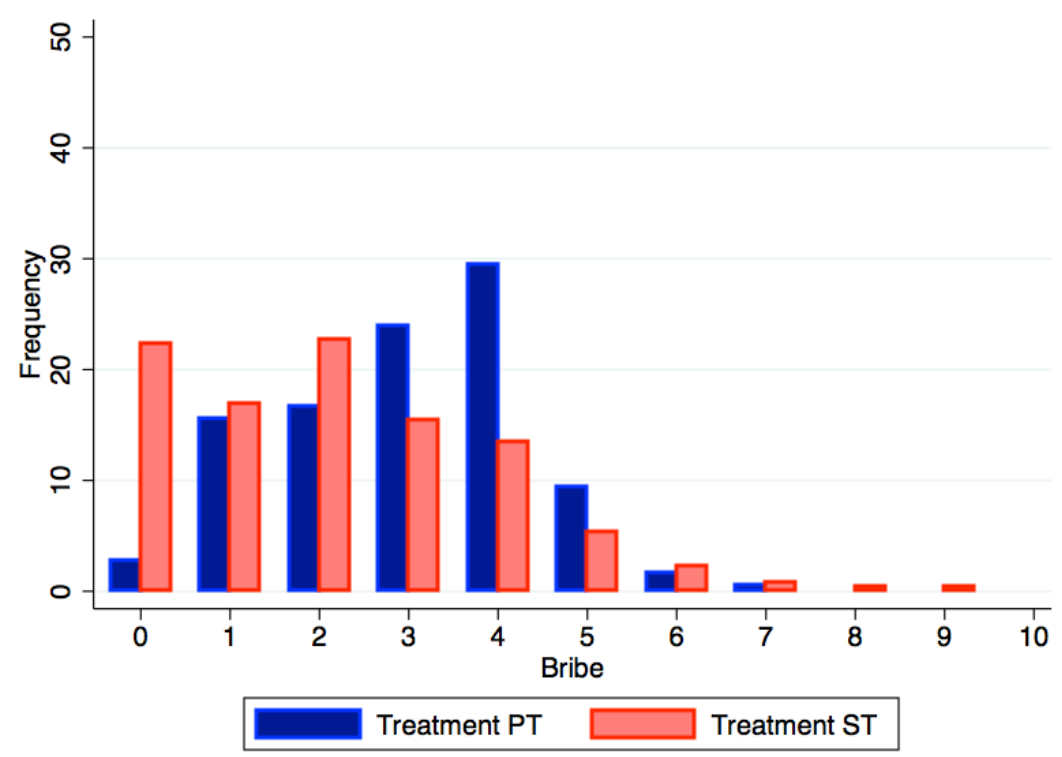

Figure 3.10: Treatment effects in distribution functions. 


\subsubsection{Efficiency and Social Welfare}

In the previous subsection we analyzed firms' decisions on bribe and quality, obtaining lower bids with a random matching (ST) than with a fixed matching (PT). We now analyze the treatment effect on efficiency and social welfare. We consider efficient decisions those decisions situated in the upper half side of the diagonal of the budget restriction, i.e. those fulfilling two conditions: first, $Q_{i}+B_{i}=10$, and, second $B_{i} \leq 5$. We remind that in the experimental implementation, the restriction for firms bids is such that $Q_{i}+B_{i} \leq 10$. Thus, given this restriction, firms have the option to not exhaust their resources, although it is inefficient.

Figure 3.11 illustrates the average time evolution of the spending $\left(Q_{i}+B_{i}\right)$ for each treatment separately and for the full sample. We clearly observe that firm-subjects are taking inefficient decisions as the average spendings are 8.71 units for the full sample. This inefficiency is even clearer for ST as the spending are 8.13 units on average, while in PT their are 9.54 units (Wilcoxon-Mann-Whitney test $\mathrm{z}=7.32$, $p<0.01)$. In ST, it seems that over time firms learn to take more efficient decisions: the average spending in period 1 is 8.00 units and it increases to 8.65 units in period 10.

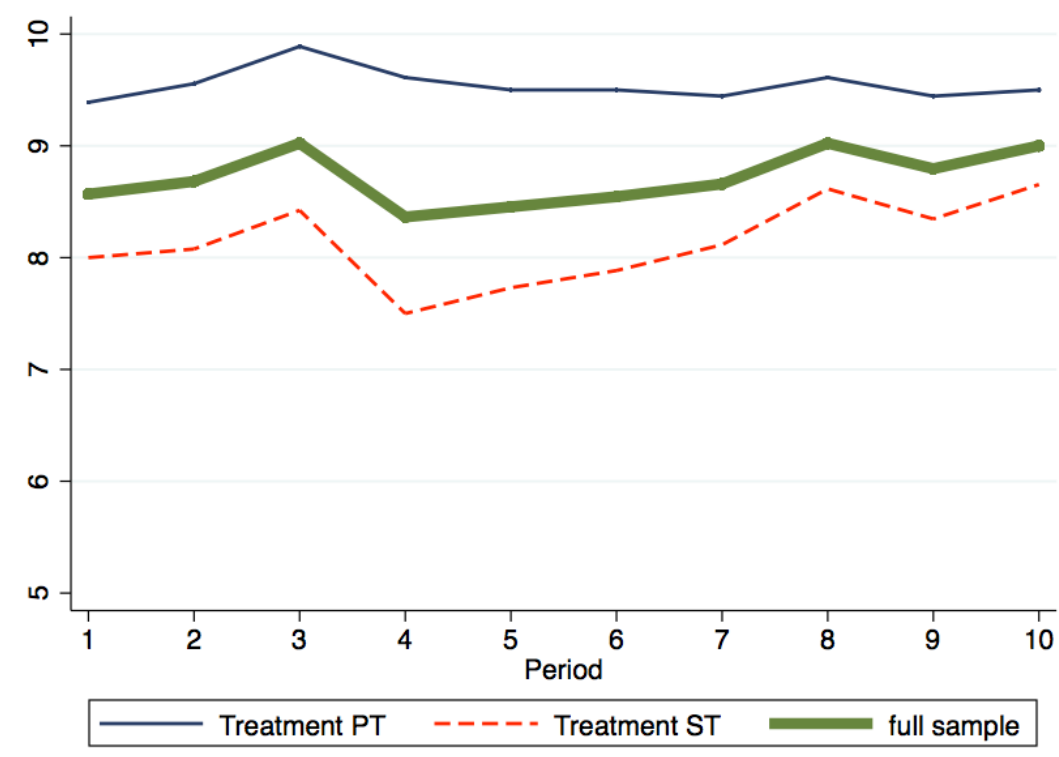

Figure 3.11: Time evolution of spendings (quality + bribe). 


\section{AN EXPERIMENTAL IMPLEMENTATION OF A PUBLIC PROCUREMENT AUCTION WITH CORRUPTION}

Figures 3.12 and 3.13 illustrate the quality and bribe bids density per treatment. The efficient decisions should be localized in the upper left side of the diagonal, combining bids of quality superior or equal than 5 units and, bids of bribe inferior or equal than 5 units. We observe a big amount of inefficient decisions, especially in treatment ST.

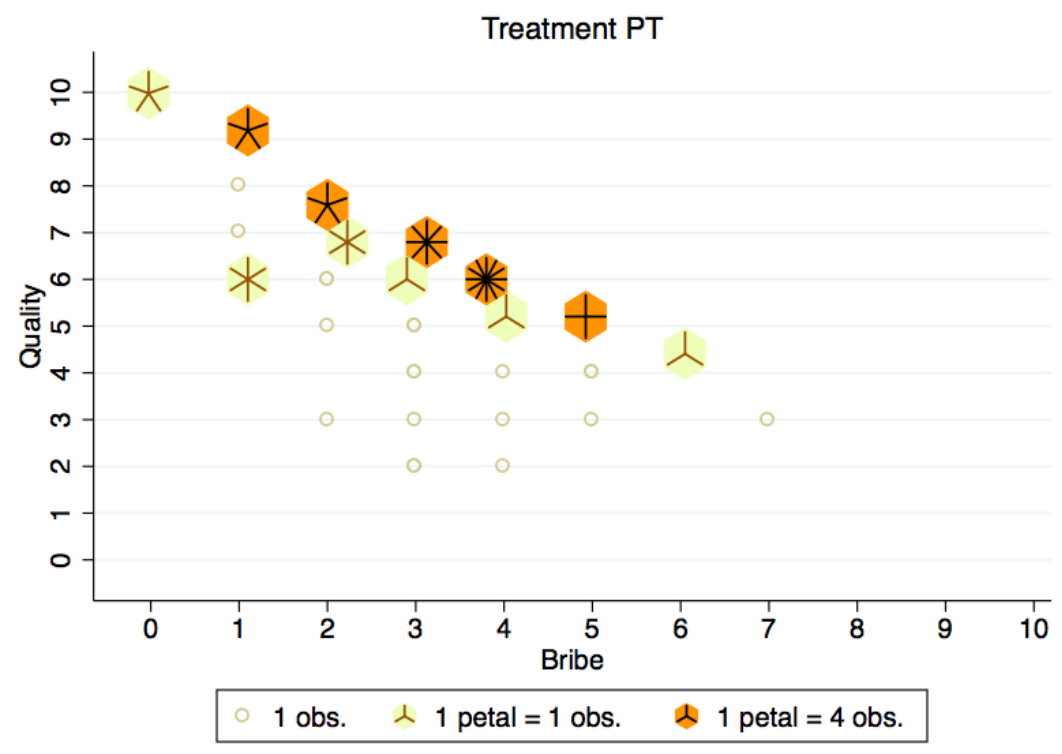

Figure 3.12: Observations density for treatment PT.

Result 4: Firms are taking inefficient decisions by not exhausting their budget restriction. This result is even more evident with a random matching protocol.

We have just analyzed how a random matching system induce firm-subjects to take inefficient decisions in the sense that they are not exhausting their restriction of quality and bribe. The question is whether the two treatments are different from a social welfare point of view. We measure social welfare as the total payoffs of each group. Thus, for any group $i: S W_{i}=\Pi_{i}^{w}+\Pi_{i}^{l}+\Pi_{i}^{o}$, where $w=$ winner firm, $l=$ loser firm, and $o=$ official.

Figure 3.14 shows the average time evolution of social welfare, by treatment. For the first 5 periods the curve of PT is always above the one of ST. The average so- 
Treatment ST

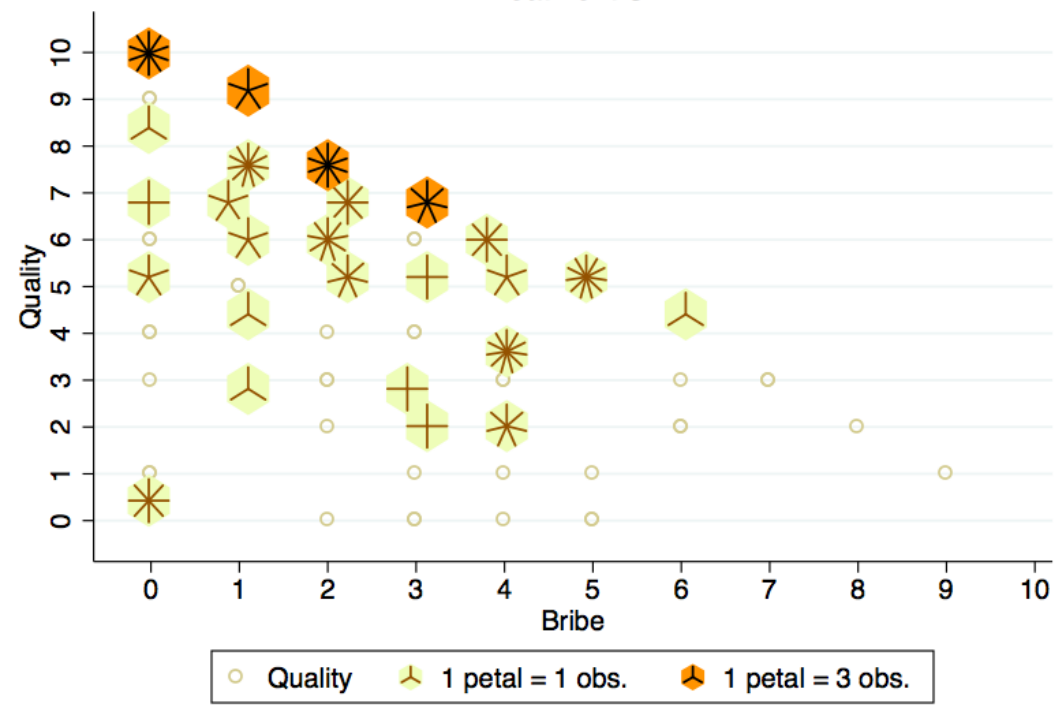

Figure 3.13: Observations density for treatment ST.

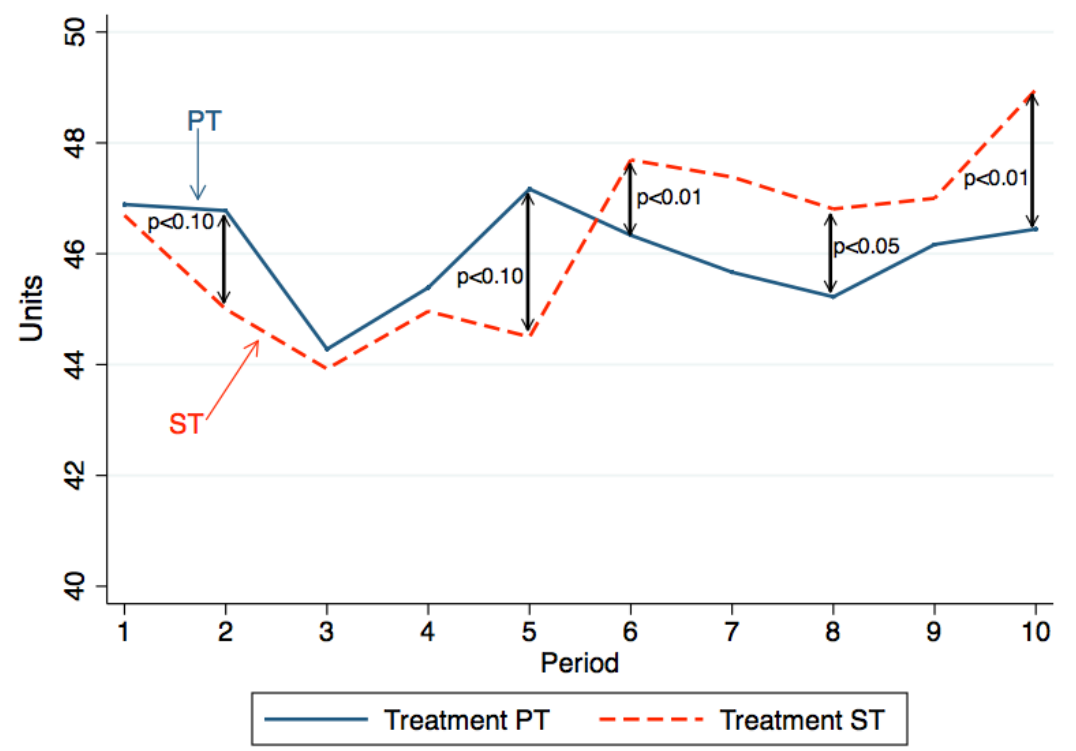

Figure 3.14: Evolution of social welfare, by treatment. 


\section{AN EXPERIMENTAL IMPLEMENTATION OF A PUBLIC PROCUREMENT AUCTION WITH CORRUPTION}

cial welfare from period 1 to 5 is 46.10 units in PT and 45.01 units in ST (WilcoxonMann-Whitney test $\mathrm{z}=1.85, p<0.10$ ). However, after period 5 we observe a switch as the average social welfare in ST (47.60 units) becomes significantly higher than in PT (45.97 units) (Wilcoxon-Mann-Whitney test $\mathrm{z}=-4.63, p<0.01$ ). On aggregate for the 10 periods, the average social welfare in ST is slightly higher than in PT (with 46.29 units and 46.03 units respectively) (Wilcoxon-Mann-Whitney test $\mathrm{z}=-1.84, p<0.10)$.

Therefore, it seems that a random matching among agents is yielding inefficient decisions, specially at the beginning of the session (period 1 to 5), thus although bribe is lower, social welfare is also lower than with fixed matching. After some periods, firm-subjects seem to learn how to take more efficient decisions in ST and social welfare becomes significantly higher than in PT.

Result 5: Inefficient decisions in the first periods yield to lower social welfare under strangers matching. After some periods, the average social welfare in strangers overtakes the one in partners.

\subsubsection{Individual characteristics: Gender}

The analysis starts by examining officials' decisions. Among men, 78.5\% of decisions are in favor of bribe and $21.95 \%$ in favor of quality. For women, these values are $63.87 \%$ and $36.13 \%$, respectively (see figure 3.15). Women playing as officials exhibit more pro-social behavior than men playing that role (Pearson $\left.\chi^{2}(1)=2.80, p<0.10\right)$

In the role of firms, men offer higher quality than women. The average quality bid made my men is significantly higher (6.48 units) than the one made by women (5.90 units) (Wilcoxon-Mann-Whitney test $\mathrm{z}=2.72, p<0.01$ ) (figure 3.16). No significant differences are found on bribe: the average bribe bid made by men is 2.44 units versus 2.56 units made by women (Wilcoxon-Mann-Whitney test $\mathrm{z}=0.86, p=0.39$ ) (figure 3.17). These results let us think that women as firms are taking more inefficient than men. In fact, the average spending of men is significantly higher than the one of women, with 8.92 units and 8.46 units respectively (Wilcoxon-Mann-Whitney test $\mathrm{z}=2.92, p<0.01$ ). 


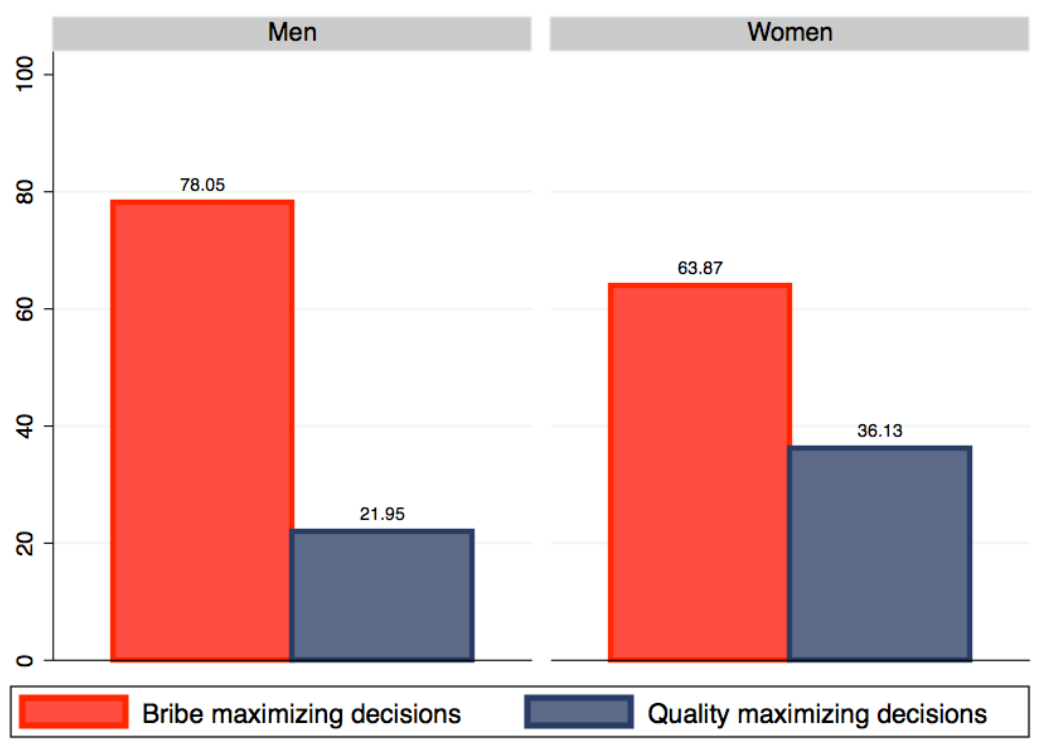

Figure 3.15: Officials' preferences, by gender.

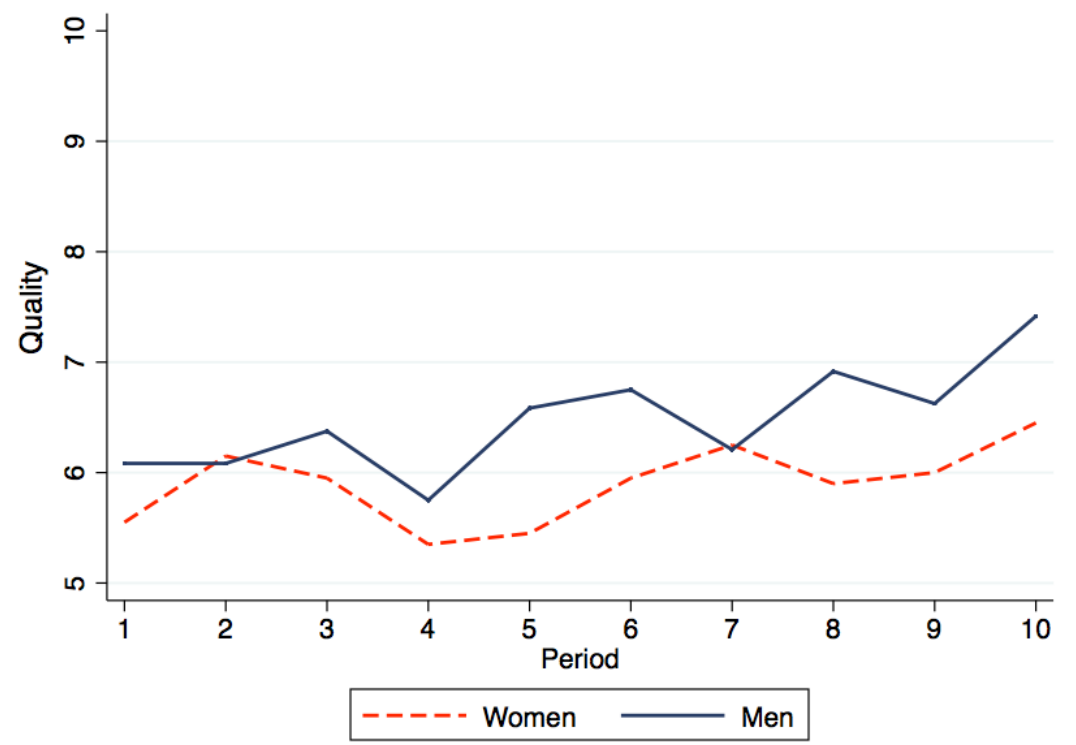

Figure 3.16: Time evolution of quality. 


\section{AN EXPERIMENTAL IMPLEMENTATION OF A PUBLIC PROCUREMENT AUCTION WITH CORRUPTION}

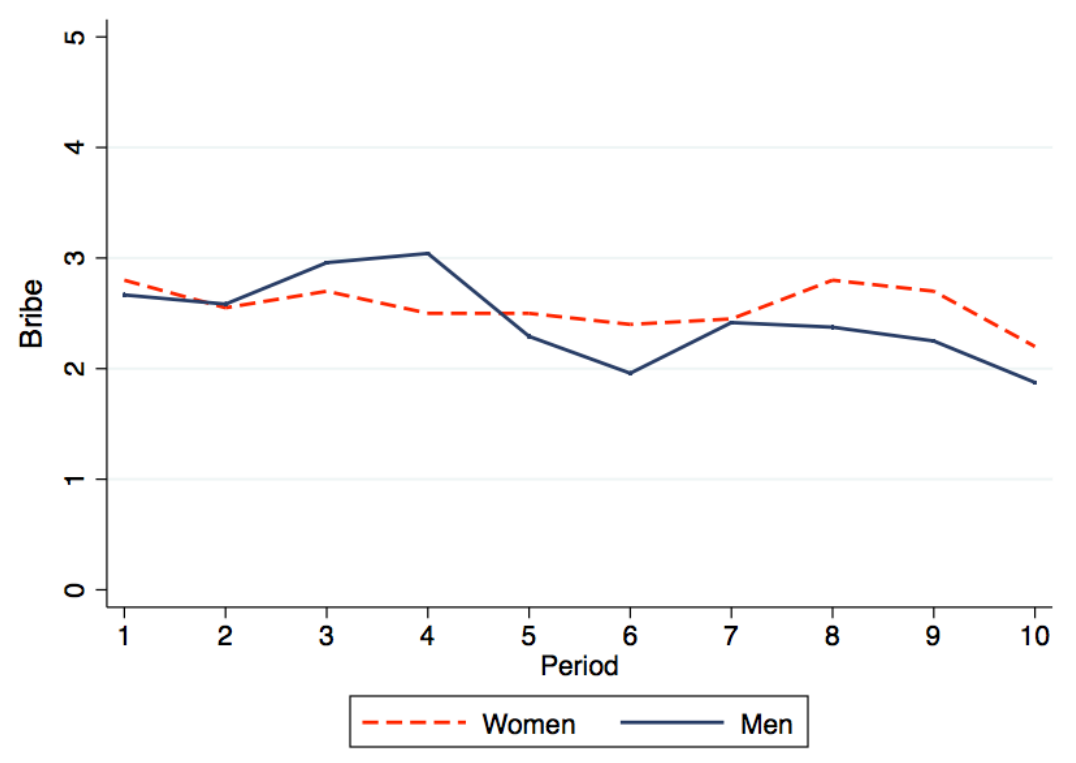

Figure 3.17: Time evolution of bribe.

Result 6: Women in the role of public officials are more willing to take prosocial decisions. However, in the role of firms they bid higher bribe and lower quality than men, mainly due to more inefficient decisions.

\subsection{Conclusions}

We experimentally test a bribery game in an auction context where two types of agents interact. Two firms competing for winning a license for a public project and one official who decides the winner of the license. Firms compete by posting simultaneously the amount of quality and bribe for this project. In the next stage, officials (according to firms' offers and to their own preferences) decide to which firm they want to assign the license. In this game, quality is endogenous and prosocial (equally increasing all players earnings). Bribe is unfair (increases inequality), anti-social, inefficient (it costs more to sender than contributes to receiver) and more attractive (than quality) to the official. The benchmark of this game is the theoretical prediction which in the discrete game there are two strong Nash equi- 
libria: $\left(Q_{i}, B_{i}, Q_{j}, B_{j}\right)=(7,3,7,3)$ and $\left(Q_{i}, B_{i}, Q_{j}, B_{j}\right)=(6,4,6,4)$ where the former is Pareto superior to the latter. In the continuous version, the equilibrium is $\left(Q_{i}, B_{i}, Q_{j}, B_{j}\right)=(5,5,5,5)$ which is a weak equilibrium and also Pareto dominated by both the other two. In this study we implemented in the laboratory the game considered in the previous chapter, as our purpose is to investigate how real people behave in this particular context. Officials' behavior reveals a clear (one third of decisions) deviation towards pro-social choice which gives a further explanation for firms' behavior. The existence of pro-social behavior favors the emergence of less corrupt behavior by firms. Although coordination on Pareto-superior equilibria and/or collusion can not be, a priori, rouled out, through the test of comparing PT and ST we get evidence against the hypothesis of collusion between firms because rather than less bribes in PT, higher bribes are found. In this line, chapter 3 extends this specific point of view with the foundation of intrinsic or extrinsic motivation.

Furthermore, in line with Abbink (2004), we confirm that staff rotation could be a precautionary measure against corruption in some levels of government. We re-matched randomly groups of firms and officials in every round and we found that levels of bribe decrease significantly with respect to the treatment in which group composition was the same along all the rounds. The fact that in each period subjects had to establish new relationships may disincentive bribery, and even more when we consider that bribery requires a trustful relationship among agents. Nevertheless, we also observe that this random re-matching mechanism also reduces quality investment. We thus wondered whether this policy that achieves at reducing bribe would finally be socially inefficient. We find subjects under a random matching are taking significantly more inefficient decisions than with a fixed matching yielding to a lower social welfare. However, our result reinforces the one of Abbink as definitively staff rotation decreases bribe and, after some periods, social welfare is increased. We do not forget the limitations that could exist from extrapolating laboratory results to real life.

We finally studied the relation between decisions on bribery and some personal characteristics. We discovered some gender effect. Women playing in the role of firms offer higher bribes and significantly lower quality than men, while when playing as officials they are more pro-social. This result advocates that women 
bribe in order not to be excluded of the system that is already perceived as corrupt, but when women have the discretionary power of deciding (i.e. they play as officials) they make public their preferences against bribery and in favor of social welfare. Following Alatas et al. (2009a) we prefer to keep this result as specific of the idiosyncrasy of the subjects' pool instead of exposing its global validity. 


\subsection{Appendix: Instructions to experimental subjects (translated from Spanish)}

Welcome and thanks for your participation in this experiment. Please switch off your mobile phones and secure your belongings away. You are going to participate in an experimental session of 10 rounds. You will earn an amount of money which will depend on your decisions and the decisions of other participants in the session. From this moment onwards you must use only the instructions and the computer in front of you. If you have any questions throughout the session, please raise your hand and you will receive an answer by one of the experimentalists. Any communication with other participants will imply your immediate exclusion from the experiment.

At the beginning of this session, you will be assigned one of two roles: 'a firm' or 'an official'. Your role is randomly assigned to you and remains fixed throughout the session. You will be anonymously and randomly assigned to a group of three players: two firms and one official. The group will be fixed throughout the session (Each group of 3 will consist of 2 firms and 1 official that will change every round but the role will remain along the experiment) [only for ST]. Rounds are independent, in the sense that the payoff consequences of decisions made in any round do not carry over to subsequent rounds.

\section{- Decision Making}

In each round, all players receive an endowment of $10 \mathrm{ExCU}^{1}$ If you are a firm: You compete with the other firm of your group for the license of a public project whose quality is beneficial to all players in the group. In each round, you have to post bids on the quality of your project and a monetary transfer which you wish to send privately to the official in your group if you are chosen to undertake the project. Firms' bids are made simultaneously, so that each firm can only know its own bids, but not the bids of the other firm. If you win the auction, apart from your round endowment, you earn a fixed extra profit. In that case, you

\footnotetext{
${ }^{1}$ Experimental Currency Unit.
} 


\section{AN EXPERIMENTAL IMPLEMENTATION OF A PUBLIC PROCUREMENT AUCTION WITH CORRUPTION}

also have to spend on the transfer to the official double the amount you promised in your bid. If you lose the auction, apart from your initial endowment from each round, your earnings include a profit which is proportional to the quality of the winning project.

If you are an official: In each round, you receive the bids from the firms in your group. Then, you have to choose one of the two projects. Apart from your initial endowment in this round, your earnings include a profit which is proportional to the winner's quality plus the amount, if any, privately transferred to you by the winner.

\section{- Exact calculation of profits}

From the description of strategies and earnings above, the specific formulas used to calculate your profits in each round $(\pi)$ are a function of the quality $(Q)$ and transfer $(B)$ bids of the winner, as shown below:

$$
\begin{gathered}
\pi_{\text {winner }}=10+\frac{1}{2} \cdot Q_{\text {winner }}+10-2 \cdot B_{\text {winner }} \\
\pi_{\text {loser }}=10+\frac{1}{2} \cdot Q_{\text {winner }} \\
\pi_{\text {official }}=10+\frac{1}{2} \cdot Q_{\text {winner }}+B_{\text {winner }}
\end{gathered}
$$

\section{- Information received}

If you are a firm: At the end of each round, you will receive information on which firm won the license, a reminder of your decisions on quality level and transfer in that round, as well as your profit for that round.

If you are an official: In each round, after firms have made their decisions, their quality and transfer bids will be displayed on your screen before you make a decision. Once you select the winning firm, you will receive information on your profits in this round.

\section{- Monetary rewards}


In order to determine your payment in the experiment, the computer will randomly choose one of the 10 rounds at the end of the session. The amount of money you will earn from this part of the experiment will be equal to your profits in the randomly chosen round, multiplied by an equivalence ratio of $1 \mathrm{ExCU}=\frac{1}{2}$ Euro. 



\section{Intrinsic and extrinsic motivations of pro-social behavior in an auction that allows for corruption}

\subsection{Introduction}

Corruption is regarded as one of the most detrimental factors that hindrance well functioning economies in both the developed and the developing world. It has been present during all times and has intruded all political systems. Trying to approximate the monetary consequences of corruption is only half correct since the non pecuniary costs of this distortion are equally harmful and are, most of the times, missing from the recording attempts. A positive correlation exists between corruption and poverty and it seems to rise when countries are suffering economical problems. In addition, the existence of corruption creates both an unhealthy economic and social environment as it is closely connected with the ethical and moral values of humanity. For economists, reducing corruption is a target that has not 


\section{INTRINSIC AND EXTRINSIC MOTIVATIONS OF PRO-SOCIAL BEHAVIOR IN AN AUCTION THAT ALLOWS FOR CORRUPTION}

been accomplished yet. In fact, it is difficult since positive as well as negative effects have been found. On the one hand, we find those researches that demonstrate the positive effects of corruption. The general claim is that corruption enhances efficiency as it corrects some public sector fails and it 'greases the wheels' of the economy (Egger and Winner, 2005; Huntington, 1968; Leff, 1964; Lui, 1986). On the other hand, others authors rather believe that corruption is the cause of inefficiency (Rose-Ackerman, 1999). Empirical researches have been addressed to support the negative consequences of corruption as Mauro (1995) who demonstrates how corruption decreases growth. Gupta et al. (2002) display the negative effects of corruption on inequality and poverty. Van Rijckeghem and Weder (2001) find evidence that corruption is lower when the public employees' wages are high relative to those of the manufacturing sector. Dollar et al. (2001) associate a higher representation of women in the parliament with lower corruption.

Measuring corruption is a big challenge as far as data are not observable. Rather most of empirical researches are based on subjective surveys 11 We believe experimental economics is a useful methodology in order to study some complicated areas, as is the case of corruption or tax evasion among others. It allows us to investigate the personal behavior towards bribery and specific patterns around it according to the specific characteristic the researcher is interested to capture. Experiments have been used to test the effect and usefulness of some policies in the sense of changing institutional context. For instance the effect of monitoring in a basic bribery scenario (Abbink et al., 2002; Schulze and Frank, 2003) and different types of monitoring (Serra, 2012), the different matching protocols testing the interaction system between agents (Abbink, 2004), varying wages (Abbink et al., 2002; Azfar and Nelson, 2007) and an institutional legal system which protects bribe givers (Abbink et al. 2014). Other studies focus on the characteristics that could encourage a bribing behavior, as subjects' background, culture, and gender (Alatas et al., 2009a b; Banuri and Eckel, 2012; Barr and Serra, 2010; Cameron et al., 2009; Frank et al., 2010; Frank and Schulze, 2000). Hence, we firmly believe in

\footnotetext{
${ }^{1}$ Transparency International publishes annually the Corruption Perceptions Index (CPI) which ranks countries by their perceived levels of corruption, as determined by expert assessments and opinion surveys. Surveys/assessments are either business people opinion surveys or performance assessments from a group of analysts.
} 
the emergency of studying the idiosyncratic factors explaining bribing propensity, and the mechanisms that could encourage/deter bribing, as well.

Based on the same framework used in the previous chapter, we aim at studying, on a bribery context, the effect of affecting two dimensions: people's extrinsic and intrinsic motivation. First, we add a new institution which permits the losing firm of an auction for a public project, to inspect whether the wining firm and the auctioneer (as a public official), were involved in some corrupt transactions. If any bribe was offered by the firm and finally accepted by the public official, the inspection institution is in charge of automatically sanctioning both. This institution allows us to study the effect of activating the extrinsic motivation on subjects. Second, we add a new player called the 'citizen' as an observer and passive receiver of the potentially corrupt transactions. We expect that this mechanism activates people's intrinsic motivation.

In addition, our experimental implementation design was carefully though in order to run 4 treatments in just one session permitting us to perform both, a between and a within subjects analysis and to control for any slight difference among treatments. Starting from a determined basic institutional environment we add the new institutions one over the other and we calibrate exactly the impact of each one separately, and combining both. This design allows us to disentangle whether the intrinsic motivation of subjects that play as firms and officials is activated just by the presence of the 'citizen' or because they are aware that their decisions determine citizens' earnings.

The two aforementioned dimensions of people have been already studied on several experiments on corruption. Although inspired by the work of Abbink et al. (2014), in which people's extrinsic motivation is activated through 'reporting' and Barr and Serra (2009), in which the intrinsic plane is activated through a negative externality produced by bribery on passive players, our design permits to capture some features that others can not.

To summarize the aim of this chapter, we enumerate the main questions we try to answer:

1. We test the effect of activating the extrinsic motivation of people by incorporating a new institution permitting the losing firm of the auction to call for inspection. 


\section{INTRINSIC AND EXTRINSIC MOTIVATIONS OF PRO-SOCIAL BEHAVIOR IN AN AUCTION THAT ALLOWS FOR CORRUPTION}

2. We test the effect of activating the intrinsic motivation of people by incorporating a passive player affected by the potentially corrupt transactions. We disentangle the effect of the passive player as just an observer from the effect of this player as an observer and affected player.

3. We seek a pattern of characteristics of bribers such as gender and risk attitudes.

4. We use a novel design where 4 treatments were run in one experimental session.

In the following section we provide a deep literature review related with our objective. In section 4.3 we briefly describe the experimental design and discuss the methodology followed in this study. Section 4.4 is dedicated to show the results in detail. We provide in section 4.5 the main conclusions of this chapter.

\subsection{Related Literature}

It is well known among researchers that attempting to study corruption is a difficult task as many are the barriers and lacks of information around this important phenomenon. We use the experimental methodology as a well-fit approach to analyze how a person who is disposed to bribe can be influenced using both, extrinsic and intrinsic motivations. We therefore consider that a way to activate the extrinsic motivation of human being could be an exogenous mechanism that threats punishing those people who are caught bribing.

\subsubsection{Literature on extrinsic motivation}

In our experiment, the extrinsic motivation is activated through an inspection option available for the loser firm of an auction which allows for bribing. By extrinsic motivation we refer to any external factor that can affect subjects' behavior. We believe that this implementation is closely related to the 'punishment' literature. Experimental economists have broadly studied punishment and its effects in human behavior. Although it has been studied in many contexts, the most common framework is the public good games. Fehr and Gächter (2000, 2002) inspired many 
researchers as they demonstrate how, even if punishment is costly, it is frequently used and has effective results in terms of reducing free-riding and, hence, increasing cooperation.

Our interest is punishment in a large sense, i.e. any action (threat, punishment, inspection) from a player that is addressed to discourage other players of deviating from the social norm. Specifically, the social norm we are interested in is the one that subjects consider as ethics.

A set of experiments on corruption are those in Alatas et al. (2009a b) or Cameron et al. (2009) who implemented a common design, consisting of a bribery one-shot game among a firm (not) offering a bribe, an official (not) accepting the bribe and a citizen who does (not) punish both the other two agents at a cost. Punishment is mainly used to measure the level of tolerance towards corruption.

Reporting behavior has been deeply studied by Abbink et al. (2014) who test the validity of Basu's (2011) theory, claiming that legal immunity for bribe-giver could encourage reporting officials for demanding bribes. The authors conducted an experiment representing the situation in which a public official asks for a bribe to a citizen, in exchange of a good or service he is obliged to provide. This is what the authors consider 'harassment bribes'. The purpose of the work is to compare the situation in which bribe-giver and bribe-taker are equally guilty when caught, with the situation in which just the bribe-taker is guilty. The former corresponds to 'symmetric liability' and is used as a baseline. The later corresponds to 'asymmetric liability' and just the official is punished if caught. The authors find that the immunity for bribe-givers increases the propensity to report, and decreases the propensity to demand bribes from officials. Interestingly, when bribes are not refund to the citizens after reporting, a minority of citizens refuse to pay bribes suggesting that this behavior comes from intrinsic motivations rather than economical ones.

Our work is somehow related to the aforementioned one, as we also study the effect of reporting, but we prefer to use the term 'inspection'. Differently from Abbink et al. (2014) we study the effect of adding an inspection option to the loser firm in the framework of a public auction. We share the authors' opinion that is not realistic that a citizen could punish the corrupt agents, specially in our public auction context. We thus believe that their are only two ways to punish corrupt people. 


\section{INTRINSIC AND EXTRINSIC MOTIVATIONS OF PRO-SOCIAL BEHAVIOR IN AN AUCTION THAT ALLOWS FOR CORRUPTION}

Either, they are caught by the responsible authorities, or they are reported/inspected internally by one of the agents participating in the corrupt interaction. Countries with high level of corruption, generally lack a reliable monitoring institutional system. Hence, giving the opportunity to one of the affected agents by corruption to call for inspection may be a more efficient solution. However, differently from Abbink et al. (2014) we believe that in the context of public procurement auctions, inspections are more plausible because companies have more political and economical power to report than citizens. Our design, however, does not permit to disentangle the intrinsic from the extrinsic motivation of reporting as Abbink et al.'s (2014) design. In our work, we are rather more interested on studying the effect of activating the extrinsic motivation through the threat of an inspection, made by the losing firm, which is completely irrational from an economical point of view as the theoretical prediction suggest that no inspection is activated on equilibrium.

The whistle-blowing mechanism has been also studied in other framework as antitrust policies by Apesteguia and Dufwenberg (2007) and Bigoni et al. (2012). Inspired by all these studies, our design introduces an inspection mechanism allowing to highly activate the extrinsic motivations of participants.

\subsubsection{Literature on intrinsic motivation}

We are also interested in the effect of activating subjects' intrinsic motivation to behave in a more pro-social way by abstaining more often from bribery. We consider intrinsic motivations as those different from the pure monetary interest. This aspect has also been studied in many fields and from different perspectives.

For instance, a participant playing as dictator in a dictator game giving any positive amount of money reveals altruistic motivation. Many researches in experimental economics demonstrate that subjects are altruistic even in anonymous contexts (Andreoni et al., 2007; Andreoni and Miller, 2002; Andreoni and Vesterlund, 2001; Eckel and Grossman, 1996; Forsythe et al., 1994; Harbaugh et al., 2007; Vesterlund, 2006). This feature is enhanced when manipulating the social distance between giver and receiver, in the sense of the giver knowing some information about the receiver, they become more willing to give. For example, if the giver sees the receivers or know just their name or a characteristic of them, the amount given 
in a dictator game is higher (Bohnet and Frey, 1999).

Other experimental techniques have an effect on increasing cooperative behavior. Interestingly, the watching eyes manipulation affects contributions in a public good game. A field experiment where a pair of eyes is displayed on a honesty box makes people pay triple than in a baseline (Bateson et al. 2006). Furthermore in MIT, a robot with eyes on subjects' computer screen yields an increase on subjects' contributions in a public good game (Burnham and Hare, 2007), and this can not be explained by standard economic theory. The watching-eyes manipulation works almost systematically as a way of increasing contributions. In fact, Burnham (2003), Haley and Fessler (2005), Rigdon et al. (2009) show that three dots are sufficient to increase giving in dictator game. Mifune et al. (2010) used the same stimuli as Haley and Fessler (2005) and showed that the eyes effect in the dictator game is working just when the giver perceives that the receiver belongs to the same ingroup than himself. Thus, just the physical presence of other people in the room or non-verbal cues are provoking an increase on contributions. More experiments on this topic are Andreoni and Petrie (2004), Hoffman et al. (1994), Kurzban (2001). However, some examples can be found where the watching-eyes or the physical presence have no effect on decisions. Lamba and Mace (2010) showed that presence of other people when playing ultimatum game do not change the behavior. In other context in which there is reciprocity, Fehr and Schneider (2010) found that the eyes images on the computer screen (the watching eyes manipulation) had no effect on the second player of a trust game.

Considering that just the presence of someone watching you can affect decisions, our design was thought accurately to disentangle whether an increase on pro-social behavior is due to an observer player from an observer and affected player.

Several experiments on corruption include an externality effect, meaning that other people of the society are negatively affected by corruption. Abbink et al. (2002) run a bribery game in which a potential briber and a bribee interact. The briber decides whether and how much bribe offers to the bribee. The bribee has the option to accept or to reject the bribe. In the 'negative externality treatment', when a bribe was offered and reciprocated by the bribee, all the other players in the same session incurred a loss. This manipulation allows the authors to study the effect of the negative externality provoked by bribery in others members of the society. No 


\section{INTRINSIC AND EXTRINSIC MOTIVATIONS OF PRO-SOCIAL BEHAVIOR IN AN AUCTION THAT ALLOWS FOR CORRUPTION}

effect was found from this treatment.

Alatas et al. (2009a b), Cameron et al. (2009), based on the same design, represent the situation in which a public official and a firm interact on a potential bribery exchange. If a bribe is offered by the firm and accepted by the official, then a third player, a citizen, is affected by the negative externality, yielding to a reduction on his payoff. In the final stage, the citizen has the option to punish the corrupt agents, at a cost.

Barr and Serra (2009) use a new design to represent a 'petty corruption' scenario. ${ }^{1}$ This design consist of a one-shot game involving a citizen who may pay a bribe to an official having the option to accept or reject, and 'other members of society' who incur a cost for every bribe offered and accepted by two potentially corrupt agents. The authors analyze the impact of framing and the effect of variating the level of the negative externality produced by bribery on 'other members of society'. They find that combining framed instructions with high negative externalities on 'other members of society' reduce the offers of bribe made by citizens. However, when just either frame or high externality are present, the offers tend to increase. Officials are more willing to reject bribes when there is no frame and with high externalities. They do not find a framing effect. We hence believe that this interesting work is closely related to ours, mainly in the externality feature. Usually designs involving a passive receiver treatment do not distinguish between the effect of being observed and main decisions affecting a passive player, because the two features are introduced simultaneously as Barr and Serra (2009). However, in our work we compare unaffected observers of the decisions versus influenced observers by the externality. Thus, our design allows to disentangle whether firms and officials' decisions are affected by the mere presence of the passive players observing them or because they are aware that their decisions are influencing the observer. In Barr and Serra (2009), the passive players are composed by groups of 5 members equally affected by the externality of 5 pairs firms and citizens, whereas in our design, each passive player is affected by each triplet of 2 firms and 1 official, in order to avoid interdependence among decisions. Their design corresponds to a 'petty corruption' scenario where a citizen offers a bribe to an official. We believe, that corrupt public auctions are really engendering negative externalities on society. Differently from

\footnotetext{
${ }^{1}$ This design has been replicated by Barr and Serra (2010) and Serra (2012) among others.
} 
Barr and Serra (2009), we do not look for a framing effect in our work.

Our experimental design includes passive observer players who are also victims of the potentially corrupt transactions.

\subsection{Experimental Design}

\subsubsection{Theoretical Framework}

Our baseline game is equivalent to the one explained in chapter 3 . We have applied the restriction $Q+B \leq A$ for each firm-subject's strategies, reflecting the trade-off between quality and bribe. We have used the parameter set (F, a, c, A, $\mathrm{R})=\left(10, \frac{1}{2}, 2,10,10\right)$. Taking this payoff structure into account, implying that agents care only for the monetary consequences of their actions and assuming a continuous strategy space, the unique Nash equilibrium is such that both firms' bids involve $(Q, B)=(5,5)$. That is, like in Bertrand competition, in equilibrium firms will be willing to spend on the bribe as much as the bonus they obtain from winning the auction. However, for simplicity, our experiment is run with a discrete strategy space, allowing only for integer quality and bribe bids. Then, multiple equilibria emerge including $(Q, B)=(7,3)$ and $(Q, B)=(6,4)$. In this case, the unique continuous-strategy equilibrium $(Q, B)=(5,5)$ becomes a weak equilibrium, since each firm is indifferent between this and posting lower bribes, then becoming a loser (with a 12.5 units payoff in both cases) 1$]$

In this chapter the novelty is the inspection treatment, which includes a new stage after the officials' decisions, allowing to highly activate the extrinsic motivations of participants. We expect that the impact of this inspection mechanism is going to be high, despite the low frequency of using it. In our design the loser firm of the license has the option to inspect the official and the winner firm. The inspecting firm has not a direct cost but incurs in the risk of losing all her payoffs if its inspection is wrong. In real life such a policy would be costless for the government if the cost for the legal prosecution of a suspicious public project would burden any company that initiated such a procedure. In our experiment the risk faced by the losing firm (being punished with a zero payoff) if the lawsuit does not reveal

\footnotetext{
${ }^{1}$ The theoretical model and its predictions are developed in chapter 2
} 


\section{INTRINSIC AND EXTRINSIC MOTIVATIONS OF PRO-SOCIAL BEHAVIOR IN AN AUCTION THAT ALLOWS FOR CORRUPTION}

any money transfer, simulates the cost that a company in real life would have to suffer to initiate a legal prosecution. In fact, an extreme version of the inspection mechanism is chosen. Inspection is a dominated strategy whose expected payoff is negative. Thus, in equilibrium no inspection is expected and equlibria do not change with respect to the baseline treatment.

\subsubsection{Procedures}

The session was conducted in the Laboratorio de Economía Experimental (LEE) at the University Jaume I. $]^{1}$ The average earnings were 19.60 euros per subject. The participants were recruited using ORSEE software (Greiner, 2004) from a pool of students, with majority of economics students. We recruited 77 subjects, 66 of them would be given the role of either firm or official, and the 11 remaining would participate in the game as citizens. Our design allowed us to run 4 treatments in one session.2

In our study we also measure also risk attitudes as a subject's willingness to choose a riskier option among a number of winning probability and prize pairs. Here, we adopt two lottery tests, firstly introduced by Sabater-Grande and Georgantzis (2002) from which we can extract subjects' risk aversion and risk aversion with losses level ${ }^{3}$ We also collected some other information about the subjects like their age and gender.

\subsubsection{Treatments}

Four treatments were run in one session. A total of 66 subjects were grouped into two groups (group $1 \&$ group 2 ) of 33 subjects each one.

Treatment B was run with group 1 and subjects play the baseline game for 15 periods. We divide the 33 subjects of group 1 into 11 markets. In each market, there are two firms and one official. We informed the 11 markets of group 1 that the amount each firm places for quality, as well as the winner of each round are going to be

\footnotetext{
${ }^{1}$ The experiment was programmed and conducted with the software z-Tree (Fischbacher, 2007).

${ }^{2}$ Instructions are provided in appendix 4.6

${ }^{3}$ Risk aversion lotteries played by subjects are provided in appendix 4.7 . From figure 4.11 we extract subjects' risk aversion and from figure 4.12 we extract subjects' risk aversion with losses.
} 


\subsection{Experimental Design}

shown in a monitor to a group of 11 citizens that observe the decision-making of the experiment from next room. Specifically, the room in which citizens are seated is separated by just a glass. So that citizens could perfectly see firms and officials decision making during the session. We denote these citizens as observe-only citizens.

In treatment $\mathrm{C}$, we divide the players of group 2 in 11 markets, following exactly the same procedures as in treatment $\mathrm{B}$. The only difference is that in treatment $\mathrm{C}$ the firms and the officials are informed that the outcome of each round is affecting the payoff of the citizens. Explicitly, they are informed that there is one citizen for each market and that citizens' payoffs for each round will be exactly the quality placed by the winning firm. We denote these citizens as affected citizens. 11 The comparison between treatment $\mathrm{B}$ and $\mathrm{C}$ allows us to investigate any impact that the externality might have on the placement of bribery and, eventually, on quality. The feature of a citizen as a passive receiver of the quality of the public project tries to illustrate how firms and officials can be affected by their awareness that their decisions may affect social welfare. The design also permits to seclude, on firms and officials, the effect of being observed from the effect of affecting other people's payoffs.

In the end of round 15 we gave new roles to the 33 subjects of group 1 and 2, so now 11 new markets of firms and officials emerged for each group while still the 11 citizen players observe through a monitor the evolution of the game. Continuing the same structure and scenario as the previous treatments, we now insert a new option for the firms. After each auction has been resolved by the auctioneer, the loser firm can activate the inspection option to reveal a possible bribe. A revealed bribe leads both players involved to the loss of their period earnings, whereas, if no bribe is revealed, the denouncing firm loses all its period profits instead. The option is available to the losing firm either it has placed a bribe or not. Hence, from round 16 to round 30, group 1 played treatment $\mathrm{Bi}$ and group 2 played treatment $\mathrm{Ci}$. To summarize, treatment $\mathrm{Bi}$ and $\mathrm{Ci}$ replicate the same conditions concerning the citizens as in treatment $\mathrm{B}$ and $\mathrm{C}$ respectively, but including the inspection option for the loser firm.

\footnotetext{
${ }^{1}$ Note that observe-only citizens and affected citizens are the same subjects but they have a different role for each group.
} 


\section{INTRINSIC AND EXTRINSIC MOTIVATIONS OF PRO-SOCIAL BEHAVIOR IN AN AUCTION THAT ALLOWS FOR CORRUPTION}

From this session we get a sample from which we could do a between subjects and within subjects analysis. Table 4.1 summarize the features containing each treatment 1

\begin{tabular}{lcc}
\hline & no-inspection & inspection \\
\hline Period & 1 to 15 & 16 to 30 \\
observe-only citizen & Treatment B (Group 1) & Treatment Bi (Group 1) \\
affected citizen & Treatment C (Group 2) & Treatment Ci (Group 2) \\
\hline
\end{tabular}

Table 4.1: Summary of treatments.

\subsection{Results}

\subsubsection{The sample}

The sample is composed of 66 people (mean age: 23, st. dev.: 2.9) playing as firm and official, 33 of whom were women and 33 men. The sample is perfectly balanced among gender, by treatment and by the role played ${ }^{2}$ Concerning firms, in each treatment the share-out was equal (11 men, and 11 women). Concerning officials, the sample was almost balanced: 6 men (and 5 women) played as officials in treatment $\mathrm{B}$ and $\mathrm{Bi}$, and 5 men (and 6 women) played as officials in treatment $\mathrm{C}$ and $\mathrm{Ci}$.

\subsubsection{Treatment effects}

In this section we test for differences among treatments. In order to organize the exposure of the results, some of the analyses will be performed by gathering treatments in couples. Specifically, no-inspection treatments gather treatments B \& C, inspection treatments gather treatments $\mathrm{Bi} \& \mathrm{Ci}$, observe-only treatments gather

\footnotetext{
${ }^{1} \mathrm{~A}$ croquis of the laboratory is provided in appendix 4.8

${ }^{2}$ Actually, 11 more participants play as citizens, who are passive players not taking decisions. Thus, an amount of 77 subjects participate in this experiment. We do not include the 11 citizens in our analysis as no decisions were taken by them.
} 
treatments $\mathrm{B} \& \mathrm{Bi}$, and affected treatments gather treatments $\mathrm{C} \& \mathrm{Ci}$. The purpose of this arrangement is to study the net effect of some of the manipulations, by omitting the features we are not interested in.

\subsubsection{The citizen}

The citizen is a passive player, it is not a decision-taker but, it is just observing and being affected by the decisions of firms and officials. The fact that the decisions of the market agents (firms and officials) can affect the citizens' payoffs can be interpreted as the activation of the intrinsic motivation of people. For this purpose, we conduct a between subjects analysis by comparing, individually, treatment $\mathrm{B}$ vs treatment $\mathrm{C}$ and treatment $\mathrm{Bi}$ vs treatment $\mathrm{Ci}$. We also compare observe-only treatments vs affected treatments in order to study the pure effect of citizen, omitting the inspection effect.

\subsection{Firms}

Figures $4.1,4.2,4.3$ illustrate the effect produced by citizens on firms' bribe decisions. In general terms, we observe lower bribe bids and consequently higher quality bids when the citizen is affected by others' decisions with respect to observeonly citizens. Figure 4.1 presents the evolution of bribe averages over time. In the treatments where the citizen is an affected citizen $(\mathrm{C} \& \mathrm{Ci})$ the curve is in the majority of periods below the one where the citizen is an observe-only citizen ( $\mathrm{B} \&$ $\mathrm{Bi})$. In fact, the average bribe offered in treatment $\mathrm{C}$ is significantly lower than in treatment $\mathrm{B}$. Likewise, the average bribe is significantly lower in treatment $\mathrm{Ci}$ than in treatment $\mathrm{Bi} \cdot 1]$

Figure 4.2 supports the previous result by displaying the distribution of bribe for each treatment. In this figure we underline the increase of the zero-bribe offers, produced by the effect of citizen. In treatment B just $1.82 \%$ of bribe offers were null, however this percentage increased up to $12.42 \%$ in treatment $\mathrm{C}$, with

\footnotetext{
${ }^{1}$ Henceforth, table 4.2 displays the bribe average bids for each treatment. Table 4.3 displays the corresponding non parametric test to compare treatment effects. In particular, Mann-Withney corresponds to Wilcoxon Mann-Withney rank sum test. Kolm.-Smir. corresponds to KolmogorovSmirnov test. Wilcoxon corresponds to Wilcoxon matched-pairs signed-rank test.
} 


\section{INTRINSIC AND EXTRINSIC MOTIVATIONS OF PRO-SOCIAL BEHAVIOR IN AN AUCTION THAT ALLOWS FOR CORRUPTION}

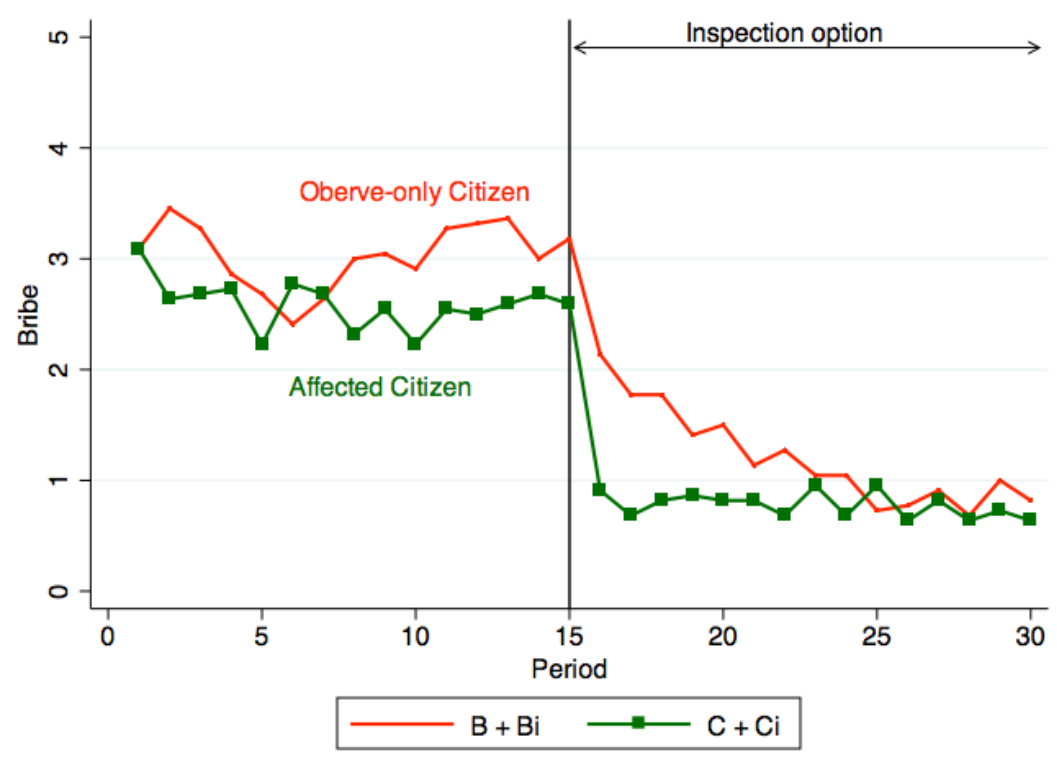

Figure 4.1: The evolution of bribe

\begin{tabular}{lllll}
\hline Treatment & $\mathrm{B}$ & $\mathrm{Bi}$ & $\mathrm{C}$ & $\mathrm{Ci}$ \\
\hline Bribe & 3.03 & 1.20 & 2.59 & 0.77 \\
standard deviation & 1.26 & 1.81 & 1.61 & 1.97
\end{tabular}

Table 4.2: Average bribe offers.

significantly different distributions. In treatment $\mathrm{Bi}, 63.33 \%$ of offers of bribe were zero vs $82.12 \%$ in treatment $\mathrm{Ci}$, with significantly different distributions (table 4.3 . Kolmogorov-Smirnov test).

Figure 4.3 presents the distribution of bribe, comparing observe-only treatments with affected treatments. Again, there is an increase on the percentage of decisions of offering zero bribes when the citizen is economically affected by the others' decisions. A $32.58 \%$ of offers of bribe are null when citizen are just observers and $47.27 \%$ when citizens are observers and receivers. Hence, omitting the inspection condition, we find statistically significant differences on distributions for the net effect of citizens (table 4.3. Kolmogorov-Smirnov test). Firms are more frequently 


\begin{tabular}{lccccccc}
\hline Treatments & \multicolumn{2}{c}{ Mann-Withney } & \multicolumn{2}{c}{ Kolm.-Smir. } & \multicolumn{2}{c}{ Wilcoxon } \\
\hline & $\mathrm{z}$ & $p$ & $\mathrm{D}$ & $p$ & $\mathrm{z}$ & $p$ \\
$\mathrm{~B}$ vs C & 3.24 & 0.00 & 0.20 & 0.00 & & \\
Bi vs Ci & 4.89 & 0.00 & 0.19 & 0.00 & & \\
[observe-only] vs [affected] & -5.76 & 0.00 & 0.18 & 0.00 & & \\
B vs Bi & & & 0.61 & 0.00 & 9.33 & 0.00 \\
C vs Ci & & & 0.70 & 0.00 & 11.24 & 0.00 \\
[no-inspection] vs [inspection] & & & 0.66 & 0.00 & 31.83 & 0.00 \\
\hline
\end{tabular}

Table 4.3: Non parametrics tests for a comparison among treatments.
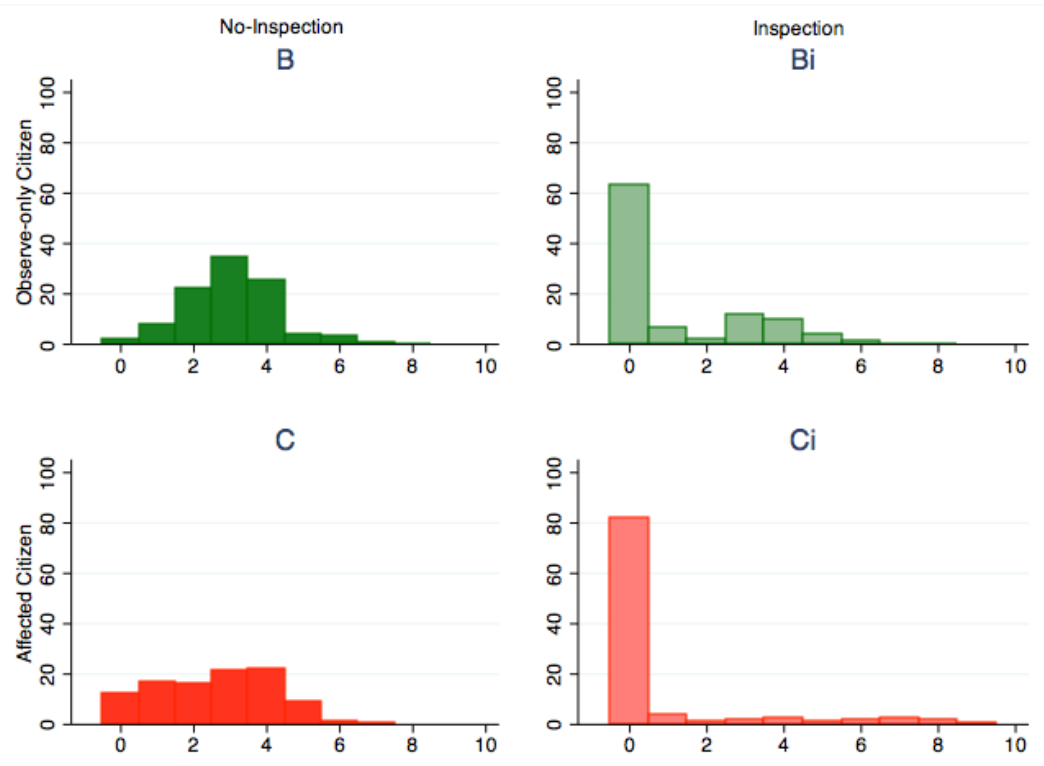

Figure 4.2: The distribution of the bribe, by treatment

abstaining from bribing when the citizen is affected by their decisions.

\subsection{Officials}

We distinguish two patterns of decisions made by officials revealing their preferences: bribe maximizing decisions and quality maximizing decisions (we discard ties for the analysis of officials). Figure 4.4 illustrates the effect of each treatment 


\section{INTRINSIC AND EXTRINSIC MOTIVATIONS OF PRO-SOCIAL BEHAVIOR IN AN AUCTION THAT ALLOWS FOR CORRUPTION}

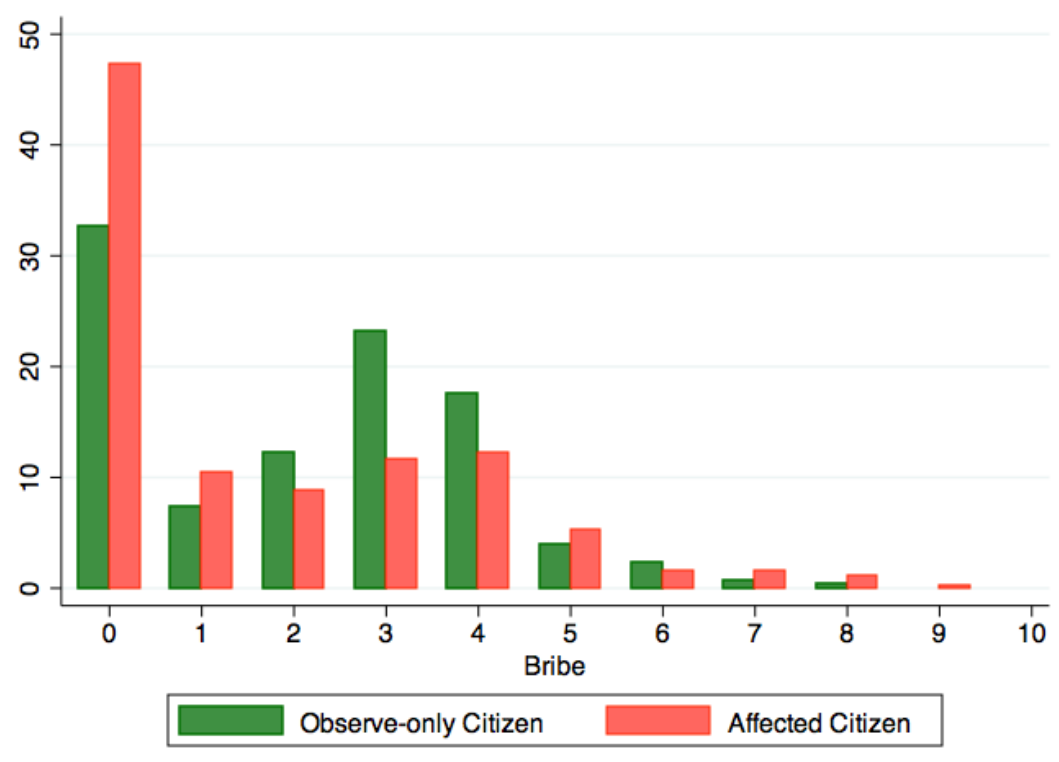

Figure 4.3: Net effect of the citizen on bribe

on the officials' preferences. In treatment $\mathrm{B}$, a $82.91 \%$ of decisions are made according to maximizing bribe while in treatment $\mathrm{C}$ these decisions are $91.43 \%$. We find statistically significant differences $\left(\chi^{2}=3.54, p=0.06\right)$. In treatment $\mathrm{Bi}, 26.73 \%$ of decisions are bribe maximizers and in treatment $\mathrm{Ci}$, this is true for $19.30 \%$ of decisions $\left(\chi^{2}=1.10, p=0.29\right)$. These results suggest that the affected citizen is not playing any significant influence on officials. In other words, contrary to firms, officials are not exhibiting a more pro-social behavior when they are aware that their decisions are determining citizens' payoffs.

To conclude this section, we have reviewed the behavior of firms and officials focusing on the net effect produced by the presence of the citizen. We compare treatments in which the citizen is just observing the decisions of the 'society' with treatments in which the citizen is positively affected by the amount of quality invested in the winning project. We see a significant effect on firms' decisions as far as bribe bids decrease (and consequently quality bids increase). Despite that citizens are passive players, the fact of being affected by others' decisions activates an intrinsic-altruistic motivation on firms by raising the offers of quality to officials. 


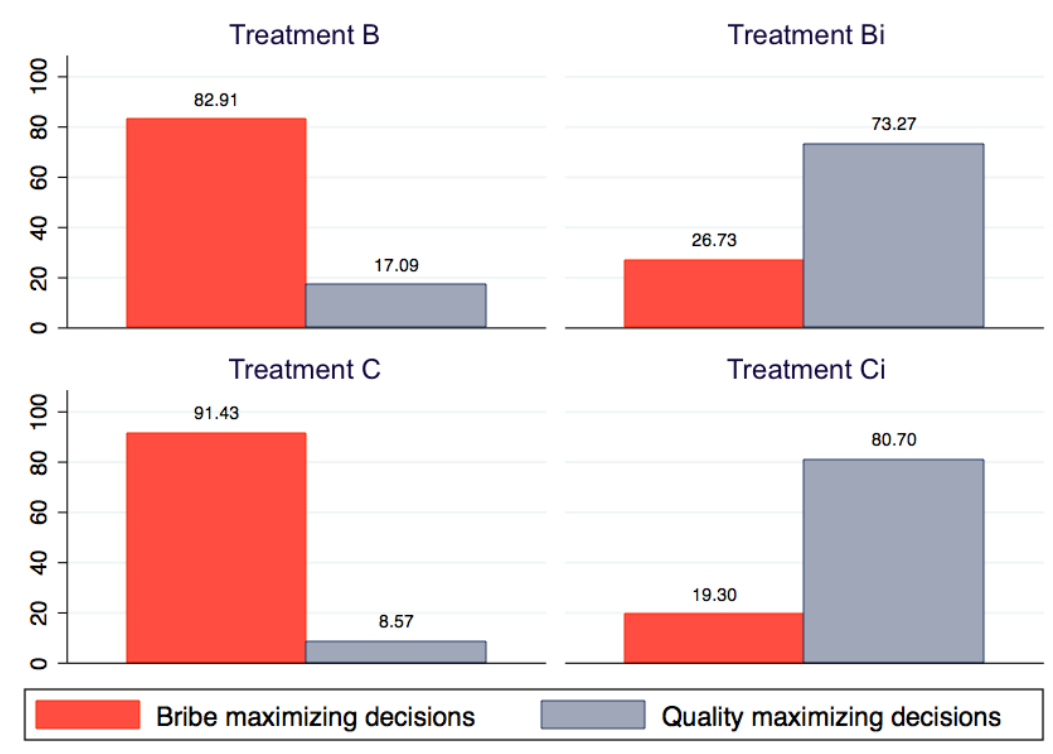

Figure 4.4: Official's preferences: differences among treatments

However, the presence of citizens affected by their decisions is not activating any empathy from officials. Our design has permitted to disentangle and understand that the decrease on bribe bids (and consequently an increase on quality bids) from firms, is due to the activation of an altruistic-intrinsic side of people, rather than just the shame of being observed.

\subsubsection{Inspection option}

In this section, we describe the effect produced by the activation of the extrinsic motivation of subjects by adding a new institution which affects firms and officials' payoffs. After being informed of the official's decision, the loser firm has the option to call for an inspection to the project assignation. A revealed bribe leads both players involved to the loss of their period earnings, whereas, if no bribe is revealed, the inspecting firm loses all its period profits instead. 


\section{INTRINSIC AND EXTRINSIC MOTIVATIONS OF PRO-SOCIAL BEHAVIOR IN AN AUCTION THAT ALLOWS FOR CORRUPTION}

\subsection{Firms}

Figures 4.2, 4.5 and 4.6 illustrate the effect of the inspection institution, on firms' decisions on bribe. There is a straightforward decrease of bribe offers when the inspection threat is present. Figure 4.5 shows the evolution of the average bribe along the 30 periods. We observe a dramatical and significant effect on bribe bids from firms: in fact, the average bribe is 2.72 units (st. dev.: 1.63) for the first 15 periods (no-inspection treatments) and 0.88 units (st. dev.: 1.72) for the last 15 periods (inspection treatments). As seen on table 4.3 all the differences are statistically significant ${ }^{1}$

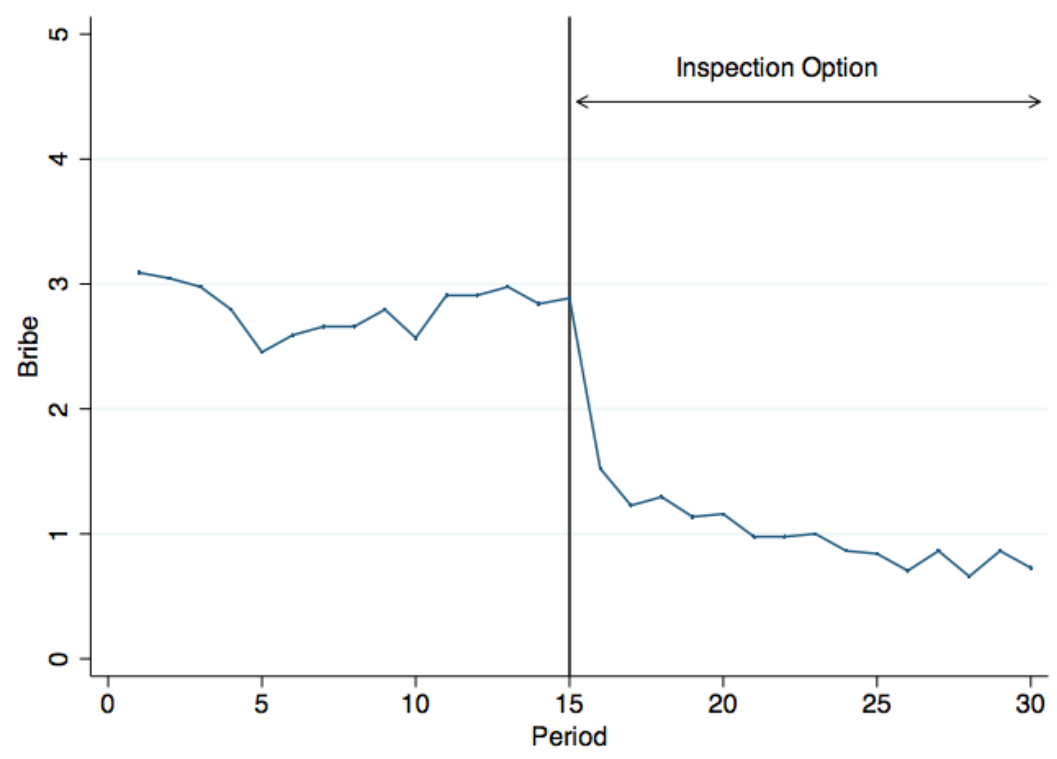

Figure 4.5: The evolution of bribe: Inspection effect.

Again, figure 4.2 confirms the effect of inspection in the distribution of bribe.

\footnotetext{
${ }^{1}$ In order to perform Wilcoxon matched-pairs signed-rank test statistical analysis, our sample became lower as we compare firm-subjects' decisions in the first 15 periods with the last 15 periods. At the end of period 15 a rematching of groups composition and roles was done. We could hence, just analyze those subjects who played as firm in the first part of the experiment and in the second part as well. Thus, considering this condition we have a sample of 13 subjects for B \& Bi and 17 subjects for $\mathrm{C} \& \mathrm{Ci}$.
} 
We highlight the huge increase of the zero-bribe offers, becoming the modal, produced by the effect of inspection. We find $1.82 \%$ in treatment B versus $63.33 \%$ in treatment $\mathrm{Bi}$ of zero-bribe offers, with significantly different distributions (table 4.3 .

Figure 4.6 compares no-inspection treatments vs inspection treatments. This arrangement is done in order to seclude the pure effect of inspection (independently of the citizen feature). This figure shows clearly the dramatical effect of the inspection threat on bribe offers. We observe a huge increase of non-bribe offers. When inspection was not available, $7.12 \%$ of offers were abstaining from bribe, however after the inspection option is available, this result is true in $72.73 \%$ of the offers. We find statistically significant differences for the net effect of the inspection feature (table 4.3).

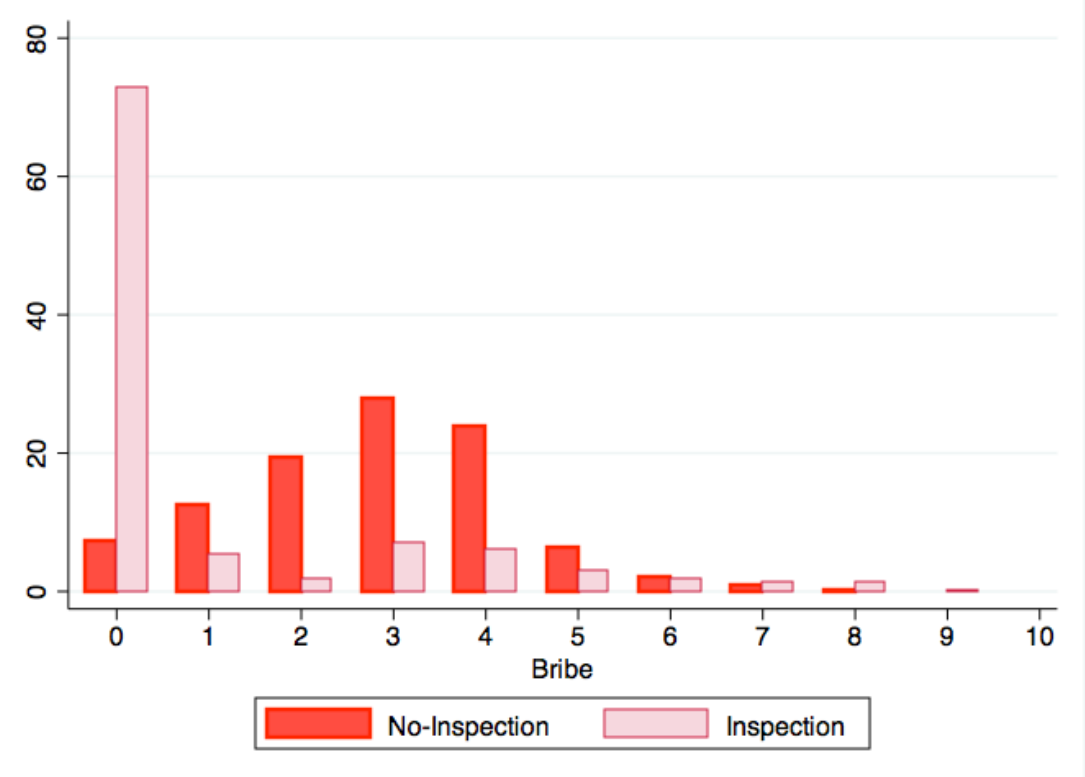

Figure 4.6: Net effect of inspection on bribe

Figure 4.7 give us an overview of the inspection pattern, concretely the evolution of the frequency of inspecting by period. We observe a clear decrease on the propensity to inspect over time. Although in the first period $72.73 \%$ of the loser firms decide to inspect, just a $4.55 \%$ called for inspection in last period. 


\section{INTRINSIC AND EXTRINSIC MOTIVATIONS OF PRO-SOCIAL BEHAVIOR IN AN AUCTION THAT ALLOWS FOR CORRUPTION}

In addition, from the total amount of inspections, 25\% were right, that is, the winning firm and official were captured as corrupts (75\% of inspections were wrong, thus loser firms should pay for inspecting). Moreover, we study the profile of firms deciding to inspect. Interestingly, in a $36.25 \%(\mathrm{~N}=29 / 80)$ of cases the loser firm called for inspection while its bribe offer was superior to the bribe offered by the winning firm, whereas in a $21.25 \%(\mathrm{~N}=17 / 80)$ of the cases was inferior. In a $42.50 \%(\mathrm{~N}=34 / 80)$ of the cases the bribe offers were equal. Hence, a significantly higher percentage $\left(\chi^{2}=5.92, p=0.01\right)$ of loser firms decides to inspect even though they offered a higher bribe than the winning firm.

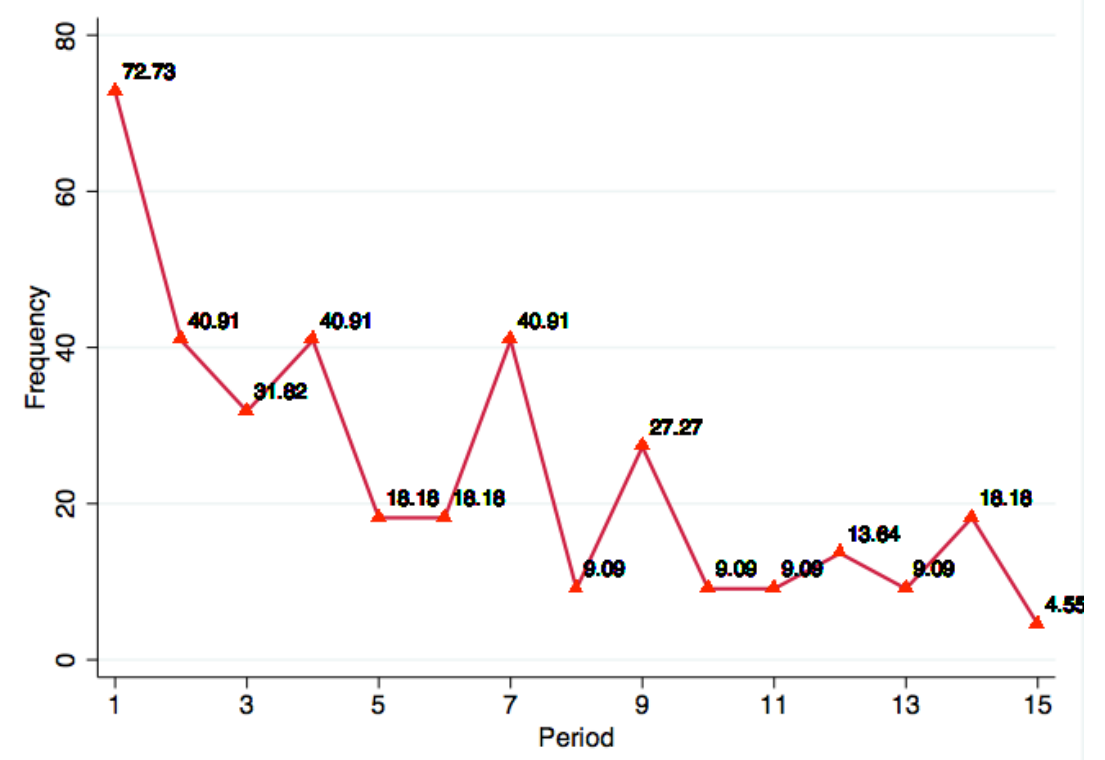

Figure 4.7: The evolution of inspecting.

\subsection{Officials}

From figure 4.4 we can extract the effect of inspection on officials. In treatment B, $82.91 \%$ of the decisions correspond to the bribe maximization whereas in treatment $\mathrm{Bi}$ there is a reversal on preferences as just $26.73 \%$ of decisions are made according to bribe, thus against the monetary maximization $\left(\chi^{2}=60.74, p=0.00\right)$. In treatment 
C, $91.43 \%$ of decisions are made according to bribe while in treatment $\mathrm{Ci}$ this is true just in $19.30 \%$ of the cases $\left(\chi^{2}=85.72, p=0.01\right)$.

In this section we explored the effect of the inspection institution on subjects as firms and officials. We observe a straightforward effect on both kind of players in the sense that firm-subjects decrease drastically their bribe bids and officialsubjects exhibit a reversal on their preferences as the majority of their decisions become pro-social since the inspection option is present. We also observe that the inspection threat is creating a huge effect, although the frequency of losing firms actually calling for inspection almost disappears over time. More interestingly, we do not observe a 'fair' way of inspecting, rather high percentage of 'corrupt' loser firms activate the inspection button.

\subsubsection{Social welfare}

In this section we calculate the effect of each treatment in terms of social welfare. We measure social welfare as the total profits of each group. Thus, for any group $i$ : $S W_{i}=\Pi_{i}^{w}+\Pi_{i}^{l}+\Pi_{i}^{o}$, where $w=$ winner firm, $l=$ loser firm, and $o=$ official. Figure 4.8 represents the evolution of the average of the groups' profits for each treatment, by period. In treatments $\mathrm{Bi}$ and $\mathrm{Ci}$, social welfare starts at lower levels with 36.27 units and 35.83 units respectively than in treatments B and C with 46.50 units and 46.55 units respectively. However, the efficiency tend to increase over time and the social welfare of treatments with inspection overtakes those without inspection. The average social welfare for all periods in treatment $B$ is 46.23 units, in treatment $\mathrm{Bi}$ is 46.71 units, in treatment $\mathrm{C}$ is 47.10 units and finally 51.13 units in treatment $\mathrm{Ci}$. All the differences are statistically significant (see table 4.4).

\begin{tabular}{lcccccc}
\hline Treatments & B vs C & B vs Bi & C vs Ci & Bi vs Ci & B vs Ci & C vs Bi \\
\hline Mann-Whitney test (Z) & 2.35 & 8.14 & -5.76 & -7.54 & 18.05 & 6.32 \\
p-value & 0.02 & 0.00 & 0.00 & 0.00 & 0.00 & 0.00 \\
\hline
\end{tabular}

Table 4.4: Mann-Withney rank-sum tests for comparison of social welfare among treatments. 


\section{INTRINSIC AND EXTRINSIC MOTIVATIONS OF PRO-SOCIAL BEHAVIOR IN AN AUCTION THAT ALLOWS FOR CORRUPTION}

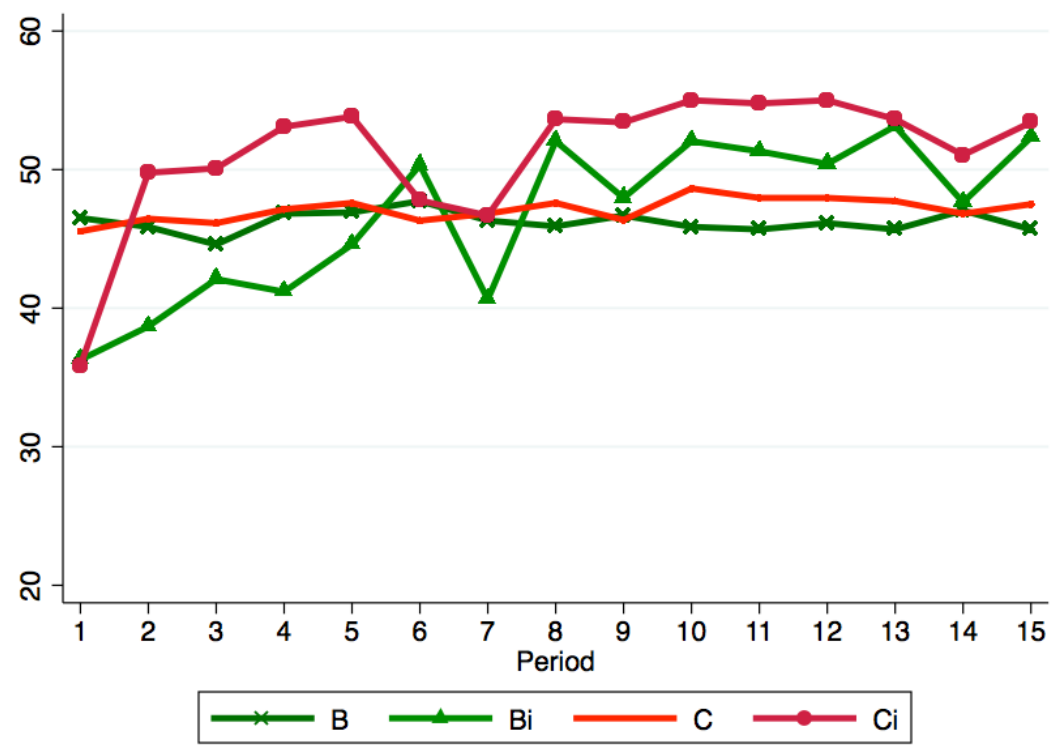

Figure 4.8: The evolution of the efficiency of groups, by treatment.

From these results we conclude that new institutions are improving the social welfare. The citizen as a passive receiver of society increase the groups' profits more than inspection alone, whereas the combination of both yields to the highest social welfare. However, the introduction of the inspection option needs a time to reach its highest point. It seems that the activation of the intrinsic motivation of people, alone, is yielding to a higher social welfare than the activation of just the extrinsic motivation.

\subsubsection{Idiosyncratic features}

This section is addressed to understand the personal characteristics of people that may help to explain some preferences related to bribe. We study, separately, the effect of gender and risk aversion on bribery.

\subsubsection{Gender}

This section studies the differences on gender behavior towards bribery. Figure 4.9 represents the evolution of the average bribe per period for women and men 
along the whole experiment. We compare no-inspection treatments with inspection treatments. This figure does not give a straightforward picture showing differences among gender. In fact, no significant differences appear in the no-inspection treatments, with men offering 2.69 units of bribe and women 2.93 units 1 , however in inspection treatments, men's average bribe is 0.83 units and women's 1.15 units, with significant differences ${ }^{2}$. In the full experiment, women (2.04 units) offer significantly higher amounts of bribe than men (1.76 units) ${ }^{3}$

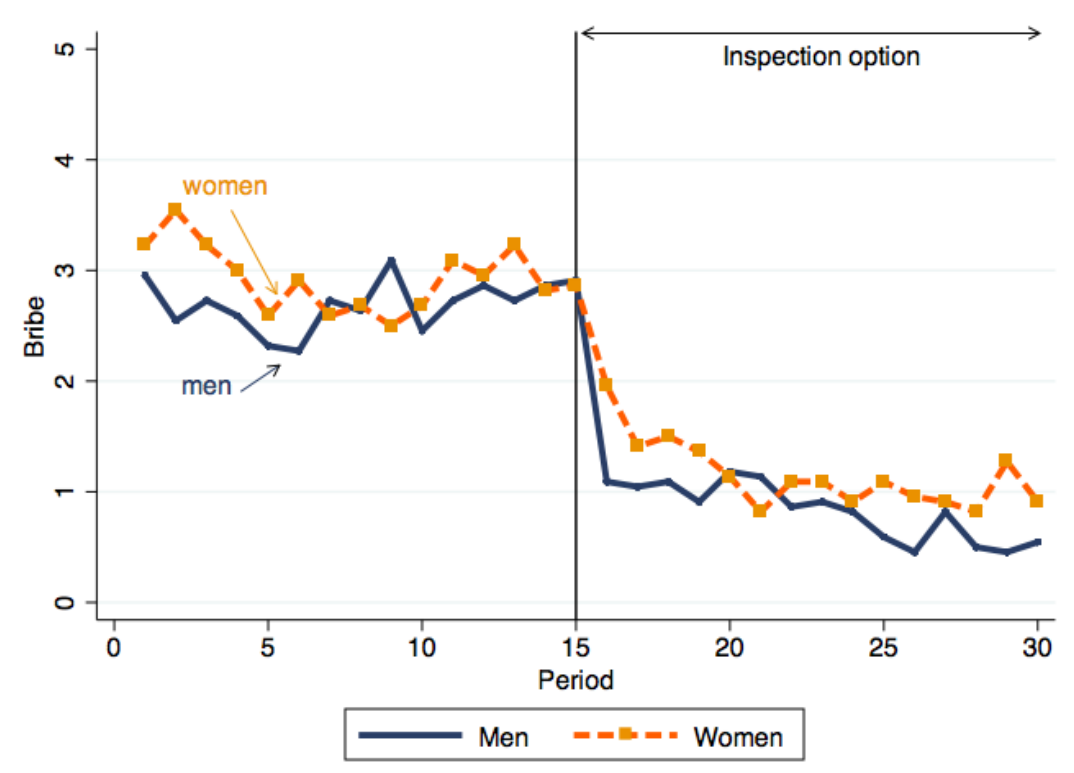

Figure 4.9: The evolution of bribe, by gender.

We do not find significant differences on the frequency of inspecting for women and men. Men loser-firms activated the inspection $23.57 \%$ of times and women loser-firms, $24.72 \%$ of times $\left(\chi^{2}=0.06, p=0.81\right)$.

Table 4.5 shows the percentage of quality maximizing decisions made by officialsubjects, comparing gender within each treatment. In no-inspection treatments, we observe a similar behavior between both genders: in treatment B, $17 \%$ of decisions

\footnotetext{
${ }^{1}$ Wilcoxon Mann-Whitney $\mathrm{z}=-1.37, p=0.17$.

${ }^{2}$ Wilcoxon Mann-Whitney $\mathrm{z}=-3.19, p=0.00$.

${ }^{3}$ Wilcoxon Mann-Whitney $\mathrm{z}=-3.05, p=0.00$.
} 


\section{INTRINSIC AND EXTRINSIC MOTIVATIONS OF PRO-SOCIAL BEHAVIOR IN AN AUCTION THAT ALLOWS FOR CORRUPTION}

made by men and $18 \%$ made by women exhibit a pro-social behavior and in treatment $\mathrm{C}$ the same is true for $10 \%$ and $7 \%$ respectively. No significant differences are found. However, in inspection treatments some differences appear: in treatment $\mathrm{Bi}$, official-men made significantly more quality maximizing decisions than women ( $81 \%$ versus $65 \%$ ) whereas the contrary occurs in Ci with $71 \%$ of men deciding according to quality versus $86 \%$ of women, with no statistically significant differences.

\begin{tabular}{lllll}
\hline Treatment & $\mathbf{B}$ & $\mathbf{B i}$ & $\mathbf{C}$ & $\mathbf{C i}$ \\
\hline Men & $17 \%$ & $81 \%$ & $10 \%$ & $71 \%$ \\
Women & $18 \%$ & $65 \%$ & $7 \%$ & $86 \%$ \\
$\chi^{2}$ & 0.02 & 3.08 & 0.25 & 1.83 \\
$p$-value & 0.89 & 0.08 & 0.62 & 0.17 \\
\hline
\end{tabular}

Table 4.5: Quality maximizing decisions comparing gender within treatments and the corresponding values for $\chi^{2}$ test.

In conclusion, we find women offer significantly higher bribe than men when the inspection is available, whereas no significant differences appear when inspection is not possible. No significant differences are found in gender in the propensity to inspect. Men in the role of official exhibit significantly a higher pro-social behavior than women when inspection is available and the citizen is just observer whereas women are more pro-social when inspection is available and the citizen is affected by others' decisions, although this difference is not significant. No more significant differences are found in gender for official-subjects.

These results seem to be in the opposite direction of the existent literature as, generally speaking, most of studies found women bribe less (Alatas et al., 2009a; Rivas, 2013; Schulze and Frank, 2003) and behave more pro-socially. However, no striking conclusions can be extracted from gender and corruption. We believe that the study of gender should go with the study of culture as the idiosyncrasy of each society determines the features of gender attitudes. In addition, an accurate study 


\subsection{Results}

of gender should demand to inform subjects about the gender of the other group members, as for instance, Rivas (2013). 1

\subsubsection{Risk Aversion}

We distinguish risk aversion lotteries where no losses are possible, from risk aversion with losses (Sabater-Grande and Georgantzis, 2002). Both samples follow a normal distribution where decisions are concentrated around a probability of 0.5 . For each subject we calculate his average risk aversion level for all lotteries. We classify from now on high risk averse subjects as those choosing on average a probability strictly higher than 0.5 , and low risk averse those with probability strictly lower than 0.5 .

Figure 4.10 shows the evolution of bribe distinguishing between high risk averse and low risk averse subjects for 30 periods. High risk averse subjects offer significantly higher bribes on average (2.39 units) than low risk averse subjects (1.56 units) This result is consistent in no-inspection treatments, where high risk averse subjects post an average of 2.91 units of bribe and low risk averse subjects post an average of 2.74 units, although no significant differences are found ${ }^{3}$. In inspection treatments we observe a clear difference by high risk averse subjects posting significantly higher bribes ( 1.77 units) than low risk averse subjects $(0.53 \text { units })^{4}$

Risk aversion and corruption remains a topic to explore as few papers investigate the relationship between risk and corruption. Berninghaus et al. (2013) expected risk lovers choose the risky/corrupt option. However, the authors found that risk attitude failed to explain subjects' decisions between corrupt and non-corrupt and claimed that beliefs are a better predictor than risk attitudes.

Our results rather than not finding a relation between risk and corruption show a relation but in the opposite direction expected by Berninghaus et al. (2013). High risk averse subjects are posting higher bribes as it increases their probability of winning the license for the project. Furthermore, when inspection is available, this

\footnotetext{
${ }^{1}$ Actually gender is not the main purpose of this study, is just a note to understand better the results of experiment. Hence, a deep review of gender and corruption can be found in Frank et al. (2010) and Chaudhuri (2012).

${ }^{2}$ Wilcoxon Mann-Whitney $\mathrm{z}=-7.51, p=0.00$.

${ }^{3}$ Wilcoxon Mann-Whitney $\mathrm{z}=-1.42, p=0.15$.

${ }^{4}$ Wilcoxon Mann-Whitney $\mathrm{z}=-7.41, p=0.00$.
} 


\section{INTRINSIC AND EXTRINSIC MOTIVATIONS OF PRO-SOCIAL BEHAVIOR IN AN AUCTION THAT ALLOWS FOR CORRUPTION}

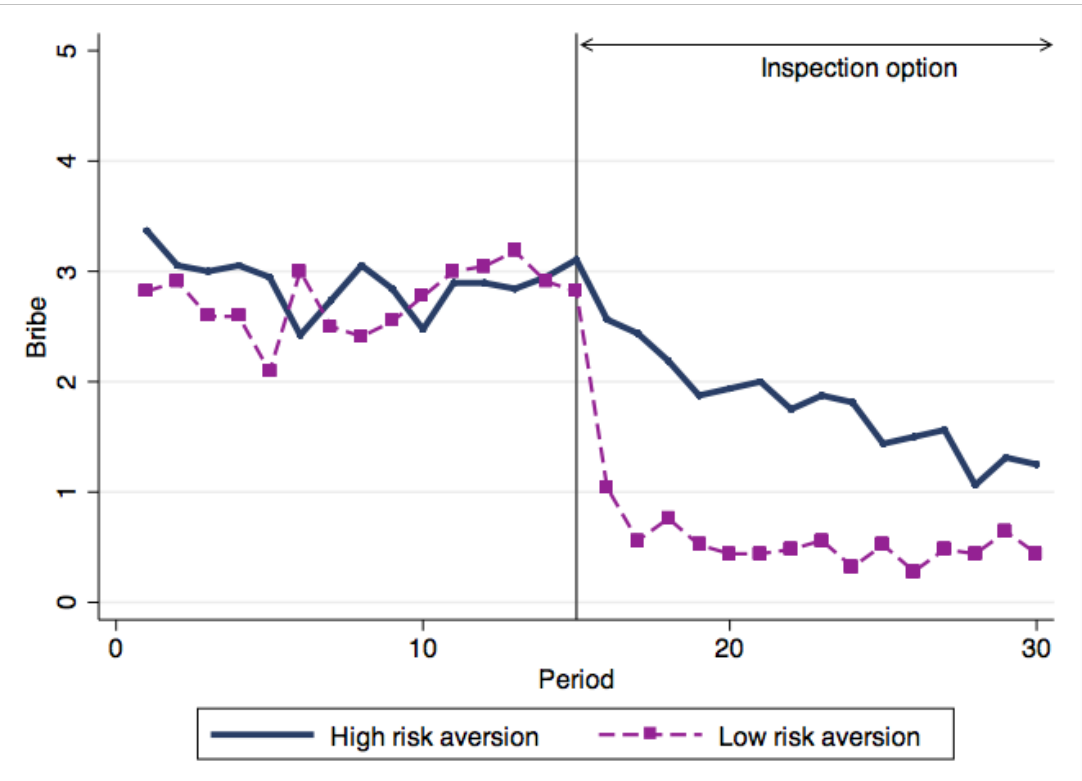

Figure 4.10: The evolution of bribe according to subjects' risk aversion levels.

behavior remains, suggesting that high risk averse subjects are averse to the risk of not winning the license, rather than the risk of being inspected. In our study we did not consider the option to study beliefs which might be a good.

\subsection{Conclusion}

This chapter explores many dimensions of bribery through the experimental methodology. On the one hand, we evaluate the impact of incorporating new institutions to a basic auction game with 2 firms and 1 official where bribes are permitted. On the other hand, we seek personal characteristics of subjects explaining a propensity to bribe or contrary, an aversion to bribe.

We first introduce an inspection option to the loser firm of the auction. If the investigation reveals no bribe, the accusing firm loses all its profit, otherwise the accused firm and official lose their profits. Despite the few times that the option is actually used, bribes fall dramatically. We found a huge effect on the sense that it reduces significantly bribe offers from firms, and bribe tolerance from officials. Thus, a well-designed institution system threatening potentially corrupt people give us the 
hope of reducing bribery.

Second, we introduce another feature: a citizen who is a passive receiver of the consequences of the potentially corrupt transaction. Our design give us an important hint as it permitted us to disentangle whether the effect of the citizen is due to its net presence as observer, and thus creating shame on firms and officials, or by the fact that citizens are activating an intrinsic altruism on people who know that their decision are affecting others. It seems that firm-subjects are feeling a social responsibility in the sense that they are bribing less when they are conscious that their decisions affect other people. Official-subjects seem not to be affected by the citizen. In terms of efficiency we found that groups' profits are higher due to the effect of the citizen alone than with just the inspection. The combination of both yields to the highest levels of social welfare.

Moreover, we seek personal characteristics, thus in a pre-play session, we elicit subjects' risk preferences. We found a positive correlation between firm-subject's risk aversion and his/her posted bribery. During the 30 periods of the session, high risk averse subjects posted higher bribes than low risk averse subjects, on average, especially when the inspection is available. It seems that high risk averse subjects feel the risk of losing the license rather than being inspected. Some results are found in gender differences. Women posted higher bribes than men when inspection is available. In the role of official, the only statistically significant difference found is in the treatment in which inspection is available and the citizen is just observing: men seem to behave in a more pro-social way than women.

Even though this chapter analyze many dimensions of bribery, we believe studying corruption is a big challenge. We still having many questions to answer, for instance, controlling for order-effect, or giving the opportunity to the official to refuse bribes, among others further researches. 


\subsection{Appendix: Instructions to experimental subjects (translated from Spanish)}

Welcome and thanks for your participation in this experiment. Please switch off your mobile phones and secure your belongings away. You are going to participate in an experimental session split into two subsessions of 15 rounds each. You will earn an amount of money which will depend on your decisions and the decisions of other participants in the session. From this moment onwards you must use only the instructions and the computer in front of you. If you have any questions throughout the session, please raise your hand and you will receive an answer by one of the experimentalists. Any communication with other participants will imply your immediate exclusion from the experiment.

\subsection{1 [Treatment B] \& [Treatment C] Subsession I}

At the beginning of this subsession, you will be assigned one of two roles: 'a firm' or 'an official'. Your role is randomly assigned to you and remains fixed throughout the subsession. You will be anonymously and randomly assigned to a group of three players: two firms and an official. The group will be fixed throughout the subsession. Rounds are independent, in the sense that the payoff consequences of decisions made in any round do not carry over to subsequent rounds. Once this part is finished, the experimentalist will give you new instructions for the second subsession.

\section{- Decision Making}

In each round, all players receive an endowment of 10 ExCU If you are a firm: You compete with the other firm of your group for the license of a public project whose quality is beneficial to all players in the group. In each round, you have to post bids on the quality of your project and a monetary transfer which you wish to send privately to the official in your group if you are chosen to undertake the project. Firms' bids are made simultaneously, so that each firm can only know its own bids, but not the bids of the other firm. The quality and

\footnotetext{
${ }^{1}$ Experimental Currency Unit.
} 
the transfer to the official must sum 10, so that if your quality bid is 9 your transfer to the official in case you win will be 1. If you win the auction, apart from your round endowment, you earn a fixed extra profit. In that case, you also have to spend on the transfer to the official double the amount you promised in your bid. If you lose the auction, apart from your initial endowment from each round, your earnings include a profit which is proportional to the quality of the winning project.

If you are an official: In each round, you receive the bids from the firms in your group. Then, you have to choose one of the two projects. Apart from your initial endowment in this round, your earnings include a profit which is proportional to the winner's quality plus the amount, if any, privately transferred to you by the winner.

If you are a citizen: You are not goint to take any decision. You are associated to a group of 2 firms and 1 official. You will observe, on the screen in front of you, the quality winning in each period and you will be paid according to the quality winning in your corresponding group. Your earnings will be determined by a random period, in the same way that all the participants in this session. ${ }^{1}$

\section{- Exact calculation of profits}

From the description of strategies and earnings above, the specific formulas used to calculate your profits in each round $(\pi)$ are a function of the quality $(Q)$ and transfer $(B)$ bids of the winner, as shown below:

$$
\begin{gathered}
\pi_{\text {winner }}=10+\frac{1}{2} \cdot Q_{\text {winner }}+10-2 \cdot B_{\text {winner }} \\
\pi_{\text {loser }}=10+\frac{1}{2} \cdot Q_{\text {winner }} \\
\pi_{\text {official }}=10+\frac{1}{2} \cdot Q_{\text {winner }}+B_{\text {winner }} \\
\boldsymbol{\pi}_{\text {citizen }}=\boldsymbol{Q}_{\text {winner }}
\end{gathered}
$$

\footnotetext{
${ }^{1}$ Text in bold corresponds to the instructions' specifications of treatments $\mathrm{C}$ and $\mathrm{Ci}$.
} 


\section{INTRINSIC AND EXTRINSIC MOTIVATIONS OF PRO-SOCIAL BEHAVIOR IN AN AUCTION THAT ALLOWS FOR CORRUPTION}

\section{- Information received}

If you are a firm: At the end of each round, you will receive information on which firm won the license, a reminder of your decisions on quality level and transfer in that round, as well as your profit for that round.

If you are an official: In each round, after firms have made their decisions, their quality and transfer bids will be displayed on your screen before you make a decision. Once you select the winning firm, you will receive information on your profits in this round.

If you are a citizen: In each round, you will observe on the screen the quality posted by the winning firm, in each group.

\section{- Monetary rewards}

In order to determine your payment in this subsession, the computer will randomly choose one of the 15 rounds at the end of the session. The amount of money you will earn from this part of the experiment will be equal to your profits in the randomly chosen round, multiplied by an equivalence ratio of $1 \mathrm{ExCU}=\frac{1}{2}$ Euro.

\subsection{2 [Treatment Bi] \& [Treatment Ci] Subsession II}

In this subsession, the context will be exactly the same as in the first one, except for the following:

The roles of subjects and the composition of groups will be re-determined randomly and will remain fixed throughout the remaining rounds of the session.

A new feature is that, in each round, after the winner of the auction has been determined by the official, the loser firm has the option to ask for an inspection of the winning bid. The decision to inspect modifies the subjects' earnings as follows: If a transfer has taken place, the official and the winner of the auction earn nothing in this round. On the contrary, if no transfer is revealed, then, the inspecting loser earns nothing in this round. Finally, if no inspection is activated, players' earnings remain unchanged. 
- Monetary rewards

In order to determine your payment in this subsession, the computer will randomly choose one of the 15 rounds at the end of the session. The amount of money you will earn from this part of the experiment will be equal to your profits in the randomly chosen round, multiplied by an equivalence ratio of $1 \mathrm{ExCU}=\frac{1}{2}$ Euro. 


\section{INTRINSIC AND EXTRINSIC MOTIVATIONS OF PRO-SOCIAL BEHAVIOR IN AN AUCTION THAT ALLOWS FOR CORRUPTION}

\subsection{Appendix: Risk aversion tests}

Welcome to the Laboratory of Experimental Economics (LEE). Before starting the experiment you have to complete some tests. Please answer seriously to them. Once all the participants have finish we can proceed to star the experiment.

Each one of the following 'panels' presents a serie of lotteries. Each lottery consist of a probability of winning the prize below of it. You have to chose the favorite lottery (example: in the Panel 1 you can choose to win 1.70 euros with a probability of 0.6 ). This means that you can win 1.70 euros with a probability of 0.6 and nothing with a probability of 0.4 . Remember, this is an hypothetical situation. It will not affect you real payoffs at the end of the experiment.

Panel 1

\begin{tabular}{|l|c|c|c|c|c|c|c|c|c|c|}
\hline Prob. & $\mathbf{1}$ & $\mathbf{0 , 9}$ & $\mathbf{0 , 8}$ & $\mathbf{0 , 7}$ & $\mathbf{0 , 6}$ & $\mathbf{0 , 5}$ & $\mathbf{0 , 4}$ & $\mathbf{0 , 3}$ & $\mathbf{0 , 2}$ & $\mathbf{0 , 1}$ \\
\hline$€$ & 1,00 & 1,10 & 1,30 & 1,50 & 1,70 & 2,10 & 2,70 & 3,60 & 5,40 & 10,90 \\
\hline Elección & & & & & & & & & & \\
\hline
\end{tabular}

Panel 2

\begin{tabular}{|l|c|c|c|c|c|c|c|c|c|c|}
\hline Prob. & $\mathbf{1}$ & $\mathbf{0 , 9}$ & $\mathbf{0 , 8}$ & $\mathbf{0 , 7}$ & $\mathbf{0 , 6}$ & $\mathbf{0 , 5}$ & $\mathbf{0 , 4}$ & $\mathbf{0 , 3}$ & $\mathbf{0 , 2}$ & $\mathbf{0 , 1}$ \\
\hline$€$ & 1,00 & 1,20 & 1,50 & 1,90 & 2,30 & 3,00 & 4,00 & 5,70 & 9,00 & 19,00 \\
\hline Elección & & & & & & & & & & \\
\hline
\end{tabular}

Panel 3

\begin{tabular}{|l|c|c|c|c|c|c|c|c|c|c|}
\hline Prob. & $\mathbf{1}$ & $\mathbf{0 , 9}$ & $\mathbf{0 , 8}$ & $\mathbf{0 , 7}$ & $\mathbf{0 , 6}$ & $\mathbf{0 , 5}$ & $\mathbf{0 , 4}$ & $\mathbf{0 , 3}$ & $\mathbf{0 , 2}$ & $\mathbf{0 , 1}$ \\
\hline$€$ & 1,00 & 1,70 & 2,50 & 3,60 & 5,00 & 7,00 & 10,00 & 15,00 & 25,00 & 55,00 \\
\hline Elección & & & & & & & & & & \\
\hline
\end{tabular}

Panel 4
\begin{tabular}{|l|c|c|c|c|c|c|c|c|c|c|}
\hline Prob. & $\mathbf{1}$ & $\mathbf{0 , 9}$ & $\mathbf{0 , 8}$ & $\mathbf{0 , 7}$ & $\mathbf{0 , 6}$ & $\mathbf{0 , 5}$ & $\mathbf{0 , 4}$ & $\mathbf{0 , 3}$ & $\mathbf{0 , 2}$ & $\mathbf{0 , 1}$ \\
\hline$€$ & 1,00 & 2,20 & 3,80 & 5,70 & 8,30 & 12,00 & 17,50 & 26,70 & 45,00 & 100,00 \\
\hline Elección & & & & & & & & & & \\
\hline
\end{tabular}

Figure 4.11: Risk aversion.

The instructions are similar to the previous one. Each probability consists of the probability of winning the price below it. Now, in the case you are not winning 
the lottery, you would loose 1 euro. You have to choose you favorite lottery in each panel.

Panel 1
\begin{tabular}{|l|c|c|c|c|c|c|c|c|c|c|}
\hline Prob. & $\mathbf{1}$ & $\mathbf{0 , 9}$ & $\mathbf{0 , 8}$ & $\mathbf{0 , 7}$ & $\mathbf{0 , 6}$ & $\mathbf{0 , 5}$ & $\mathbf{0 , 4}$ & $\mathbf{0 , 3}$ & $\mathbf{0 , 2}$ & $\mathbf{0 , 1}$ \\
\hline$€$ & 0,00 & 0,10 & 0,30 & 0,50 & 0,70 & 1,10 & 1,70 & 2,60 & 4,40 & 9,90 \\
\hline Elección & & & & & & & & & & \\
\hline
\end{tabular}

Panel 2

\begin{tabular}{|l|c|c|c|c|c|c|c|c|c|c|}
\hline Prob. & $\mathbf{1}$ & $\mathbf{0 , 9}$ & $\mathbf{0 , 8}$ & $\mathbf{0 , 7}$ & $\mathbf{0 , 6}$ & $\mathbf{0 , 5}$ & $\mathbf{0 , 4}$ & $\mathbf{0 , 3}$ & $\mathbf{0 , 2}$ & $\mathbf{0 , 1}$ \\
\hline$€$ & 0,00 & 0,20 & 0,50 & 0,90 & 1,30 & 2,00 & 3,00 & 4,70 & 8,00 & 18,00 \\
\hline Elección & & & & & & & & & & \\
\hline
\end{tabular}

Panel 3

\begin{tabular}{|l|c|c|c|c|c|c|c|c|c|c|}
\hline Prob. & $\mathbf{1}$ & $\mathbf{0 , 9}$ & $\mathbf{0 , 8}$ & $\mathbf{0 , 7}$ & $\mathbf{0 , 6}$ & $\mathbf{0 , 5}$ & $\mathbf{0 , 4}$ & $\mathbf{0 , 3}$ & $\mathbf{0 , 2}$ & $\mathbf{0 , 1}$ \\
\hline$€$ & 0,00 & 0,70 & 1,50 & 2,60 & 4,00 & 6,00 & 9,00 & 14,00 & 24,00 & 54,00 \\
\hline Elección & & & & & & & & & & \\
\hline
\end{tabular}

Panel 4

\begin{tabular}{|l|c|c|c|c|c|c|c|c|c|c|}
\hline Prob. & $\mathbf{1}$ & $\mathbf{0 , 9}$ & $\mathbf{0 , 8}$ & $\mathbf{0 , 7}$ & $\mathbf{0 , 6}$ & $\mathbf{0 , 5}$ & $\mathbf{0 , 4}$ & $\mathbf{0 , 3}$ & $\mathbf{0 , 2}$ & $\mathbf{0 , 1}$ \\
\hline$€$ & 0,00 & 1,20 & 2,80 & 4,70 & 7,30 & 11,00 & 16,50 & 25,70 & 44,00 & 99,00 \\
\hline Elección & & & & & & & & & & \\
\hline
\end{tabular}

Figure 4.12: Risk aversion with losses 2 . 


\subsection{Appendix: Croquis of the laboratory.}

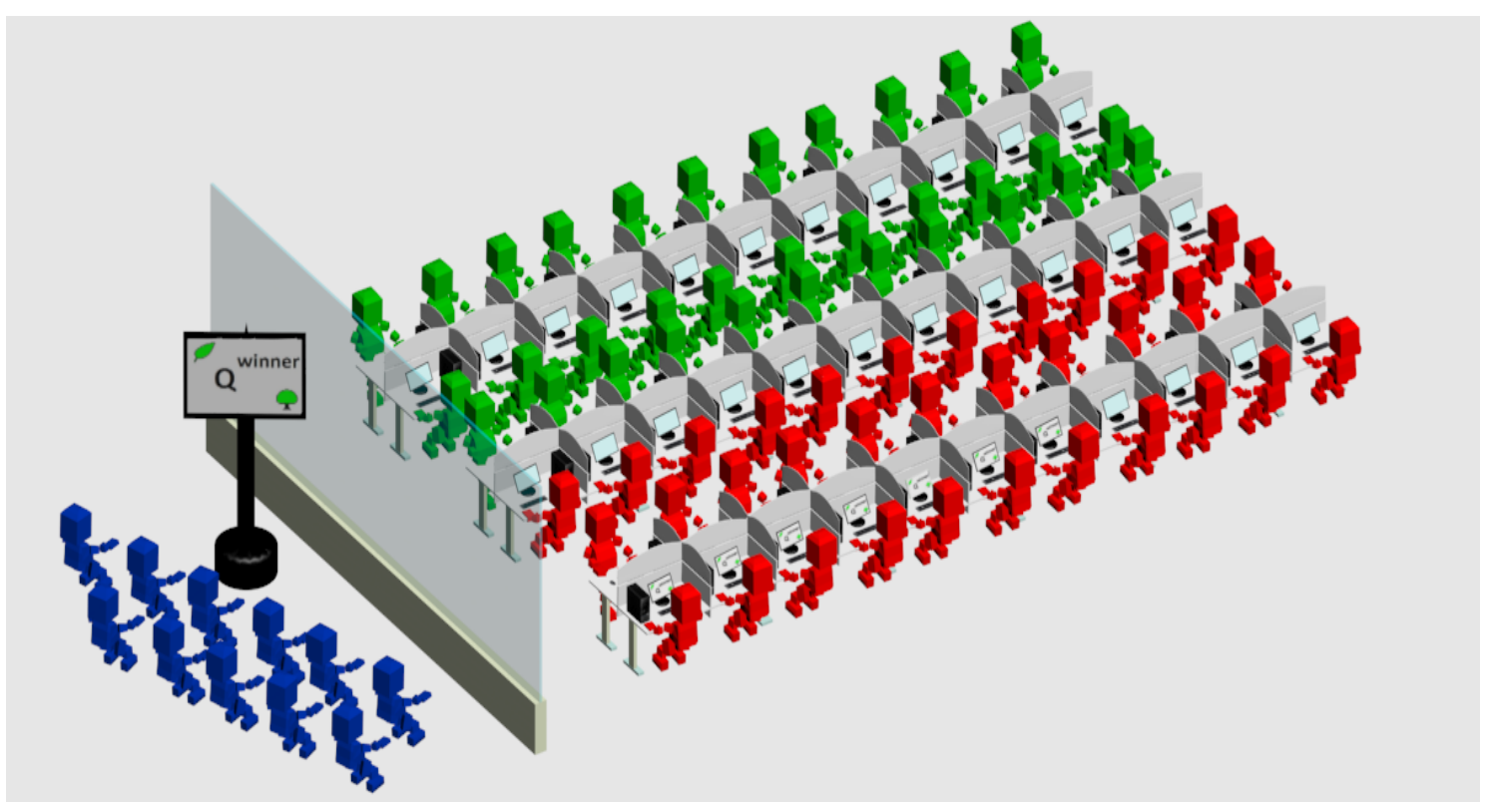

Figure 4.13: 'Blue' players represent citizens, 'green' players represent firm and officials playing treatments $\mathrm{B}$ and $\mathrm{Bi}$, 'red' players represent firms and officials playing treatments $\mathrm{C}$ and $\mathrm{Ci}$. 


\section{Physiological and behavioral patterns of corruption}

\subsection{Introduction}

A moral dilemma emerges when different motivations of human behavior dictate opposite actions in a given decision-making context. In economic situations, the most appealing type of dilemma concerns the conflict between selfish monetary reward maximization and adherence to some ethical pro-social norm, especially when the latter implies an economic loss. The emotional implications of such conflicts seem to originate, from the interplay between a basic impulse for greedy money-seeking motivations and alternative, more sophisticated social and personal ethical norms.1 1 In this chapter, we obtain behavioral data and emotional responses by the participants in a laboratory experiment based on a moral dilemma designed as a public procurement auction with the option of an anti-social bribe by the winner of the auction to the auctioneer. Our results indicate that strong emotions are associated with actions against monetary reward maximization, rather than with the fulfillment or the violation of an ethical norm per se.

\footnotetext{
${ }^{1}$ As for example, in Bolton and Ockenfels (2000).
} 


\section{PHYSIOLOGICAL AND BEHAVIORAL PATTERNS OF CORRUPTION}

Despite the broadly criticized reductionist construct of an emotionless utilitymaximizing machine known as Homo Oeconomicus, there is growing consensus among economists that emotions matter in economic decisions. In everyday economic transactions, people act according to intrinsic motivations and ethical standards, often against their pure economic interests. In fact, in many financial decisions, non-economic motivations like a mother's altruism or an activist's ideology, may dominate economic motives. The basic research agenda aimed at explaining human behavior in the presence of conflicting motivations relies on models assuming coexisting alternative objectives in the decision-maker's utility function. Two exceptions to this are Sen (1977) idea of economically costly commitments to an ethical norm, and a much more recent approach allowing for potentially conflicting multiple selves (Gómez-Miñambres, 2014). While both the harmonic and the conflictive approaches can potentially offer explanations for the behavior observed in the presence of incompatible needs and alternatives, it is a major question whether the conflict is perceived as such by the decision-maker or whether it is internalized as a unified problem leading after all to the satisfaction of one's own needs and preferences. The former hypothesis would require accounting for the conflict among opposite attractors of human behavior, potentially leading to emotional arousal.

Several authors have addressed different aspects of corruption in a variety of experimental settings. Regarding the framework adopted, we can distinguish between single-subject $1^{1}$ and multi-subject settings. Within the multi-subject paradigm, a variation of which is also adopted in our study, several issues have been addressed, like for example, the role of the matching protocol and the framing of the experi-

\footnotetext{
${ }^{1}$ For example, the studies by Frank and Schulze (2000); Schulze and Frank (2003)) use a singlesubject setting to address the issue of compliance to a rule in the context of a student film club in the presence of probabilistic detection. The studies find that economics students are more propense to corruption and that extrinsic motivations work at the cost of crowding out intrinsic moral motivations.
} 
mental setup ${ }^{1}$, as well as the role of the subjects' gender and culture ${ }^{2}$ or identity $5^{3}$ Many studies seem to focus on mechanisms and institutions which could enhance or mitigate corruption. 4 Also related to our second treatment, Abbink et al. (2014) report a bribery experiment run in India, including a whistle-blowing option. They find that immunity for bribe givers reduces the propensity of bribe-takers to demand bribes and increases the willingness to report, which is found to depend on intrinsic motivations. Finally, a setup which has some similarities with our setting is used by Gneezy et al. (2013), assuming a game involving two workers and a referee, finding that when the referee keeps both workers' bribes, the judgment seems to be more motivated by the workers' real performance. Despite similarities with other settings, our framework is novel and yields interesting insights on the emotional and behavioral aspects of corruption.

The literature on integra $5^{5}$ emotions associated with specific economic decisions has focused both on the conflicts preceding the decision and on the feelings triggered by feedback received after a decision is made. The existence of emotional arousal

\footnotetext{
1 Abbink (2004); Abbink and Hennig-Schmidt (2006); Abbink et al. (2002) study a two stagetwo player game played between a potential briber and a bribee. If a bribe is sent and accepted, respectively, a negative externality is experienced by other subjects in the session. The authors find that less corruption is observed under a strangers matching protocol and that the framing of the situation as bribery matters. The framing matters in the setup adopted by Lambsdorff and Frank (2010, 2011), exposing subjects to an ultimatum game with endogenous framing of first movers' offers as a bribe or a gift.

2 Cameron et al. (2009) and Alatas et al. (2009a b) consider a bribery game between a firm and a public official. Decisions affect the contamination of a river, yielding a negative externality to other players. Culture, gender and experience are shown to matter in this context. Recently, the effects of culture and gender were revisited by Barr et al. (2009); Barr and Serra (2009) in a setup in which the externality affects passive players (citizens). The role of citizens in cultural differences between Pakistan and the US was investigated by Banuri and Eckel (2012) in a setup based on Abbink et al. (2002).

${ }^{3}$ Based on a design by Azfar and Nelson (2007), focusing on the ease of corruption detection and the effect of wages on bribes, Barr et al. (2009) study the role of framing and identities in an experiment run in Ethiopia.

${ }^{4}$ For example, Serra 2012) inverts the usual timing of the underlying game, assuming that the public official is the one who asks for a bribe and the citizen may accept paying it or not.

${ }^{5}$ As opposed to incidental emotions, which are not the effect but may cause to some extent the decision. For discussion, see Peters et al. (2006). Examples can be found in Van Dijk and Zeelenberg (2006) and Ariely and Loewenstein (2006).
} 


\section{PHYSIOLOGICAL AND BEHAVIORAL PATTERNS OF CORRUPTION}

during economic decision-making has been confirmed by several studies ${ }^{1}$. In fact, physiological measures of emotion, mostly skin conductance responses, have demonstrated that decision-making may influence and be influenced by somatic markers activated in bioregulatory processes ${ }^{2}$. We contribute to this literature using skin conductance reactions to specific decisions and feedback from them. The framework proposed involves a moral dilemma emerging in the presence of competing motivations resulting from the contrast between selfish monetary reward maximization and pro-social attractors of individual action. Related to our approach, Coricelli et al. (2010) and Coricelli et al. (2014) have established that economic decisions involving some degree of conflict with ethics cause significant emotional and, eventually, somatic reactions. The main conclusion seems to be that violations of specific pro-social norms is reflected on higher levels of arousal, which was shown to relate to the emergence of negative self-reported emotions. Our research extends this view by being the first to show that high emotional arousal may also relate to ethical behavior when a specific decision is made against the purely selfish motivation of monetary reward maximization.

\subsection{Material \& Methods}

\subsubsection{Theoretical framework}

The framework studied here is inspired by Beck and Maher (1986); Burguet and Che (2004); Che (1993); Lien (1986) and, especially, Büchner et al. (2008). We explicitly introduce a tradeoff between bribe and quality bids. In the bidding stage, two firms post simultaneously sealed quality bids and bribes to be paid in case the bidder is the winner of the auction. In the final stage, on the basis of the bids received, an official chooses one of the bids. The winner's quality benefits all players, whereas the bribe is antisocial and inefficient, as it is paid at the cost of a lower quality and an extra loss by the bribing winner. Thus, firms face a moral dilemma in the sense that the higher a firm's promised bribe, the more likely for the firm to

${ }^{1}$ Sanfey et al. (2003), Bechara (2004), Schwarz (2000) and Naqvi et al. (2006).

2 Van 't Wout et al. (2006), Crone et al. (2004), Bechara and Damasio (2005). 
be the winner of the auction. Also, officials face a dilemma, as their selfish preference for bids entailing higher bribes goes against the interest of all other players and overall welfare.

In the experiment, we implement the following payoffs:

$$
\begin{gathered}
\pi_{\text {official }}=F+a \cdot Q_{\text {winner }}+B_{\text {winner }} \\
\pi_{\text {winner }}=F+a \cdot Q_{\text {winner }}-c \cdot B_{\text {winner }}+R \\
\pi_{\text {loser }}=F+a \cdot Q_{\text {winner }}
\end{gathered}
$$

where $\boldsymbol{F}$ is a fixed amount earned by each subject in each period, $\boldsymbol{Q}$ and $\boldsymbol{B}$ are, respectively, the quality and bribe bids. $\boldsymbol{R}$ is the extra monetary reward earned by the winner of the auction. Finally, $\boldsymbol{a}$ denotes the social return of the winning project's quality on each player's utility and $c$ the cost per monetary unit of bribe transferred by the winner to the official. In order to limit the actions of firm-subjects to pressing a single button, we have applied the restriction $Q+B=A$ for each firm-subject's strategies, reflecting the trade-off between quality and bribes. We have used the parameter set $(F, a, c, A, R)=\left(10, \frac{1}{2}, 2,10,10\right) ! 1$

\subsubsection{Monetary payoff equilibrium prediction}

Taking this payoff structure into account, implying that agents care only for the monetary consequences of their actions and assuming a continuous strategy space, the unique Nash equilibrium is such that both firms' bids involve $(\boldsymbol{Q}, \boldsymbol{B})=$ $(5,5)$. That is, like in Bertrand competition, firms will be willing to spend on the bribe as much as the bonus they obtain from winning the auction. However, as usual, our experiment is run with a discrete strategy space, allowing only

\footnotetext{
${ }^{1}$ The use of round numbers facilitates subjects' calculations of the consequences of their actions.
} 


\section{PHYSIOLOGICAL AND BEHAVIORAL PATTERNS OF CORRUPTION}

for integer quality and bribe bids. Then, multiple equilibria ${ }^{1}$ emerge including $(Q, B)=(7,3)$ and $(Q, B)=(6,4)$. In this case, the unique continuousstrategy equilibrium $(Q, B)=(5,5)$ becomes a weak equilibrium, because each firm is indifferent between this and posting lower bribes, becoming a loser (with a payoff of 12.5 in both cases).

\subsubsection{Psychological payoff equilibrium prediction}

We generalize the monetary payoff structure of the setup in (1)-(3), using a linear specification of utilities with an agent-specific psychological cost parameter, $\gamma$, capturing an agent's aversion to bribe due to ethical reasons, expressed as a loss per monetary unit of bribe received by the official. Thus, the three agents' utility levels after the end of the auction are given by:

$$
\begin{gathered}
\pi_{\text {official }}=F+a \cdot Q_{\text {winner }}+\left(1-\gamma_{\text {official }}\right) \cdot B_{\text {winner }} \\
\pi_{\text {winner }}=F+a \cdot Q_{\text {winner }}-\left(c+\gamma_{\text {winner }}\right) \cdot B_{\text {winner }}+R \\
\pi_{\text {loser }}=F+a \cdot Q_{\text {winner }}
\end{gathered}
$$

Assuming perfect information on the agents' preferences and symmetry in the sense that each firm correctly predicts that its rival has a similar attitude to ethics, the following cases emerge:

1. If $\boldsymbol{a} \geq \mathbf{1}-\gamma_{\text {official }}$, the highest quality project will be chosen by the official and firms will bid only in qualities, leading to the equilibrium: $(\boldsymbol{Q}, \boldsymbol{B})=$ $(\boldsymbol{A}, \mathbf{0})$ independently of the firms' preferences.

2. If $\boldsymbol{a}<\mathbf{1}-\gamma_{\text {official }}$, the highest bribe will be preferred by the auctioneer. In that case, firms will bid with the maximum bribe they can, as long as the

\footnotetext{
${ }^{1}$ The corresponding expected payoff matrix for the firms' bidding subgame is provided in chapter 2, figure 2.1 .
} 
generalized bribing cost does not exceed the fixed amount $\boldsymbol{R}$ earned by the winner. Thus, in equilibrium, firm $i$ will bid $\left.\left(Q_{i}, B_{i}\right)=\left(A-\frac{R}{c+\gamma_{i}}, \frac{R}{c+\gamma_{i}}\right)\right]^{1}$

Summarizing, the model predicts that officials may choose the highest quality proposal if they are sufficiently bribery-averse, while they will choose the bidder with the highest bribe otherwise. In the perfect information setting discussed above, firms faced with a quality-maximizing auctioneer, will not bid with bribes, independently of their own preferences, whereas firms anticipating a bribery-maximizing behavior by the auctioneer will promise higher bribes, the less bribery-averse they are. In the case of uncertainty regarding the official's type, a generalized version of this model would produce a continuum of equilibrium predictions, depending on the percentage of pro-social officials and the distribution of bribery-aversion costs. While the development of a general model with these characteristics is beyond the scope of this chapter, it is rather straightforward consequence of our setup that the distribution of officials' and firms' bribery-aversion parameters will have the expected result of less bribery and more pro-social project choices, the higher the density of bribery-aversion parameters on larger values.

\subsubsection{Experimental design}

Two treatmens were run, using a within-subject design. Subjects were aware of the fact that new, supplementary instructions would be given after period 15. During the first 15 periods, the Baseline (T0) treatment was run, corresponding to the auction described above, played repeatedly by fixed triplets of players, each representing an economy of two firms and an official. At the beginning of period 16, the Inspection (T1) treatment was introduced with further instructions and new fixed roles and matching of players. In T1, after each auction has been resolved by the auctioneer, the loser can activate the 'Inspect' option to reveal a possible bribe. A revealed bribe leads both players involved to the loss of their period earnings, whereas, if no bribe is revealed, the denouncing firm loses all its period profits instead. This extreme setup for the inspection and punishment mechanism does not

\footnotetext{
${ }^{1}$ These equilibrium bids correspond to the continuous strategy case. With discrete strategies, equilibrium $\left(Q_{i}, B_{i}\right)=(5,5)$ disappears for $\gamma_{i}>\mathbf{0}$, while as $\gamma_{i}$ increases, equilibria $\left(Q_{i}, B_{i}\right)=(8,2),\left(Q_{i}, B_{i}\right)=(9,1)$ and $\left(Q_{i}, B_{i}\right)=(10,0)$ emerge.
} 


\section{PHYSIOLOGICAL AND BEHAVIORAL PATTERNS OF CORRUPTION}

affect the theoretical equilibrium predictions of the model, given that, in theory, losers should not use the inspection option because of its negative expected payoff. Given the lower complexity of T0 compared to T1, we kept the order of the two conditions fixed to guarantee that subjects' learning in T0 helped them adapt faster to the more complex situation in T1. This also helped us to avoid having too few observations in any of the subcases (like for example no bribe in $\mathrm{T} 0$ ).

\subsubsection{Procedures}

A total of 93 subjects participated in the experiment following the usual recruitment and ethical clearance protocols used in the LEE at the Universitat Jaume I (Castellón, Spain) 1 1 Given the technical restrictions associated with the continuous measurement of skin conductance, each session consisted of small groups of 12 or 9 subjects each. 2

\subsubsection{Behavioral and physiological data collection procedures}

The experiment was computerized using the z-Tree toolbox (Fischbacher (2007)). Continuous electrodermal activity was recorded during the entire experimental session using a BIOPAC MP150 system and four TEL100C telemetry modules (BIOPAC systems, Inc). Two $\mathrm{Ag} / \mathrm{AgCl}$ electrodes filled with isotonic gel were placed on each subject's distal phalanges of the middle and the index fingers of the non-dominant hand. The BIOPAC amplifier applies a constant voltage of $0.5 \mathrm{~V}$ to provide a continuous measure of the skin conductance level between the two electrodes, as this varies with sweat gland activity. Specifically, activation of the sympathetic nervous system due to emotional arousal results in marked increases of the skin conductance level. When evoked by particular experimental events, these increases in conductance are called skin conductance responses (SCRs) (Dawson et al. (2007)). The skin conductance signal was sampled at $125 \mathrm{~Hz}$ and low-pass filtered offline at $0.5 \mathrm{~Hz}$ using a Butterworth digital filter. SCRs were automatically

\footnotetext{
${ }^{1}$ Specifically, 46 male and 47 female undergraduate student-subjects were recruited by means of the ORSEE software Greiner (2004).

27 sessions of 12 subjects and one of 9 subjects.
} 
detected and their amplitudes were quantified using a custom version of the Matlab EDA toolbox freely available at: https://github.com/mateusjoffily/EDA. False SCRs were removed after visual inspection of the entire signal. SCRs were associated to a specific decision if their onset appeared at least $1.0 \mathrm{~s}$ after subjects were informed about their choices and before the moment of the decision. SCRs were associated to a feedback event when their onset appeared between 1.0 and $3.0 \mathrm{~s}$ after the display of the feedback screen. Only responses above 0.02 microSiemens $(\mu \mathrm{S})$ were considered as valid. Group average SCRs were obtained by averaging across events of the same condition (e.g. decisions involving bribe) the values at each time sample. A nonparametric permutations test based on 200 surrogate data sets, obtained by permutating the data points at each sample from all individual trials of each subject, was subsequently carried out to detect statistical differences between conditions. To control for false positive statistical error, the false discovery rate correction method for multiple comparisons was used.

\subsubsection{Timing of behavioral events for continuous-time physiological meas- urements}

Physioeconomics is a new interdisciplinary area of research, combining experimental economics and psychophysiology. Both disciplines use computerized solutions to manage stimuli, strategies, feedback and collect the data. The hardware and software used in our study pose a challenge regarding the need to collect and interactively communicate the timing of behavioral and physiological events across the two computer systems. We have used a solution which to the best of our knowledge has not been previously used in any physioeconomics study so far. As argued in Perakakis et al. (2013), it is the most accurate methodology for the synchronized timing of behavioral data and physiological reactions. The main challenge is how to synchronize, free of undesirable network-related lags, the z-Tree-assisted strategy submission, information screens and feedback on one hand, with the accurate timing (with 2 millisecond precision) of events necessary for the association of SCR data to their corresponding stimuli. The method relies on the use of photodiodes 1 , detecting the change across subsequent $\mathrm{z}$-Tree screens, on which a small

\footnotetext{
${ }^{1} \mathrm{~A}$ photodiode is a type of photodetector capable of converting light changes into electric signals.
} 


\section{PHYSIOLOGICAL AND BEHAVIORAL PATTERNS OF CORRUPTION}

'black box' appears on the upper left corner of each odd-number screen.

\subsection{Results}

\subsubsection{The sample}

The behavioral results reported here are based on the sample of 93 participants (31 officials and 62 firm-subjects). Following the two random matchings and role assignments, in T0 there were 15 male officials and 32 male firm-subjects, whereas in T1 there were 13 male officials and 34 male firm-subjects 11 Physiological results are based on a slightly smaller sample of 89 subjects, given that 4 subjects were excluded due to partly or fully missing information on the recording of their electrodermal activity.

\subsubsection{Behavioral results}

Figure 5.1 presents the main patterns observed regarding the behavior of subjects. As seen on Figure 5.1a, in T0, 81.4\% of the decisions by officials are compatible with monetary reward maximization (excluding ties, in which the distinction is not meaningful). The remaining decisions (18.6\%) are pro-social, corresponding to the choice of the bid with the highest quality, against the official's monetary reward maximization. The pattern is reversed in the presence of an inspection option. Specifically, in T1, the majority of officials' choices $(54.55 \%)$ become pro-social. Regarding the behavior of firm-subjects in T0, Figure $5.1 \mathrm{~b}$ shows a stable pattern of bribe averages slightly below 3 in T0 and a rapidly decreasing trend of bribes in T1. On average, the inclusion of an inspection option in T1 leads to a statistically significant (Mann-Whitney $\mathrm{z}=15.78, \mathrm{p}<0.01$ ) decrease of bribes from 2.66 to 0.81 monetary units. In fact, as seen on Figure 5.1c, bribe bids in $\mathrm{T} 1$ exhibit a high concentration on 0 , which becomes the modal strategy chosen by firm-subjects in over a $70 \%$ of the cases as opposed to slightly above $10 \%$ in

\footnotetext{
${ }^{1}$ Gender differences were statistically non-significant for behavioral results in $\mathrm{T} 1$ and physiological responses throughout the study. The only gender differences found in $\mathrm{T} 0$ is that women in the role of firms bribe more (Mann-Whitney $\mathrm{z}=-2.07, \mathrm{p}<0.05)$ and in the role of officials exhibit a stronger preference for higher quality bids $\left(\chi^{2}=14.43, \mathrm{p}<0.01\right)$.
} 
T0. Nevertheless, in T0, subjects' behavior has remained within the pro-social range, with almost a fifth of officials' decisions being compatible with a briberyaverse parameter of $\gamma>1 / 2$ and a bribe average slightly below 3, which is the minimum predicted in the monetary reward-maximizing equilibria. In fact, over $40 \%$ of bribe choices are 0,1 or 2 units. In T1, the introduction of the inspection option has drastically enhanced pro-social behavior, by both officials and firmsubjects, especially towards the last periods, in which average bribes fall below 1 , despite the fact that the inspection option has been rarely used (in 87 of 465 or $18.71 \%$ of all instances possible) and gradually abandoned by the losers, as shown on Figure 5.1d, falling from $41.93 \%$ (13 out of 31 cases) in period 16 to $6.45 \%$ (2 out of 31 cases) in period 30. Interestingly, from all the cases in which an inspection has been activated $(\mathrm{N}=87)$, a $44.83 \%(\mathrm{~N}=39)$ corresponds to losing firm-subjects who had offered a bribe in the same period, whereas the majority $(55.17 \%$ of them, $\mathrm{N}=48$ ) of inspecting losers had not offered a bribe. In few words, our behavioral results reveal the presence of intrinsic pro-social motivations, but the presence of the extrinsic threat posed by the possibility of an inspection is shown to have a drastic pro-social effect, despite the fact that inspection is only activated in the minority of cases, rendering the threat ex post efficient, as it enhances pro-social behavior at a negligible social cost.

\subsubsection{Physiological results}

From the discussion so far, we have seen that in our setup intrinsic pro-social motivations co-exist with extrinsic motivations like standard monetary reward maximization and the additional threat of punishment for anti-social behavior. Having created these motivations in the laboratory environment, we are now interested in the emotions triggered by different stages of the decision-making process, as well as by the feedback received. Figures 5.2, 5.3, 5.4, and 5.5, display average SCRs associated to decisions made by officials and firm-subjects. Specifically, Figure 5.2 shows SCRs related to officials' project assignment decisions in T0. We compare the average SCR related to decisions favorable to bribes with those favorable to a bribe-free bid. We find that decisions deviating from monetary maximization are associated to higher arousal than those giving the license to bribers as dictated by 


\section{PHYSIOLOGICAL AND BEHAVIORAL PATTERNS OF CORRUPTION}

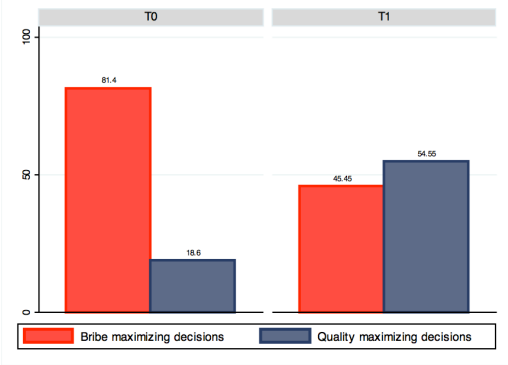

(a) Officials' decisions

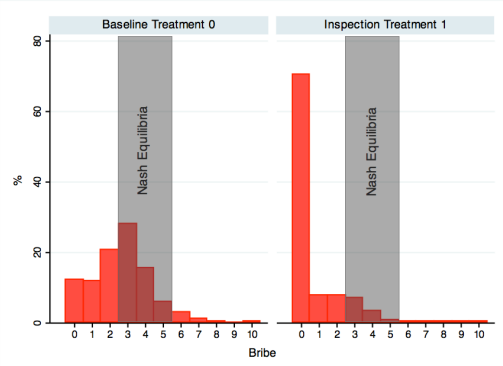

(c) Bribe distribution

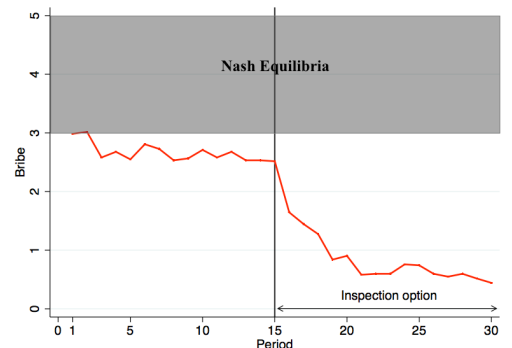

(b) Bribe evolution

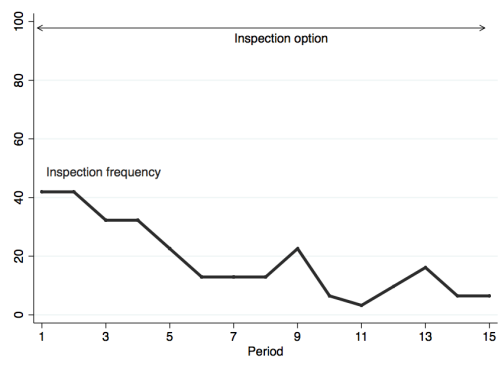

(d) Inspection frequency evolution

Figure 5.1: Behavioral results: (a) Officials' decisions. (b) Bribe evolution. (c) Bribe distribution. (d) Inspection frequency evolution

monetary reward maximization (significant differences at $\mathrm{p}<0.05$ were found at a latency range between 6.27 and $7.08 \mathrm{sec}$ post-stimulus). Figure 5.3 shows SCRs corresponding to the officials' project assignment decisions in T1. In this case, decisions opting for the bid with a bribe demonstrate a higher emotional response $(\mathrm{p}<0.05$ between 11.8 and $12.2 \mathrm{sec})$. Before interpreting these findings, we turn to the decisions of firm-subjects. Figure 5.4 compares the average SCRs associated to decisions made by firms at the moment of posting their bids in T0. Decisions not to bribe entail an increased emotional arousal compared to those who do bribe $(\mathrm{p}<0.01$ between 3.57 and $4.71 \mathrm{sec})$. Finally, Figure 5.5 represents the same decision event in the inspection treatment (T1), where higher arousal is associated with bribing ( $\mathrm{p}<0.01$ between 2.45 and $2.72 \mathrm{sec}$ ). Therefore, higher arousal levels in $\mathrm{T} 0$ are not associated with bribe-giving or bribe-taking but, rather, with individually unprofitable choices. Contrary to T0, in T1, higher arousal levels are associated with bribery. However, observe that while accepting or offering a bribe in T0 is a 
dominant strategy if we assume that subjects are bribe-neutral and maximize own monetary payoffs, in $\mathrm{T} 1$, bribes entail the risk of a significant monetary loss, rendering anti-social behavior individually unprofitable. Thus, a coherent explanation of the 4 patterns observed is that higher arousal levels correspond to decisions deviating from the objective of maximizing the decision-maker's monetary reward. It is interesting to note that such exciting decisions deviate from the majority choice. In fact, the results obtained for $\mathrm{T} 1$ under the threat of being discovered and punished are in accordance with those obtained by Coricelli et al. (2010) and Coricelli et al. (2014), indicating that the negative emotions found in those studies were more likely related with the fear of being discovered to evade than with regret due to non-compliance with a pro-social norm. Therefore, an alternative way to frame or complement the aforementioned explanation is that subjects deviating from pure monetary reward maximization do not only deviate from the strategy dictated by their own pecuniary interest, but also from the strategy chosen by the majority of subjects. An important implication of this finding is that, when choosing in the presence of conflicting motivations, human actions do not equalize (dis)utilities across the alternatives available to them. Instead, conflicts are reflected on emotions which persist after the decision is made and they are perceived stronger, the more a given decision deviates from the basic motivation of monetary reward maximization. Therefore, skin conductance results show an interesting overall pattern concerning bribers. They demonstrate higher arousal when they do not bribe in the baseline treatment and when they do in the inspection one, namely, when they opt for the least common and potentially least profitable strategy in each case. Bribetakers react in a similar manner, indicating that passive bribery carries also a moral burden.

While the discussion so far concerns emotions triggered by subjects' decisions, emotional arousal may also emerge from the anticipation of the consequences of others' actions. A rather expected pattern concerns the emotional response obtained due to the anxiety experienced by the winners while waiting for the loser's decision to activate an inspection or not. Figure 5.6 shows that bribing winners waiting for losers to decide whether to audit them or not exhibit significantly higher emotional 


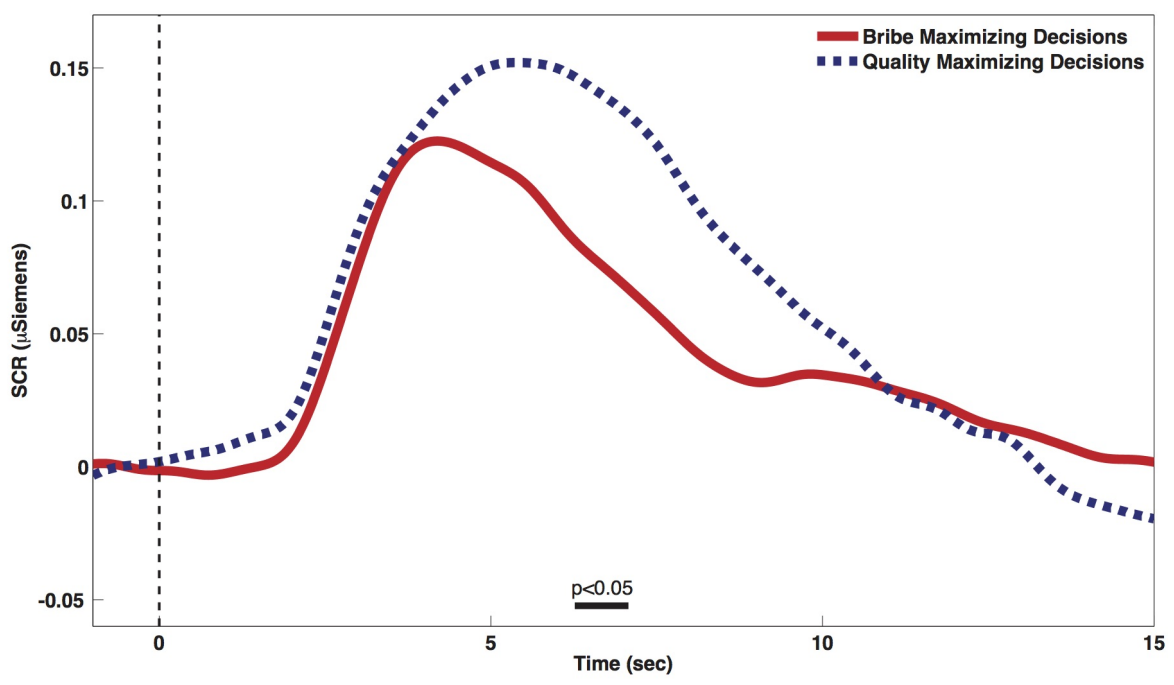

Figure 5.2: Officials' SCR following project choice screen (T0).

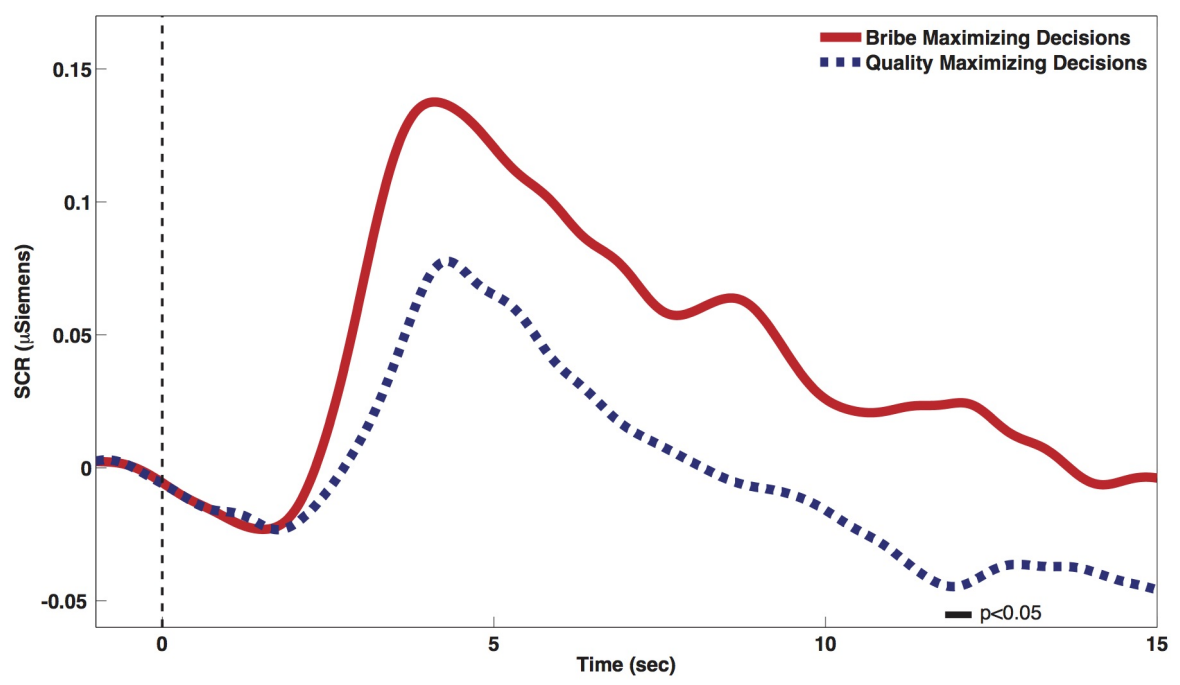

Figure 5.3: Officials' SCR following project choice screen (T1). 


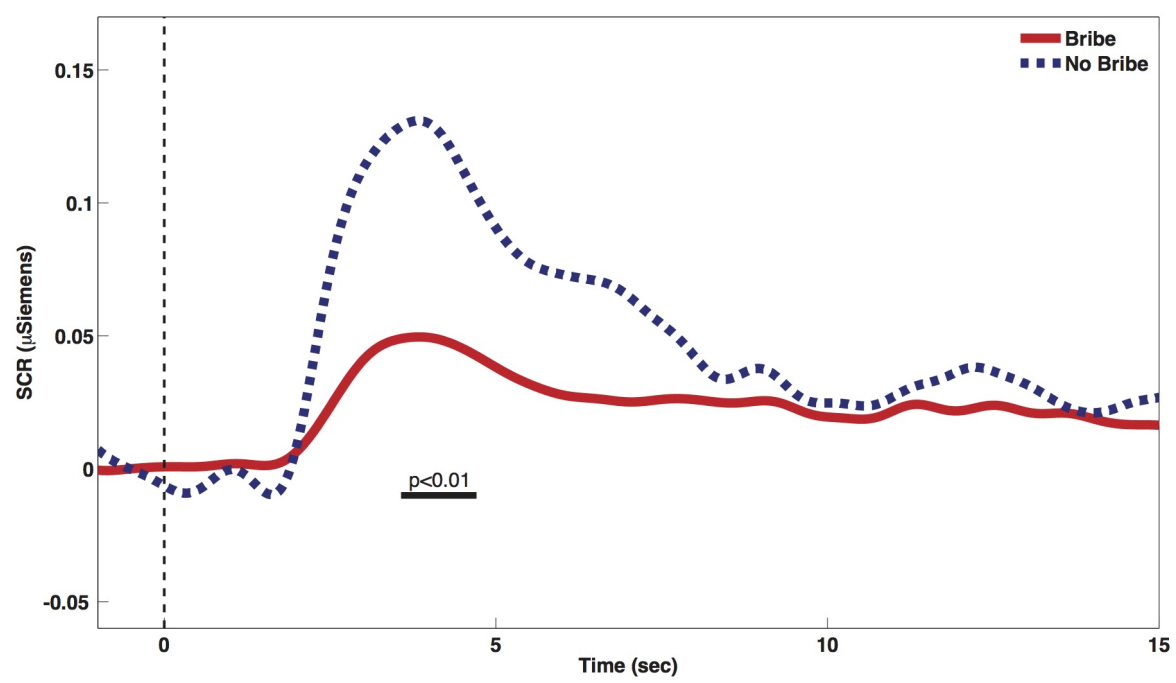

Figure 5.4: Firms' SCR following bid decision screen (T0).

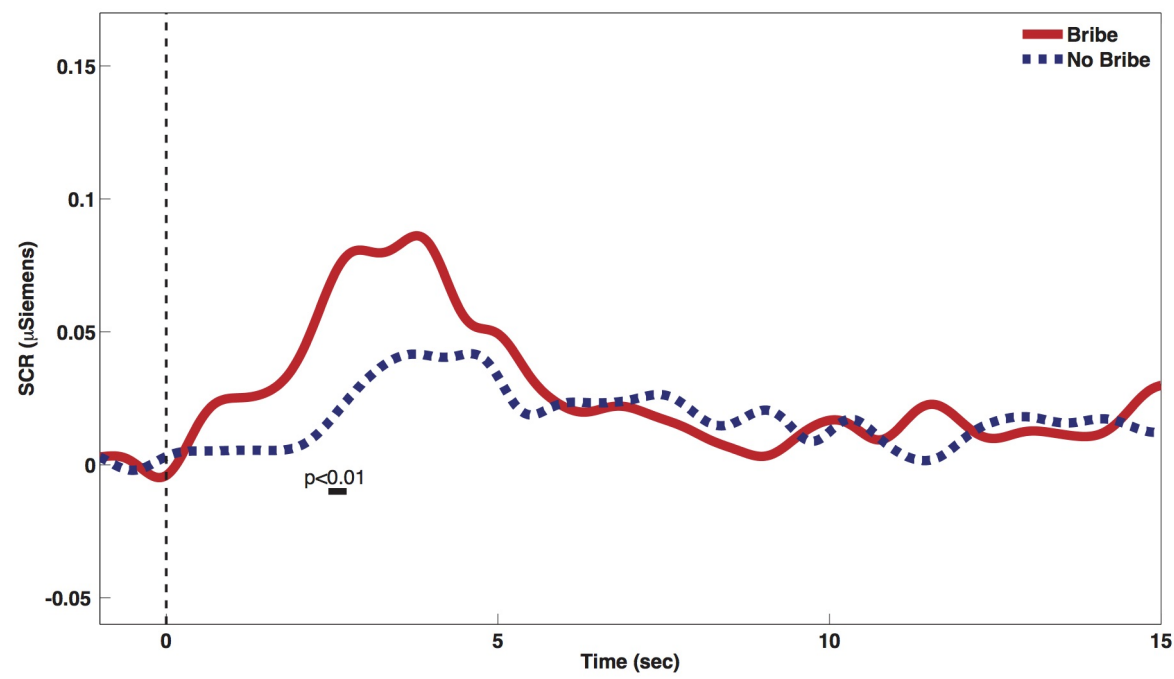

Figure 5.5: Firms' SCR following bid decision screen (T1). 


\section{PHYSIOLOGICAL AND BEHAVIORAL PATTERNS OF CORRUPTION}

arousal compared to honest winners $(\mathrm{p}<0.05$ between 1.8 and $3.4 \mathrm{sec})$.

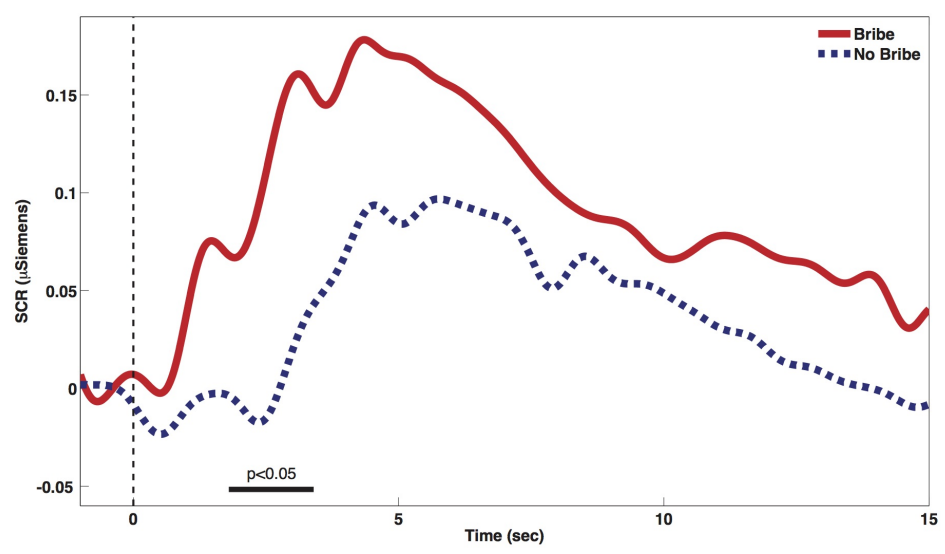

Figure 5.6: Winners' skin-conductance while waiting for loser to decide whether to order an inspection.

\subsubsection{Response times}

We argue here that emotional arousal emerges from a conflict between monetary and ethical attractors of behavior. Thus, we would expect ethical decisions dictated by pro-social incentives to lead to emotional arousal if the corresponding decision contradicts the basic instinct of selfish monetary reward maximization. Our results are compatible with this view. First of all, we find a positive and significant correlation (Spearman $\rho=0.12, \mathrm{p}<0.01$ ) between arousal and response times. To be more specific, in figures 5.7, 5.8, and 5.9 we plot the distribution of response times in the Inspection treatment per decision type. Recall that in this treatment, the majority choice was the pro-social one, because of the inspection risk. First, in Figure 5.7 it is seen that officials decide faster when they choose higher quality projects. Similarly, according to Figure 5.8, bribing firms take longer to make their decisions. Finally, on Figure 5.9 we see that losers take less time to decide not to inspect than to inspect. In all these cases, the negative expected profit of the anti-social decision corresponds to higher emotional arousal, as shown by our SCR data. In few words, 
the more subjects do something against their expected monetary interest, the longer it takes for them to decide, presumably because of conflicting internal motivations.

Thus, in our case, emotional choices can be seen as choices that create conflict or internal dissonance that probably needs even more cognitive processing or reasoning in order to resolve the conflict and make a decision. Rubinstein (2014) associates longer response times with contemplative decisions, as opposed to instinctive and thus faster ones. In Rubinstein (2007), it was argued that instinctive, thus emotional, decisions are usually made faster than those resulting from a cognitively demanding processing. So, in accord with Rubinstein and common sense, more cognitive processing requires more time, although the term instinctive used in Rubinstein (2007) should not be confused with emotional, which, as we show here is more likely in the presence of a moral conflict and specifically, when the decisions made contradict reward maximization.

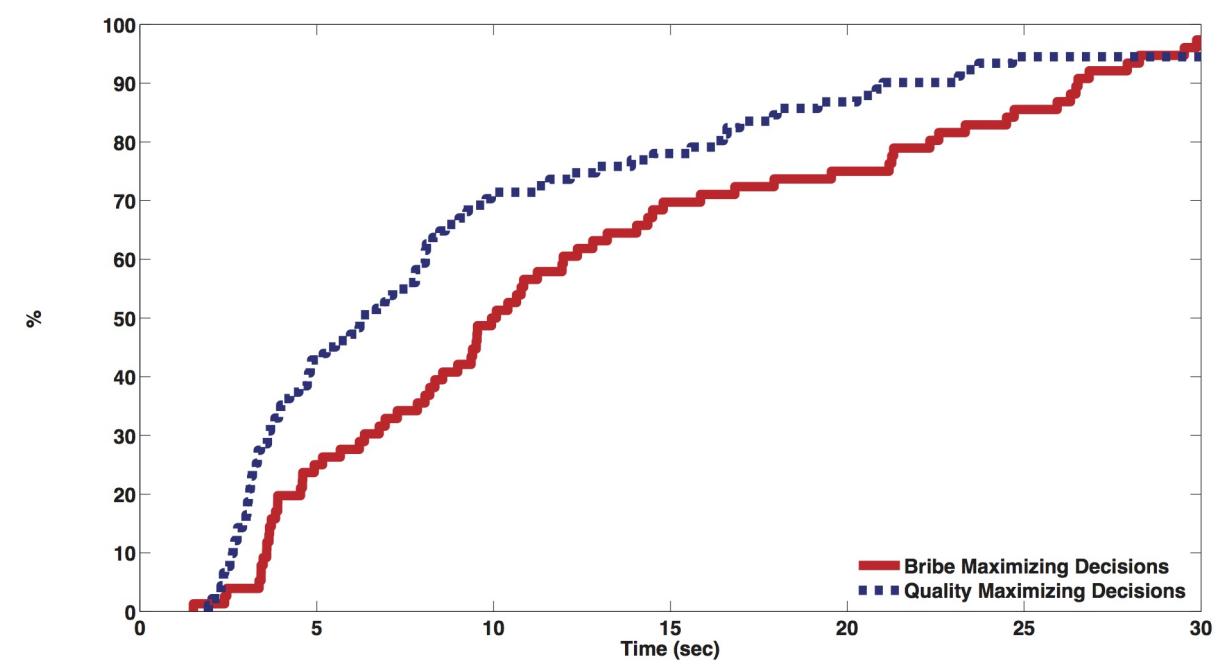

Figure 5.7: Response time for T1: Bribe vs Quality maximization (officials). 


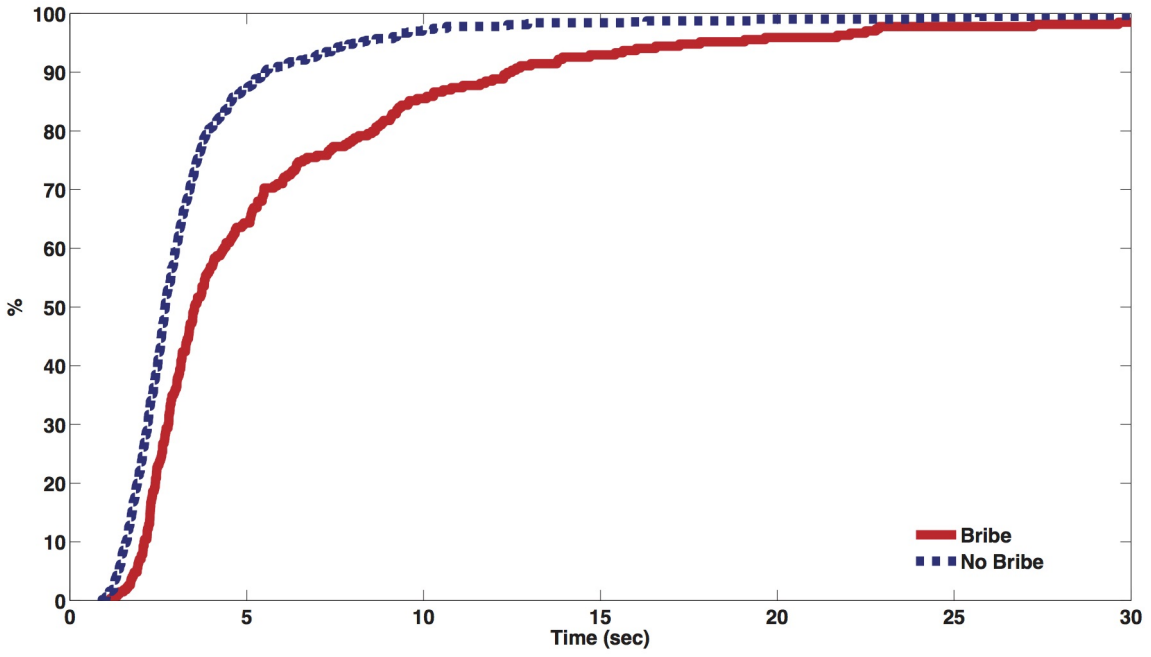

Figure 5.8: Response time for T1: Bribe vs No Bribe (firms).

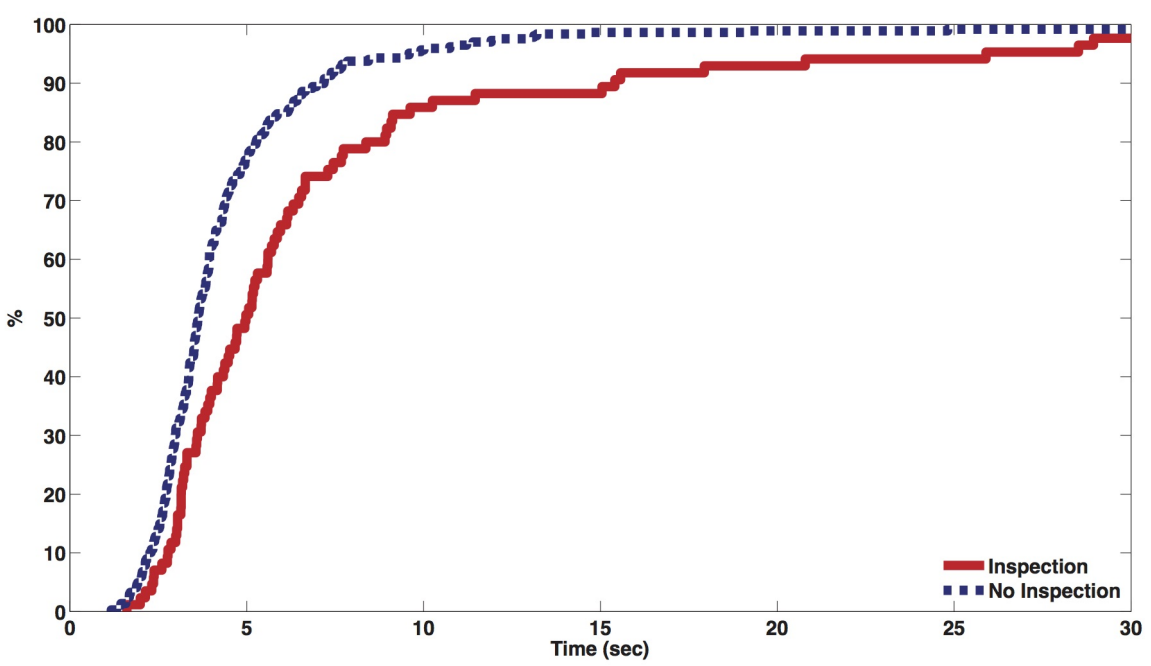

Figure 5.9: Response time for $T 1$ : Inspection vs No Inspection. 


\subsection{Discussion}

Economic decisions are often made in contexts generating conflicting motivations. Such conflicts have increasingly attracted the attention of economists, psychologists and decision theorists. Several studies, like Coricelli et al. (2010, 2014) have shown that selfish economic decisions with a negative public externality may cause a moral conflict reflected on the decision-maker's emotional arousal. In fact, both studies had also obtained subjects' self-reported emotions, finding that negative feelings were triggered by non-compliance with a pro-social norm. However, in both of these papers, non-compliance occured in the presence of a threat of punishment through publicity of the photos of subjects engaging in tax evasion. Therefore, any intrinsic aversion to tax evasion or regret for it co-existed with extrinsic threats against anti-social behavior. In this chapter, in the context of a public procurement auction with a bribe possibility and punishment options, we find that it is not the violation or compliance with a given ethical norm per se which triggers the emotional arousal, but rather the actual decision to act against one's own monetary interest. Complementing our SCR data with response times, we establish that decisions which may or may not be pro-social may cause an increased emotional arousal, as long as they deviate from the objective of monetary reward maximization. From a methodological point of view, our results suggest that, so far, emotional arousal may have been wrongly associated only with unethical behavior, because it may have been triggered by an ethical decision against the decisionmaker's selfish motivation. However, emotional arousal is a reliable marker to detect a subject's anxiety due to unethical behavior, while waiting for inspection and punishment by another person.

Future research should pursue obtaining more evidence on the correlation between response times and physiological manifestations of emotions. The extent to which the former can be used as a proxy of the other is of great interest to behavioral economists. Furthermore, more evidence is needed in order to establish the share of fear of being punished in the negative emotions associated with the violation of a pro-social norm. 


\section{PHYSIOLOGICAL AND BEHAVIORAL PATTERNS OF CORRUPTION}

\subsection{Appendix: Instructions to experimental subjects (translated from Spanish)}

Welcome and thanks for your participation in this experiment. Please switch off your mobile phones and secure your belongings away. You are going to participate in an experimental session split into two subsessions of 15 rounds each. You will earn an amount of money which will depend on your decisions and the decisions of other participants in the session. From this moment onwards you must use only the instructions and the computer in front of you. If you have any questions throughout the session, please raise your hand and you will receive an answer by one of the experimentalists. Any communication with other participants will imply your immediate exclusion from the experiment.

\subsection{1[T0]}

At the beginning of this subsession, you will be assigned one of two roles: 'a firm' or 'an official'. Your role is randomly assigned to you and remains fixed throughout the subsession. You will be anonymously and randomly assigned to a group of three players: two firms and an official. The group will be fixed throughout the subsession. Rounds are independent, in the sense that the payoff consequences of decisions made in any round do not carry over to subsequent rounds. Once this part is finished, the experimentalist will give you new instructions for the second subsession.

\section{- Decision Making}

In each round, all players receive an endowment of $10 \mathrm{ExCU}{ }^{1}$ If you are a firm: You compete with the other firm of your group for the license of a public project whose quality is beneficial to all players in the group. In each round, you have to post bids on the quality of your project and a monetary transfer which you wish to send privately to the official in your group if you are chosen to undertake the project. Firms' bids are made simultaneously, so that each firm can only know its own bids, but not the bids of the other firm. The quality and

\footnotetext{
${ }^{1}$ Experimental Currency Unit.
} 
the transfer to the official must sum 10, so that if your quality bid is 9 your transfer to the official in case you win will be 1 . If you win the auction, apart from your round endowment, you earn a fixed extra profit. In that case, you also have to spend on the transfer to the official double the amount you promised in your bid. If you lose the auction, apart from your initial endowment from each round, your earnings include a profit which is proportional to the quality of the winning project.

If you are an official: In each round, you receive the bids from the firms in your group. Then, you have to choose one of the two projects. Apart from your initial endowment in this round, your earnings include a profit which is proportional to the winner's quality plus the amount, if any, privately transferred to you by the winner.

\section{- Exact calculation of profits}

From the description of strategies and earnings above, the specific formulas used to calculate your profits in each round $(\pi)$ are a function of the quality $(\boldsymbol{Q})$ and transfer $(\boldsymbol{B})$ bids of the winner, as shown below:

$$
\begin{gathered}
\pi_{\text {winner }}=10+\frac{1}{2} \cdot Q_{\text {winner }}+10-2 \cdot B_{\text {winner }} \\
\pi_{\text {loser }}=10+\frac{1}{2} \cdot Q_{\text {winner }} \\
\pi_{\text {official }}=10+\frac{1}{2} \cdot Q_{\text {winner }}+B_{\text {winner }}
\end{gathered}
$$

\section{- Information received}

If you are a firm: At the end of each round, you will receive information on which firm won the license, a reminder of your decisions on quality level and transfer in that round, as well as your profit for that round. 


\section{PHYSIOLOGICAL AND BEHAVIORAL PATTERNS OF CORRUPTION}

If you are an official: In each round, after firms have made their decisions, their quality and transfer bids will be displayed on your screen before you make a decision. Once you select the winning firm, you will receive information on your profits in this round.

\section{- Monetary rewards}

In order to determine your payment in this subsession, the computer will randomly choose one of the 15 rounds at the end of the session. The amount of money you will earn from this part of the experiment will be equal to your profits in the randomly chosen round, multiplied by an equivalence ratio of $1 \mathrm{ExCU}=\frac{1}{2}$ Euro.

\subsection{2 [T1]}

In this subsession, the context will be exactly the same as in the first one, except for the following:

The roles of subjects and the composition of groups will be re-determined randomly and will remain fixed throughout the remaining rounds of the session.

A new feature is that, in each round, after the winner of the auction has been determined by the official, the loser firm has the option to ask for an inspection of the winning bid. The decision to inspect modifies the subjects' earnings as follows: If a transfer has taken place, the official and the winner of the auction earn nothing in this round. On the contrary, if no transfer is revealed, then, the inspecting loser earns nothing in this round. Finally, if no inspection is activated, players' earnings remain unchanged.

\section{- Monetary rewards}

In order to determine your payment in this subsession, the computer will randomly choose one of the 15 rounds at the end of the session. The amount of money you will earn from this part of the experiment will be equal to your profits in the randomly chosen round, multiplied by an equivalence ratio of $1 \mathrm{ExCU}=\frac{1}{2}$ Euro. 


\section{Bibliography}

Abbink, K. (2004). Staff rotation as an anti-corruption policy: An experimental study. European Journal of Political Economy, 20(4):887-906. 13, 17, 23, 26, 37, 44, 79

Abbink, K., Dasgupta, U., Gangadharan, L., and Jain, T. (2014). Letting the briber go free: An experiment on mitigating harassment bribes. Journal of Public Economics, 111:17-28. 16, 44, 45, 47, 48, 79

Abbink, K. and Hennig-Schmidt, H. (2006). Neutral versus loaded instructions in a bribery experiment. Experimental Economics, 9(2):103-121. 15, 79

Abbink, K., Irlenbusch, B., and Renner, E. (2002). An experimental bribery game. Journal of Law, Economics, and Organization, 18(2):428-454. 17, 44, 49,79

Alatas, V., Cameron, L., Chaudhuri, A., Erkal, N., and Gangadharan, L. (2009a). Gender, culture, and corruption: Insights from an experimental analysis. Southern Economic Journal, 75(3):663-680. 15, 38, 44, 47, 50, 66, 79.

Alatas, V., Cameron, L., Chaudhuri, A., Erkal, N., and Gangadharan, L. (2009b). Subject pool effects in a corruption experiment: A comparison of Indonesian public servants and Indonesian students. Experimental Economics, 12(1):113132. 14, 44, 47, 50,79

Andreoni, J., Harbaugh, W. T., and Vesterlund, L. (2007). Altruism in experiments. New Palgrave Dictionary of Economics, 2nd Edition, 2007. 48 
Andreoni, J. and Miller, J. (2002). Giving according to GARP: An experimental test of the consistency of preferences for altruism. Econometrica, 70(2):737753. 48

Andreoni, J. and Petrie, R. (2004). Public goods experiments without confidentiality: A glimpse into fund-raising. Journal of Public Economics, 88(7-8):16051623. 49

Andreoni, J. and Vesterlund, L. (2001). Which is the fair sex? Gender differences in altruism. The Quarterly Journal of Economics, 116(1):293-312. 48

Apesteguia, J. and Dufwenberg, M. (2007). Blowing the whistle. Economic Theory, 31(1):143-166. 48

Ariely, D. and Loewenstein, G. (2006). The heat of the moment: The effect of sexual arousal on sexual decision making. Journal of Behavioral Decision Making, 98(2):87-98. 79

Armantier, O. and Boly, A. (2011). A controlled field experiment on corruption. European Economic Review, 55(8):1072-1082. 16

Azfar, O. and Nelson, W. R. (2007). Transparency, wages, and the separation of powers: An experimental analysis of corruption. Public Choice, 130(3-4):471493. 44, 79

Banuri, S. and Eckel, C. (2012). Experiments in culture and corruption: A review. New Advances in Experimental Research on Corruption (Research in Experimental Economics, Volume 15), pages 51-76. 14, 44,79

Barr, A., Lindelow, M., and Serneels, P. (2009). Corruption in public service delivery: An experimental analysis. Journal of Economic Behavior and Organization, 72(1):225-239. 79

Barr, A. and Serra, D. (2009). The effects of externalities and framing on bribery in a petty corruption experiment. Experimental Economics, 12(4):488-503. 15 , 45, 50, 51, 79 
Barr, A. and Serra, D. (2010). Corruption and culture: An experimental analysis. Journal of Public Economics, 94(11-12):862-869. 14, 44, 50

Basu, K. (2011). Why, for a class of bribes, the act of giving a bribe should be treated as legal. Ministry of Finance Working Paper. 16,47

Bateson, M., Nettle, D., and Roberts, G. (2006). Cues of being watched enhance cooperation in a real-world setting. Biology Letters, 2(3):412-414. 49

Bechara, A. (2004). The role of emotion in decision-making: evidence from neurological patients with orbitofrontal damage. Brain and Cognition, 55(1):30-40. 80

Bechara, A. and Damasio, A. R. (2005). The somatic marker hypothesis: A neural theory of economic decision. Games and Economic Behavior, 52(2):336-372. 80

Beck, P. J. and Maher, M. W. (1986). A comparison of bribery and bidding in thin markets. Economics Letters, 20(1):1-5. 6, 80

Berninghaus, S. K., Haller, S., Krüger, T., Neumann, T., Schosser, S., and Vogt, B. (2013). Risk attitude, beliefs, and information in a corruption game - An experimental analysis. Journal of Economic Psychology, 34:46-60. 67

Bigoni, M., Fridolfsson, S.-O., Le Coq, C., and Spagnolo, G. (2012). Fines, leniency, and rewards in antitrust. The RAND Journal of Economics, 43(2):368-390. 48

Bohnet, I. and Frey, B. S. (1999). Social distance and other-regarding behavior in dictator games: Comment. The American Economic Review, 89(1):335-339. 49

Bolton, G. and Ockenfels, A. (2000). ERC: A theory of equity, reciprocity, and competition. The American Economic Review, 90(1):166-193. 77

Büchner, S., Freytag, A., González, L. G., and Güth, W. (2008). Bribery and public procurement: An experimental study. Public Choice, 137(1-2):103-117. 6, 7 , 80 
Burguet, R. and Che, Y.-K. (2004). Competitive procurement with corruption. The RAND Journal of Economics, 35(1):50-68. 6, 80

Burnham, T. C. (2003). Engineering altruism: A theoretical and experimental investigation of anonymity and gift giving. Journal of Economic Behavior and Organization, 50(1):133-144. 49

Burnham, T. C. and Hare, B. (2007). Engineering human cooperation. Does involuntary neural activation increase public goods contributions? Human Nature, 18(2):88-108. 49

Cameron, L., Chaudhuri, A., Erkal, N., and Gangadharan, L. (2009). Propensities to engage in and punish corrupt behavior: Experimental evidence from Australia, India, Indonesia and Singapore. Journal of Public Economics, 93(7-8):843-851. 14, 44, 47, 50, 79

Chaudhuri, A. (2012). Gender and corruption: A survey of the experimental evidence. In Serra, D. and Wantchekon, L., editors, Research in Experimental Economics, volume 15, chapter 2, pages 13-49. 67

Che, Y.-K. (1993). Design competition through multidimensional auctions. The RAND Journal of Economics, 24(4):668-680. 6, 80

Coricelli, G., Joffily, M., Montmarquette, C., and Villeval, M. C. (2010). Cheating, emotions, and rationality: An experiment on tax evasion. Experimental Economics, 13(2):226-247. 80, 89, 95

Coricelli, G., Rusconi, E., and Villeval, M. C. (2014). Tax evasion and emotions: An empirical test of re-integrative shaming theory. Journal of Economic Psycho$\log y, 40: 49-61.80,89,95$

Crone, E. a., Somsen, R. J. M., Van Beek, B., and Van Der Molen, M. W. (2004). Heart rate and skin conductance analysis of antecendents and consequences of decision making. Psychophysiology, 41(4):531-40. 80

Dawson, M., Schell, A., and Filion, D. (2007). The electrodermal system. In The Handbook of Psychophysiology, chapter 7, pages 159-181. Cambridge. 84 
Dollar, D., Fisman, R., and Gatti, R. (2001). Are women really the "fairer" sex? Corruption and women in government. Journal of Economic Behavior and Organization, 46(4):423-429. 6, 12,44

Eckel, C. C. and Grossman, P. J. (1996). Altruism in anonymous dictator games. Games and Economic Behavior, 16(2):181-191. 48

Egger, P. and Winner, H. (2005). Evidence on corruption as an incentive for foreign direct investment. European Journal of Political Economy, 21(4):932-952. 44

Fehr, E. and Gächter, S. (2000). Cooperation and punishment in public goods experiments. The American Economic Review, 90(4):980-994. 46

Fehr, E. and Gächter, S. (2002). Altruistic punishment in humans. Nature, 425:137-140. 46

Fehr, E. and Schneider, F. (2010). Eyes are on us, but nobody cares: Are eye cues relevant for strong reciprocity? Proceedings of the Royal Society B: Biological Sciences, 277(1686):1315-23. 49

Fischbacher, U. (2007). z-Tree: Zurich toolbox for ready-made economic experiments. Experimental Economics, 10(2):171-178. 19, 84

Forsythe, R., Horowitz, J. L., Savin, N., and Sefton, M. (1994). Fairness in simple bargaining experiments. Games and Economic Behavior, 6(3):347-369. 48

Frank, B., Lambsdorff, J. G., and Mohnen, P. (2010). Gender and corruption: Lessons from laboratory corruption experiments. European Journal of Development Research, 23(1):59-71. 15, 44, 67

Frank, B. and Schulze, G. G. (2000). Does economics make citizens corrupt? Journal of Economic Behavior and Organization, 43(1):101-113. 14, 15, 44, 78

Gneezy, U., Saccardo, S., and Veldhuizen, R. V. (2013). Bribery: Greed versus reciprocity. Mimeo San Diego, pages 1-27. 79

Gómez-Miñambres, J. (2014). Temptation, horizontal differentiation and monopoly pricing. Theory and Decision (Forthcoming). 78 
Greiner, B. (2004). The online recruitment system ORSEE 2.0 - A guide for the organization of experiments in economics. University of Cologne, Working Paper Series in Economics, 10(23):63-104. 84

Gupta, S., Davoodi, H., and Alonso-terme, R. (2002). Does corruption affect income inequality and poverty? Economics of Governance, 3(1):23-45. 6, 11 , 44

Haley, K. J. and Fessler, D. M. (2005). Nobody's watching? Evolution and Human Behavior, 26(3):245-256. 49

Harbaugh, W. T., Mayr, U., and Burghart, D. R. (2007). Neural responses to taxation and voluntary giving reveal motives for charitable donations. Science, 316(5831):1622-1625. 48

Hoffman, E., McCabe, K., Shachat, K., and Smith, V. (1994). Preferences, property rights, and anonymity in bargaining games. Games and Economic Behavior, 7(3):346-380. 49

Huntington, S. P. (1968). Political order in changing societies. New have, edition. 44

Kaufmann, D. (2005). Myths and realities of governance and corruption. Global Competitiveness Report 2005-06, pages 81-98. 5

Kurzban, R. (2001). The social psychophysics of cooperation: Nonverbal communication in a public goods game. Journal of Nonverbal Behavior, 25(4):241-259. 49

Lamba, S. and Mace, R. (2010). People recognise when they are really anonymous in an economic game. Evolution and Human Behavior, 31(4):271-278. 49

Lambsdorff, J. G. and Frank, B. (2010). Bribing versus gift-giving - An experiment. Journal of Economic Psychology, 31(3):347-357. 15, 79

Lambsdorff, J. G. and Frank, B. (2011). Corrupt reciprocity - Experimental evidence on a men's game. International Review of Law and Economics, 31(2):116125. 79 
Leff, N. H. (1964). Economic development through bureaucratic corruption. American Behavioral Scientist, 8(3):8-14. 44

Levitt, S. and List, J. (2007). What do laboratory experiments measuring social preferences reveal about the real world? The Journal of Economic Perspectives, 21(2):153-174. 12

Lien, D.-H. D. (1986). A note on competitive bribery games. Economics Letters, 22(4):337-341. 6, 80

Lui, F. T. (1986). A dynamic model of corruption deterrence. Journal of Public Economics, 31(2):215-236. 44

Mauro, P. (1995). Corruption and growth. The Quarterly Journal of Economics, 110(3):681-712. 6, 11,44

Mifune, N., Hashimoto, H., and Yamagishi, T. (2010). Altruism toward ingroup members as a reputation mechanism. Evolution and Human Behavior, 31(2):109-117. 49

Naqvi, N., Shiv, B., and Bechara, A. (2006). The role of emotion in decision making: A cognitive neuroscience perspective. Current Directions in Psychological Science, 15(5):260-264. 80

Olken, B. a. (2009). Corruption perceptions vs. corruption reality. Journal of Public Economics, 93(7-8):950-964. 12

Perakakis, P., Guinot, J. V., Conde, A., Jaber-López, T., García-Gallego, A., and Georgantzis, N. (2013). A technical note on the precise timing of behavioral events in economic experiments. Universitat Jaume I, Working Papers, 12. 85

Peters, E., Västfjäll, D., Gärling, T., and Slovic, P. (2006). Affect and decision making: A "hot" topic. Journal of Behavioral Decision Making, 19(2):79-85. 79

Rigdon, M., Ishii, K., Watabe, M., and Kitayama, S. (2009). Minimal social cues in the dictator game. Journal of Economic Psychology, 30(3):358-367. 49 
Rivas, M. F. (2013). An experiment on corruption and gender. Bulletin of Economic Research, 65(1):10-42. 15, 66, 67

Rose-Ackerman, S. (1999). Corruption and government: Causes, consequences, and reform. Cambridge University Press. 44

Rubinstein, A. (2007). Instinctive and cognitive reasoning: A study of response times. The Economic Journal, 117(523):1243-1259. 93

Rubinstein, A. (2014). A typology of players: Between instinctive and contemplative. Mimeo Tel Aviv, pages 1-27. 93

Sabater-Grande, G. and Georgantzis, N. (2002). Accounting for risk aversion in repeated prisoners' dilemma games: An experimental test. Journal of Economic Behavior and Organization, 48(1):37-50. 52, 67

Sanfey, A., Rilling, J., and Aronson, J. (2003). The neural basis of economic decision-making in the ultimatum game. Science, 300(5626):1755-1759. 80

Schulze, G. G. and Frank, B. (2003). Deterrence versus intrinsic motivation: Experimental evidence on the determinants of corruptibility. Economics of Governance, 4(2):143-160. 15, 16, 44, 66, 78,

Schwarz, N. (2000). Emotion, cognition, and decision making. Cognition and Emotion, 14(4):433-440. 80

Sen, A. (1977). Rational fools: A critique of the behavioral foundations of economic theory. Philosophy and Public Affairs, 6(4):317-344. 78

Serra, D. (2012). Combining top-down and bottom-up accountability: Evidence from a bribery experiment. Journal of Law, Economics, and Organization, 28(3):569-587. 16, 44, 50, 79

Van Dijk, E. and Zeelenberg, M. (2006). The dampening effect of uncertainty on positive and negative emotions. Journal of Behavioral Decision Making, 19(2):171-176. 79 
Van Rijckeghem, C. and Weder, B. (2001). Bureaucratic corruption and the rate of temptation: Do wages in the civil service affect corruption, and by how much? Journal of Development Economics, 65(2):307-331. 6, 12, 44

Van 't Wout, M., Kahn, R. S., Sanfey, A. G., and Aleman, A. (2006). Affective state and decision-making in the Ultimatum Game. Experimental Brain Research, 169(4):564-8. 80

Vesterlund, L. (2006). Why Do People Give? In Powell, W. and Steinberg, R., editors, The nonprofit sector: A research handbook, volume 2, pages 568-587. Yale University Press New Haven, CT. 48 


\section{Declaration}

I herewith declare that I have produced this work without the prohibited assistance of third parties and without making use of aids other than those specified; notions taken over directly or indirectly from other sources have been identified as such. This work has not previously been presented in identical or similar form to any examination board.

The dissertation work was conducted from 2011 to 2015 under the supervision of Aurora García Gallego and Nikolaos Georgantzís at the University Jaume I (Castellón).

Castellón, 
This dissertation was finished writing in Castellón on Wednesday $3^{\text {rd }}$ June, 2015 
This page is intentionally left blank 